Andrews University

Digital Commons @ Andrews University

\title{
The Effect of the Vocabulary Spelling City App on Student Performance in Spelling, Vocabulary, and Reading Comprehension in Grades 5-8 at Glenview Adventist Academy
}

Fernando Oleynick Lista

Andrews University, listaole@andrews.edu

Follow this and additional works at: https://digitalcommons.andrews.edu/dissertations

Part of the Educational Administration and Supervision Commons

\section{Recommended Citation}

Lista, Fernando Oleynick, "The Effect of the Vocabulary Spelling City App on Student Performance in Spelling, Vocabulary, and Reading Comprehension in Grades 5-8 at Glenview Adventist Academy" (2021). Dissertations. 1746.

https://digitalcommons.andrews.edu/dissertations/1746

https://dx.doi.org/10.32597/dissertations/1746

This Dissertation is brought to you for free and open access by the Graduate Research at Digital Commons @ Andrews University. It has been accepted for inclusion in Dissertations by an authorized administrator of Digital Commons@ Andrews University. For more information, please contact repository@andrews.edu. 


\begin{abstract}
THE EFFECT OF THE VOCABULARY SPELLING CITY APP ON STUDENT PERFORMANCE IN SPELLING, VOCABULARY, AND READING COMPREHENSION IN GRADES 5-8 AT GLENVIEW ADVENTIST ACADEMY
\end{abstract}

by

Fernando Lista Oleynick

Chair: Bordes Henry-Saturné 


\title{
ABSTRACT OF GRADUATE STUDENT RESEARCH
}

\author{
Dissertation
}

Andrews University

School of Education

\section{Title: THE EFFECT OF THE VOCABULARY SPELLING CITY APP ON STUDENT PERFORMANCE IN SPELLING, VOCABULARY, AND READING COMPREHENSION IN GRADES 5 THROUGH 8 AT GLENVIEW ADVENTIST ACADEMY}

Name of researcher: Fernando Lista Oleynick

Name and degree of faculty chair: Bordes Henry-Saturné, Ph. D.

Date completed: March 2021

\section{Problem and Purpose}

Students in fifth through eighth grades at Glenview Adventist Academy (GAA) presented difficulties in the subjects of spelling, vocabulary and reading comprehension. The school had not followed the previous 10-year trend of technology implementation in the classroom, in spite of conclusive research on its advantages. This study was conducted to determine to what extent teaching methodology and the use of technology could affect academic performance in the areas of spelling, vocabulary, and reading comprehension. Research on the implementation of software and the use of tablets (iPad Minis) in the classroom has been scarce and contradictory in the past decade (Heinrich, 2012; Roser, 2017). Hence, the need to conduct a study which would provide input in this 
area to guide future curriculum and technology implementation decisions for GAA and the Arizona Conference of Seventh-day Adventists Department of Education.

\section{Method}

A quantitative quasi-experimental design was utilized. Elementary students from Grades 5 through 8, enrolled at GAA during school years 2013-2016 (the experimental or technology group), were exposed to the use of the software Vocabulary Spelling City (VSC) through a technology medium named iPad minis. Students from the same grades from the other schools of the Arizona Conference of Seventh-day Adventist were chosen to be the control group. All students from the Arizona Conference of Seventh-day Adventists were tested academically in the areas of spelling, vocabulary, and reading comprehension using ITBS (Iowa Test of Basic Skills) during September and again in April for three consecutive years. SPSS software was used to enter the test results, and to conduct a sample paired t test, an analysis of covariance (ANCOVA), and a repeated measures of covariance.

\section{Findings}

A significant difference between groups was found among the students who experienced the technology intervention when compared to their performance during the previous year when they were taught using the traditional methods of teaching spelling ( $p$ $=0.038$ ). No group difference was found in both groups of students (experimental and control) between pretest and posttest in spelling $\left(p=0.652 ; \eta^{2}=0.002\right)$ during the first year of technology and software implementation (iPad mini and VSC). After conducting a repeated measures ANCOVA to track the experimental group of students at GAA over a period of two years, there was no significant difference in spelling performance when 
compared to their counterparts from the other Seventh-day Adventist schools in Arizona $\left(p=0.702 ; \eta^{2}=0.003\right)$. Furthermore, after conducting a repeated measures ANCOVA to track the experimental group of students at GAA over a period of three years, there was no significant difference in spelling performance when compared with the control group $\left(p=0.369 ; \eta^{2}=0.027\right)$

No significant difference in growth was found among the GAA students who experienced the technology intervention when compared to their performance during the prior year when they were taught by using the traditional methods of teaching vocabulary $(p=0.331)$. No difference was found for the GAA students in vocabulary when compared to their peers in other Seventh-day Adventist schools in Arizona after the end of the first year of the technology implementation $\left(p=0.203 ; \eta^{2}=0.014\right)$. After conducting a repeated measures ANCOVA to track the experimental group of students at GAA over a period of two years, there was no significant difference in vocabulary performance when compared to their counterparts from the other Seventh-day Adventist schools in Arizona $\left(p=0.572 ; \eta^{2}=0.006\right)$. Furthermore, after conducting a repeated measures ANCOVA to track the experimental group of students at GAA over a period of three years, there was no significant difference in vocabulary performance when compared with the control group $\left(p=0.134 ; \eta^{2}=0.073\right)$.

No significant group differences was found among the students who experienced the technology intervention when compared to their performance during the prior year, when they were taught using the traditional methods of teaching reading comprehension $(p=0.735)$. No difference was found for the GAA students in reading comprehension when compared to their peers in other Seventh-day Adventist schools in Arizona after the 
end of the first year of the technology implementation $\left(p=0.362 ; \eta^{2}=0.007\right)$. After conducting a repeated measures ANCOVA to track the experimental group of students at GAA over a period of two years, there was no significant difference in reading comprehension performance when compared to their counterparts from the other Seventh-day Adventist schools in Arizona $\left(p=0.181 ; \eta^{2}=0.032\right)$. Furthermore, after conducting a repeated measures ANCOVA to track the experimental group of students at GAA over a period of three years, there was no significant difference in reading comprehension performance when compared with the control group $\left(p=0.073 ; \eta^{2}=\right.$ $0.103)$.

\section{Conclusions and Recommendations}

Based on the results from this study, the use of tablets and educational software did not provide statistical significant academic benefits to GAA students in the areas of spelling and reading comprehension. Although, when looking to the unadjusted means between the technology group in comparison with the control group, an increase in academic performance can be observed. Hence, the recommendation for future research to use a more sensitive instrument for measuring intervention effects than the standardized academic test used in this study (ITBS).

That students at GAA, who were part of the technology group for three years, were not at a disadvantage academically in the areas of spelling, vocabulary, and reading comprehension when compared to the fifth- through eighth-grade students from the other Seventh-day Adventist schools in Arizona provided valuable information regarding students' academic performance when using tablets and educational software. These findings were consistent with several studies (ASCD \& OverDrive, 2016; Moon et al., 
2017; Schoology, 2017; Wang, 2017). Furthermore, the implementation of immersive technology in the classroom concurs with educational and curricular trend of equipping students with $21^{\text {st }}$-Century skills (Alliance for Excellent Education, 2016; Federal Communications Commission, 2012; Gross, 2013; US Department of Education, Office of Educational Technology, 2010).

In summary, further research could investigate the degree of student involvement, engagement, self-motivation, teachers' perception toward technology, impact of technology instruction and the workforce, and satisfaction in classrooms when tablets and educational apps are implemented. (Singleton \& Simmons, 2001). 
Andrews University

School of Education

\title{
THE EFFECT OF THE VOCABULARY SPELLING CITY APP ON STUDENT PERFORMANCE IN SPELLING, VOCABULARY, AND READING COMPREHENSION IN GRADES 5-8 AT GLENVIEW ADVENTIST ACADEMY
}

\author{
A Dissertation \\ Presented in Partial Fulfillment \\ of the Requirements for the Degree \\ Doctor of Philosophy
}

by

Fernando Lista Oleynick

March 2021 
CCopyright by Fernando Lista Oleynick, 2021

All Rights Reserved 


\title{
THE EFFECT OF THE VOCABULARY SPELLING CITY APP ON STUDENT PERFORMANCE IN SPELLING, VOCABULARY, AND READING COMPREHENSION IN GRADES 5-8 AT GLENVIEW ADVENTIST ACADEMY
}

\author{
A dissertation \\ presented in partial fulfillment \\ of the requirements for the degree of \\ Doctor of Philosophy
}

by

Fernando Lista Oleynick

APPROVAL BY THE COMMITTEE:

Chair: Dr. Bordes Henry-Saturne

Dr. Alayne Thorpe

Dean, College of Education and

International Services

Methodologist: Dr. Jimmy Kijai

Member: Dr. Randy Siebold

External: Dr. Ruth Horton

Date approved 


\section{DEDICATION}

First and foremost, to God, the Giver of life and intellect. To my wife for her unconditional support, and to those who appreciate innovation in education. 
TABLE OF CONTENTS

LIST OF FIGURES …...................................................................... vii

LIST OF TABLES ................................................................................ viii

LIST OF ABBREVIATIONS ...................................................................

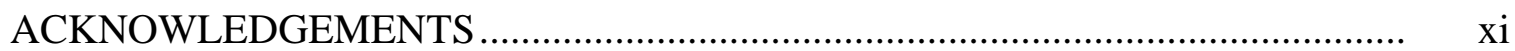

Chapter

1. INTRODUCTION ....................................................................... 1

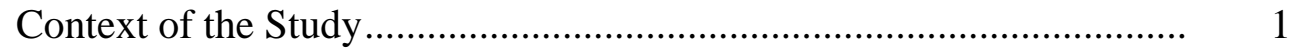

Description of the Problem .............................................................. 2

Implications for Instructional Leadership ...................................... 6

Statement of the Problem ........................................................... 7

Purpose of the Study ............................................................................ 8

Research Questions ...................................................................... 8

Theoretical Framework ................................................................... 9

Significance of the Study .................................................................. 11

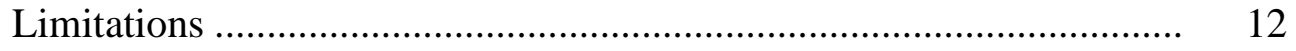

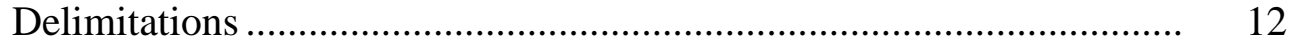

Key Terms and Definitions .............................................................. 13

List of Variables ........................................................................ 14

Summary .............................................................................. 16

Organization of the Study .......................................................... 17

2. $\quad$ LITERATURE REVIEW .................................................................. 18

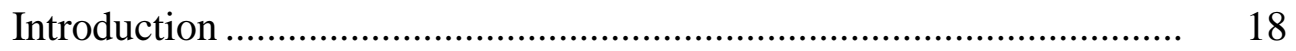

Reading Comprehension and Vocabulary ......................................... 18

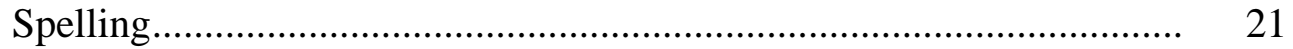

The Use of Technology for Language Arts Instruction and Practice.... 24

The Impact on Learning Literacy of Using iPads .............................. 27

Benefits of Using Tablets in the Classroom ......................................... 28

Considerations for Using Tablets in the Classroom ............................ 30

Instructional Leadership and Technology .......................................... 31

Theories of Learning .................................................................... 31

Behaviorism ......................................................................... 33

Cognitive/Constructivist Learning ......................................... 35

Social Constructivism .............................................................. 37 
Multiple Intelligences and Learning Styles.............................. 39

Vocabulary Spelling City ................................................................ 41

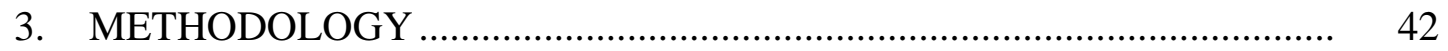

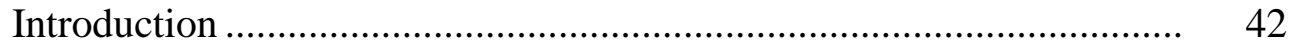

Research Questions ................................................................ 42

Research Design ...................................................................... 43

Intervention ........................................................................... 44

Vocabulary Spelling City App ................................................... 45

Population and Sample................................................................... 48

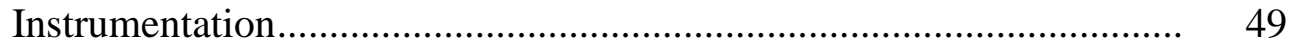

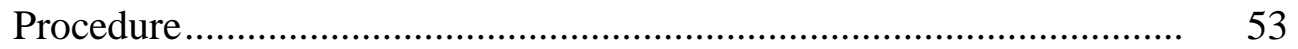

Treatment of Data..................................................................... 54

Data Analysis ............................................................................... 54

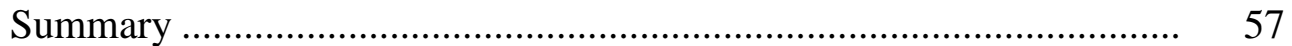

4. RESEARCH FINDINGS ............................................................... 58

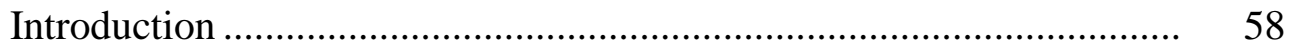

Description of the Population and Sample ........................................ 58

Statistical Analyses ........................................................................ 59

Research Question 1: Spelling ........................................................ 60

Comparison of GAA Students Before and After Technology Implementation for Spelling ........................................... 60

First-Year Comparison of Control Group with Technology Group for Spelling

Comparison of Control and Technology Groups Over Time for Spelling .................................................................... 64

Research Question 2: Vocabulary ................................................ 71

Comparison of GAA Students Before and After Technology Implementation for Vocabulary ....................................... 71

First-Year Comparison of Control Group with Technology Group for Vocabulary

Comparison of Control and Technology Groups Over Time for Vocabulary

Research Question 3: Reading Comprehension

Comparison of GAA Students Before and After Technology Implementation for Reading Comprehension

First-Year Comparison of Control Group with Technology Group for Reading Comprehension

Comparison of Control and Technology Groups Over Time for Reading Comprehension

5. DISCUSSION, CONCLUSIONS, AND RECOMMENDATIONS 
Introduction .......................................................................... 93

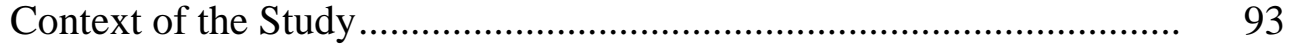

Description of the Problem .................................................................. 94

Benefits of Using Tablets in the Classroom ......................................... 98

Considerations for Using Tablets in the Classroom ............................ 100

Implications for Instructional Leadership ....................................... 101

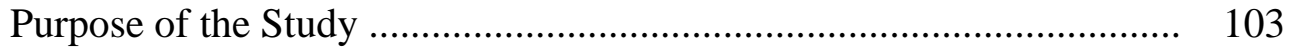

Summary of the Literature ........................................................... 103

Research Methodology ................................................................ 106

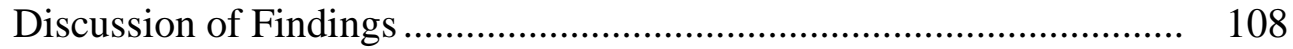

Research Question 1........................................................... 110

Research Question 2............................................................. 110

Research Question 3........................................................... 111

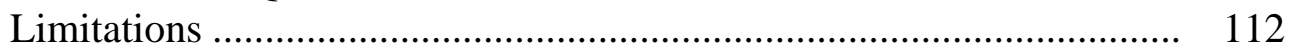

Conclusions .......................................................................... 113

Recommendations for Practice......................................................... 114

Recommendations for Further Research .......................................... 116

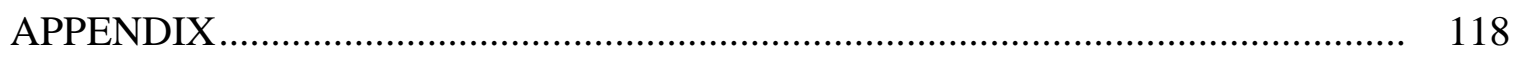

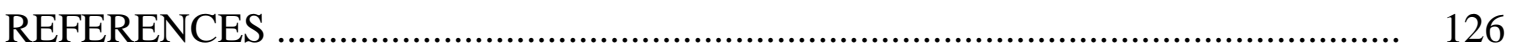

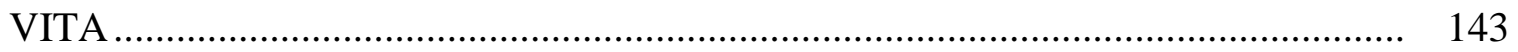




\section{LIST OF FIGURES}

1. Technology-Pedagogical-Content Knowledge Model ................................... 10

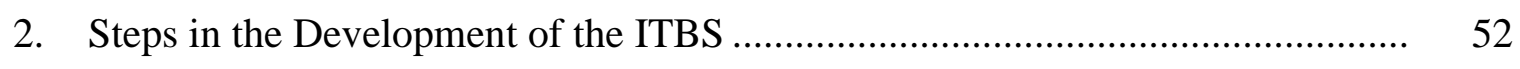

3. Spelling Mean Comparison Over Time for Technology and Control Groups..... 71

4. Vocabulary Mean Comparison Over Time for Technology and Control Groups 81

5. Reading Mean Comparison Over Time for Technology and Control Groups .... 92 


\section{LIST OF TABLES}

1. Mean National Percentile Ranks of GAA Students on ITBS, Fall 2013 ............ 5

2. Vocabulary Spelling City Games and Activities .......................................... 46

3. Description of Participants .................................................................... 49

4. ITBS Number of Items and Test Durations ........................................... 51

5. Reliability Coefficients for Form E of the ITBS ….................................. 51

6. Testing Dates for Administration of the ITBS in the Arizona Conference .......... 54

7. ITBS, Intervention, Pre Test, and Post Test Schedule by Analysis .................... 56

8. Number of Subjects by Grade and Year who Participated in the Study .............. 59

9. GAA Students Before and After the Technology Intervention for Spelling ........ 61

10. Means and Standard Deviations for Spelling Pretest and Posttests, Fifth Through Seventh Grades

11. ANCOVA Results for Spelling, Technology, and Control Groups..................... 64

12. ANCOVA Repeated Measures for Spelling, Fifth Through Seventh Grades, Technology and Control Groups

13. Means and Standard Deviations for Spelling Pretest and Posttests, Fifth and Sixth Grades

14. ANCOVA Repeated Measures for Spelling, Fifth and Sixth Grade, Technology and Control Groups

15. GAA Students Before and After the Technology Intervention for Vocabulary ...

16. Means and Standard Deviations for Vocabulary Pretest and First Posttest

17. ANCOVA Results for Vocabulary, Technology and Control Groups

18. Means and Standard Deviations for Vocabulary Pretest and Posttest S, Fifth Through Seventh Grades 
19. ANCOVA Repeated Measures for Vocabulary, Fifth Through Seventh Grade, Technology and Control Groups

20. ANCOVA Repeated Measures Results for Vocabulary, Fifth and Sixth Grades, Technology and Control Groups

21. GAA Students Before and After the Technology Intervention for Reading Comprehension

22. Means and Standard Deviations for Reading Comprehension Pretest and First Posttest

23. ANCOVA Results for Reading Comprehension, Technology and Control Groups

24. Means and Standard Deviations for Reading Pretest and Posttests, Fifth Through Seventh Grades

25. ANCOVA Repeated Measures for Reading, Fifth Through Seventh Grade, Technology and Control Groups

26. Means and Standard Deviations for Reading Comprehension Pretest and Posttests, Fifth and Sixth Grades

27. ANCOVA Repeated Measures Results for Reading Comprehension, Fifth and Sixth Grades, Technology and Control Groups

28. Mean National Percentile Ranks of GAA Students on ITBS, Fall 2013. 


\section{LIST OF ABBREVIATIONS}

$\begin{array}{ll}\text { CAI } & \text { Computer-Assisted Instruction } \\ \text { CBI } & \text { Computer-Based Instruction } \\ \text { GAA } & \text { Glenview Adventist Academy } \\ \text { ICT } & \text { Information and Communication Technologies } \\ \text { IRA } & \text { International Reading Association } \\ \text { ITBS } & \text { Iowa Test of Basic Skills } \\ \text { NAD } & \text { North American Division } \\ \text { SAT-9 } & \text { Stanford Achievement Test, } 9^{\text {th }} \text { edition; may occur as SAT-8 } \\ \text { SPSS } & \text { Statistical Package for Social Sciences } \\ \text { TPACK } & \text { Technology Pedagogy Content Knowledge } \\ \text { US } & \text { United States } \\ \text { VSC } & \text { Vocabulary Spelling City } \\ \text { ZPD } & \text { Zone of Proximal Development }\end{array}$




\section{ACKNOWLEDGEMENTS}

Although change is the only constant in life (Heraclitus), there are certain values and principles that remain the same throughout the ages. As we move toward a more technology-driven society, I believe there is a need to change and adapt without sacrificing the tenets or the identity of Seventh-day Adventist education, which is to restore the image of God in humankind.

Another concept that does not change is God. "God remains the same, yesterday, today, and forever" (Heb13:8, KJV). As He is the Life Giver, I am forever indebted to Him for allowing me to participate in His redemption plan through my participation in Seventh-day Adventist education.

To my father, who always demonstrated passion for innovation and technology, I am most thankful.

To my fellow Seventh-day Adventist teachers who sacrifice so much for a higher calling, thank you for your example of dedication and determination.

To the Seventh-day Adventist educational leaders and administrators for their expertise and desire to see Seventh-day Adventist education taken to higher levels, thank you for your vision.

To my dear friend Dr. Gus Martin, who supported me in different ways along this journey and encouraged me to work even harder, thank you!

To my advisors and professors at Andrews University who worked perseveringly with me all these years. Special thanks to Dr. Sylvia Gonzalez, my first academic advisor 
when I entered the doctoral program at Andrews; Dr. Bordes Henry-Saturne, my later academic advisor; Dr. Jimmy Kijai; Dr. Janet Ledesma; and Dr. Eileen White—all of whom provided advice, critiques, words of encouragement, and support.

To my family — wife Cristine, and sons Dallan and Kian — who were and are and will always be my favorite cheerleaders! I started this journey alone with my wife, and now God has blessed us with two precious souls for which to be responsible. Thank you for your endless patience and understanding during the countless hours that daddy and hubby had to spend away in order to complete his degree. I will be forever indebted to you! 


\section{CHAPTER 1}

\section{INTRODUCTION}

This chapter discussed the increasing use of technology in the classroom and presented a plan to study the use of software and hardware to establish their efficacy for improving language and literacy skills in faith-based classrooms. A description of the problem was followed by discussion of the use of tablets in the classroom, a statement of the problem and purpose of the study; a theoretical framework; research questions, limitations, delimitations, definitions, and variables. A summary and outline for the remainder of the project concludes the chapter.

\section{Context of the Study}

This study was conducted in the Seventh-day Adventist educational system, which is part of the Seventh-day Adventist Church, in the state of Arizona, particularly in one school, Glenview Adventist Academy (GAA), a kindergarten through eighth grade school. Seventh-day Adventist education is a worldwide institution with more than 7,500 schools and 1.5 million students (www.nadeducation). In North America, Seventh-day Adventist churches and schools are divided geographically into unions and conferences. The Arizona Conference of Seventh-day Adventists is part of the Pacific Union, with 13 schools scattered throughout the state. Glenview Adventist Academy is located in the western part of the Phoenix. 
GAA was founded in 1936 and has remained in operation ever since it was

opened. During the period in which this study was conducted (2013-2016) the school's enrollment increased steadily from 95 students in 2013 to 124 students in 2016.

Traditionally, Seventh-day Adventist schools in North America are supported financially by tuition payments from parents, private scholarship programs, donors, and churches. At GAA, only one church, Glendale Seventh-day Adventist, provided a subsidy to members who had children enrolled at the school. The school facility was located in the back part of the property of the Glendale church and had two wings of classrooms, a sports field, and a gymnasium. Financially, during the period of this study, GAA was going through a process of financial restructuring in an attempt to reverse the high receivables status. In addition to the large accounts receivable, GAA had a loan for a quarter-million dollars on which it was making monthly payments.

As stated in the mission statement, "Honoring our rich diverse community, developing independent learners into Christ-centered leaders," GAA has been characterized as ethnically diverse. Phoenix alone has an estimated 42\% Latino population, without counting the satellite towns of Phoenix (US Census Bureau, 2019). At GAA the percentage of Latino students during the period of this study was $65 \%$. The rest of the GAA population was completed by other ethnic groups.

\section{Description of the Problem}

The US federal government implemented policies, grants, and research, financing billions of dollars to provide digital access to most elementary and high schools across the nation (Alliance for Excellent Education, 2016; Federal Communications Commission, 2012; Gross, 2013; US Department of Education, Office of Educational 
Technology, 2010). Those federal funds were to be used for acquiring digital technology, teacher-training on the use of technology in the classroom and developing online curricula. Some states required implementation of digital technology in K-12 school districts, while others allowed and encouraged their use. Some states dedicated funding to acquire devices and software to be implemented in the classroom (Fox \& Jones, 2018). For example, on June 18th, 2013, the Los Angeles Unified School District approved almost $\$ 40$ million to start equipping students, teachers, and administration with educational iPads. This was a significant step toward technology implementation in the second largest school district of the nation, and the first step of a one-billion-dollar investment to provide one-to-one iPads for all students in the district (Blume, 2013).

Tablets, particularly iPads, had been flooding classrooms ever since they came onto the market in 2010. Internet access increased from 51\% in 1998 to $98 \%$ in 2012 within K-12 schools in the United States (LearnStuff, 2012). By the year 2018, 98\% of the K-12 school districts in the nation, covering 81,000 schools and almost 45 million students had high-speed broadband connectivity services, compared to $31 \%$ in 2013 (Education Super-Highway, 2018). Systematically, school districts and private schools in multiple countries invested in these devices, assuming that implementation provided a higher level of student performance and student engagement.

When this research project and implementation began in 2013, Norris \& Soloway (2012) stated that there were 1.5 million students in the Unites States using iPads as part of their regular instruction; since then, the number of students using this technology had increased steadily. The speed at which this mobile technology was being implemented surpasses all other technology devices used as instructional aids in the past, including 
desktops and laptops. As of 2018, $81 \%$ of 8- to 17-year-old children owned a tablet and used it for educational purposes (Pew Research Center, 2019). Seventy-five percent of teachers believed that by the year 2026 textbooks would be published in digital formats and students would need digital devices to access them (Deloitte Development, 2016).

This phenomenon raised questions from taxpayers, investors, and educators about the efficacy of tablets as instructional tools. Magruder (as cited in Blume, 2013), demonstrated concern when Los Angeles Unified School District board members approved the multi-millionaire investment in iPads in spite of the lack of conclusive research data corroborating a positive correlation between iPad use and student academic achievement. Only in recent years have studies suggested that the use of educational apps with tablets could lead to increases in student achievement (Moon et al., 2017; Wang, 2017). A survey in 89 different countries found the majority of teachers (95\%), students (75\%), parents (84\%), and school administrators (63\%) expressed improved academic performance and student engagement as a result of using digital devices for instructional purposes (ASCD \& OverDrive, 2016; Schoology, 2017).

Correlated to the dramatic increase in iPad use, hundreds of thousands of educational applications were developed and continued to increase (Mendelsohn, 2012). Following this national educational trend, during fall 2013, GAA invested approximately $\$ 40,000$ to implement iPads and Mac Minis in Grades 5 through 8; the objective being to provide state-of-the-art technology and valuable educational resources to its students.

One of the challenges that arose with the implementation of one-per-student iPads at GAA was determination of which applications would be used by teachers and students, especially in spelling, vocabulary acquisition, and reading comprehension. Traditionally, 
due to the singular characteristics of the English language, spelling, vocabulary, and reading comprehension instruction included worksheets, flashcards, and crossword puzzles to help students learn to decode words and their meaning. Another challenge and part of the problem at GAA was the below average performance of most students in Grades 5 through 8 in these subjects when taking the Iowa Test of Basic Skills (ITBS).

As shown in Table 1, GAA students were performing at or below the $50^{\text {th }}$ percentile in most of the grades and subjects. All grades performed below the national mean $\left(50^{\text {th }}\right.$ percentile $)$ in reading comprehension; for GAA only spelling averages were slightly above the national mean.

\section{Table 1}

Mean National Percentile Ranks of GAA Students on ITBS, Fall 2013

\begin{tabular}{lccccc}
\hline & \multicolumn{5}{c}{ Percentile Results by Grade for GAA } \\
\cline { 2 - 6 } ITBS Test & Grade 5 & Grade 6 & Grade 7 & Grade 8 & Totals \\
\hline Vocabulary & 50 & 37 & 37 & 52 & 44 \\
Spelling & 81 & 58 & 35 & 47 & 55 \\
Reading Comprehension & 45 & 28 & 32 & 33 & 34 \\
\hline Totals & 59 & 41 & 35 & 44 & \\
\hline
\end{tabular}


School administration, in the search for methods to improve that finding, decided to implement iPad Minis and a spelling app named Vocabulary Spelling City (VSC), for the fifth- through eighth-grade students at GAA. Students and teachers would be able to implement a different learning and teaching approach with the intent that knowledge about the efficacy and efficiency of this method of teaching spelling, vocabulary, and reading comprehension would assist in the quest for academic excellence, in addition to improving student performance.

\section{Implications for Instructional Leadership}

The implementation and use of technology in the classroom stems from decisions made by educational leaders which affect what happens in the classroom regarding the use of those technologies irrevocably. As mentioned before, Magruder (as cited in Blume, 2013), raised concerns regarding the Los Angeles school district 40-million dollar investment for acquiring educational iPads in spite of lacking conclusive evidence that this technology could provide significant academic improvement among elementary and high school students.

Instructional decisions made by educational leaders regarding the implementation of expensive technologies in the classroom has, therefore, an impact on the finances of educational institutions, consequently affecting the order of priorities when it comes to expenses (Blazer, 2013; Bowie, 2017; Kolb, 2019; Wilson, 2012). Naturally, in the public school sector, financing technology for schools affects public funds directly that could be used very well for something other than technology that could provide more benefits in the way those public funds are administered (Blume, 2013). 
On the other hand, there is a perceived need that students must be exposed to the latest technological advances in preparation for the increasingly technology-driven workforce (Bybee, 2010; Goldin \& Katz, 2009). Technology literacy is part of the new objectives in equipping students with 21 st-century skills. Dalton and Grisham (2011) noted that information and communication technologies (ICTs) are tools which literacy educators must incorporate into the 21 st century skills required for students to learn. The International Reading Association ([IRA], 2009) stated that "to become fully literate in today's world, students must become proficient in the new literacies of the 21 st century" (p. 16). Therefore, instructional and educational leaders are required to find a fine balance between budgetary concerns and technology instruction goals.

Another area of concern with which instructional leaders are faced with is the amount of professional development often required to prepare teachers for the use of technology (Mishra \& Koehler, 2009). In addition, according to Penski (2001), there seems to be a degree of reluctance among teachers to learn new technologies as well as the generational gap between teachers and their students making the acquisition of technological skills by the teachers difficult. Therefore, it is imperative that principals and teachers work together to improve the use of technology in the classroom through supervision, evaluation, and professional development (Di Paola \& Wagner, 2018).

\section{Statement of the Problem}

As technologies developed rapidly, there was increased need to integrate them into the classroom to prepare students for careers that do not even exist yet (Bybee, 2010; Goldin \& Katz, 2009). Because of the challenges GAA middle-school students were having in spelling, vocabulary, and reading comprehension, performing below the 
national percentile rank of 50 on the ITBS, school leaders proposed a technology implementation program to use tablets (iPad Mini) and the software VSC. The software was and continues to be a popular resource for literacy in elementary Seventh-day Adventist schools across the nation. However, not until recently was a study conducted about the efficacy of VSC among elementary school students (Arens \& Mace, 2017). In addition to the minimal research conducted then regarding the use of VSC, there were no research studies from faith-based school systems, including the unknown efficacy of VSC regarding students' academic growth in the areas of spelling, vocabulary, and reading comprehension.

\section{Purpose of the Study}

The purpose of this study was to determine the efficacy of using VSC software and iPad Minis as the main instruction and practice tool among students in Grades 5 through 8 at GAA, in the areas of vocabulary, spelling, and reading comprehension. A quantitative quasi-experimental research design was selected for this study because it best suits the research questions, which focus on the efficacy of using VSC with iPad Minis.

\section{Research Questions}

This research study proposes to answer the following research questions:

1. Is there a difference in student performance in spelling when exposed to a technology-based curriculum while controlling for the covariate pretest among students in Grades 5 through 8 at GAA?

2. Is there a difference in student performance in vocabulary when exposed to a technology-based curriculum while controlling for the covariate pretest among students in Grades 5 through 8 at GAA? 
3. Is there a difference in student performance in reading comprehension when exposed to a technology-based curriculum while controlling for the covariate pretest among students in Grades 5 through 8 at GAA?

\section{Theoretical Framework}

Dalton and Grisham (2011) noted that information and communication technologies (ICTs) are tools which literacy educators must incorporate into the $21 \mathrm{st}$ century skills required for students to learn. The International Reading Association ([IRA], 2009) stated that “to become fully literate in today's world, students must become proficient in the new literacies of the 21 st century" (p.16). Yet many teachers and educators lacked the theoretical foundation to implement the use of technology in the classroom.

The theory that sustained this research project was based on the technologicalpedagogical-content knowledge (TPACK) framework (Koehler \& Mishra, 2009; Mishra \& Koehler, 2006; Schmidt, et al., 2009). This theoretical framework identified the complex interactions among the teacher's technological knowledge, pedagogical knowledge, and content knowledge (Hutchison et al., 2012). The TPACK theoretical framework was based on Shulman's approach to the integration of teacher's knowledge and pedagogical practices (as cited in Mishra \& Koehler, 2006). According to Mishra and Koehler (2006) the TPACK “emphasizes the connections, interactions, affordances, and constraints between and among content, pedagogy, and technology" (p. 1025). The purpose of this approach was to consider the complexities and interactions that exist among these three bodies of knowledge: content, pedagogy, and technology. 
Mishra and Koehler (2006) represented this interconnectivity graphically as three intertwined circles in which every circle represented a body of knowledge, presented in Figure 1.

The difference between this model and Schulman's, according to Mishra and Koehler (2006) was that it incorporates two new pairs, technology-content knowledge (TCK), and technological-pedagogical knowledge (TPK), and one triad, technologicalpedagogical-content knowledge (TPACK). In summary, based on Mishra and Koehler (2006),

TPACK is the basis of good teaching with technology and requires an understanding of the representation of concepts using technologies; pedagogical techniques that use technologies in constructive ways to teach content; knowledge of what makes concepts difficult or easy to learn and how technology can help redress some of the problems that students face; knowledge of students' prior knowledge and theories of epistemology; and knowledge of how technologies can be used to build on existing knowledge and to develop new epistemologies or strengthen old ones ( $\mathrm{p}$. 1029).

\section{Figure 1}

Technology-Pedagogical-Content Knowledge model (Mishra \& Koehler, 2006)

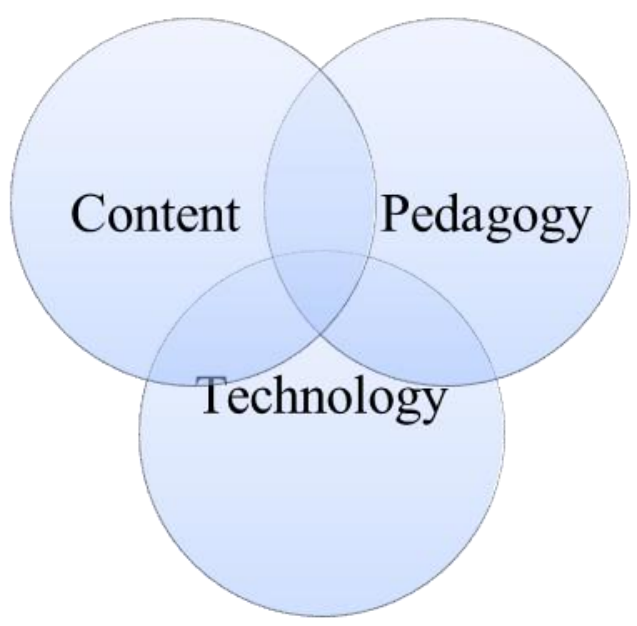


Since none of these areas could be viewed in isolation, they were intertwined and affected by one another; Mishra and Koehler (2006) argued that this TPACK framework provided a dynamic transactional relationship. In other words, any change in one of the disciplines needs to be compensated in the other two. An example was the use of online instruction and how this new technology had forced educators to rethink the entire educational process and its ramifications. Knowing how to use the technology does not guarantee knowing how to teach with it.

\section{Significance of the Study}

This study contributed to the sparse knowledge existing about applying technology, particularly iPad Minis and specific software, to instructional purposes among middle-school students (Heinrich, 2012; Roser, 2017). More and more schools had implemented tablet technology in their classrooms, but the majority were unaware of the implications in terms of student performance, attitude, and engagement with this technology. Furthermore, this study enlightened controversies about teaching methodologies and didactics. Prensky (2001) stated there was a breach between those generations who were digital natives and the teachers, pedagogues, and lawmakers who were digital immigrants. That fissure affected how teaching and instruction were approached when working with this digital-native generation.

Specifically, this study contributed to the implementation of VSC, a computer tablet app, using iPad Minis, as a way of delivering spelling and vocabulary content to middle-school students, allowing them to train and practice by using VSC with iPad minis provided by GAA. 


\section{Limitations}

According to Creswell and Guetterman (2018), the quasi-experimental approach, which was the research design used in this study, introduced considerably more threats to internal validity when compared to a true experimental design. In this study, random selection was not used, and the author worked with intact groups; therefore, there were potential threats of maturation, selection, mortality, and interaction among other uncollected variables.

Because of the nature of this study and the peculiar characteristics of the site and subjects, a control group could not be used from the same site nor facility. Thus, the academic performance of students in Grades 5 through 8 in Seventh-day Adventist schools where the traditional way of teaching these subjects was compared to the GAA students (Grades 5 through 8) who had access to the app VSC, using iPad minis. All schools were located within the Arizona Conference of Seventh-day Adventists

This study was limited by time and space and was an attempt to glimpse a particular and unique reality of students and teachers belonging to a geographicallylimited educational system. In spite of the efforts made to control all the possible variables affecting student testing, it was impossible to control them all. Although this study was a snapshot of a particular place in time, it contributed to the limited but increasing body of knowledge about technology in the classroom, the use of tablets, and of educational software as part of the instructional curriculum.

\section{Delimitations}

This study was conducted among students from GAA and was a comparison of their academic performance throughout a three-year technology implementation with that 
of students from sister schools within the Arizona Conference of Seventh-day Adventists which were using traditional ways of teaching spelling, vocabulary, and reading comprehension (i.e., text- and handwritten-based methods).

Conducting this study only among the schools in the Arizona Conference of Seventh-day Adventists facilitated collection of data. Thus, the results of this study might not be applicable to the general population.

\section{Key Terms and Definitions}

App: An application or software, especially as downloaded by a user to a mobile device.

Software: The programs and other operational information used by a computer

Computer hardware: Any physical device used in or with a computer.

Conference: "Smaller administrative units within each of the nine union

conferences in the North American Division of Seventh-day Adventists (NAD). There are 58 conferences within the NAD; the NAD is one of 13 divisions in the world church" (Bayer, 2017, p. 13).

Faith-based schools: "A faith-based school or school program is operationalized as schools or authorities that publicly self-identify themselves as religious, openly affiliate with a religious group, or are run by, or exclusively serve, a religious group or society" (Hiemstra \& Brink, 2006, p. 1158).

Tablet: A mobile computer that operates with a touchscreen as its primary input device. Most tablets are smaller than and weigh less than the average laptop. Tablets without keyboards allow you to enter text using a pop-up keyboard that appears on the screen. 
iPad mini: Is a line of mini-tablet computers designed, developed, and marketed by Apple, Inc.

\section{List of Variables}

Following is a list of the variables, an explanation of each one, and the rationale for consideration for this study.

Gender: Male or female. A descriptive variable.

Grade: The grade level of each student. To determine whether each student belonged to the fifth grade, the sixth grade, the seventh grade, or the eighth grade. To determine whether there were any differences between and among grades.

Teaching Method: The traditional method of teaching, involving textbooks and lecturing, vs. the technology-based method in which the student used a tablet and software to learn spelling, vocabulary, and reading comprehension. There was no lecturing involved in the latter method of teaching. The independent variable.

Spelling Pretest SO: The Spring 2013 ITSB, a standardized test, was used to collect preliminary performance data on spelling the year before the intervention.

Spelling Pretest: The Fall ITSB, a standardized test, was used to collect student performance data on spelling before the technology-based or traditional curriculum was administered to students.

Spelling Posttest S1: Seven months later, in Spring, both groups (control and technology) were administered the ITSB to compare the students' performance levels.

Spelling Posttest S3: Spring testing of both groups of students during year two after the intervention was implemented. 
Spelling Posttest S5: Spring testing of both groups of students during year three since intervention was implemented.

Vocabulary Pretest SO: The Spring 2013 ITSB, a standardized test, was used to collect preliminary performance data on vocabulary the year before the intervention.

Vocabulary Pretest: The Fall administration of the ITSB, a standardized test, was used to collect student performance data on vocabulary before the technology-based curriculum was administered to students.

Vocabulary Posttest S1: Seven months later, in Spring, both groups (control and technology) were administered the same test to compare the students' performance levels.

Vocabulary Posttest S3: Spring testing of both groups of students during year two since intervention was implemented.

Vocabulary Posttest S5: Spring testing of both groups of students during year three since intervention was implemented.

Reading Comprehension Pretest S0: The Spring 2013 ITSB, a standardized test, was used to collect preliminary performance data on reading comprehension the year before the intervention.

Reading Comprehension Pretest: The Fall ITSB, a standardized test, was used to collect student performance data on reading comprehension before the technology-based curriculum was administered to students.

Reading Comprehension Posttest S1: Seven months later, in Spring, both groups (control and technology) were administered the same test to compare the student performance data on reading comprehension skills. 
Reading Comprehension Posttest S3: Spring testing of both groups of students during year two since intervention was implemented.

Reading Comprehension Posttest S5: Spring testing of both groups of students during year three since intervention was implemented.

Control Group: Members of this group were students in Grades 5 through 8 from Seventh-day Adventist schools in the Arizona Conference who were not exposed to VSC through the use of iPad minis.

Experimental Group: Members of this group were students from Grades 5 through 8 at GAA who were exposed to VSC through the use of an iPad mini for a minimum of 30 minutes a day, five days a week. Hereafter, this was referred to as the technology group.

\section{Summary}

A review of the research suggested that the use of tablets for language arts instruction and practice was beneficial to the academic development and growth of elementary school students. Furthermore, one study (Arens \& Mace, 2017) demonstrated a positive change in student vocabulary and reading comprehension skills while using VSC as the medium for delivering content. On the contrary, some research suggested that the use of tablets and apps for delivering literacy content could be detrimental to the students' academic performance in those areas (Gasser \& Palfrey, 2009; Lanir, 2012).

This study was an attempt to assess and evaluate the results of implementing VSC, through the use of iPad minis, among middle school students at GAA on their performance in spelling, vocabulary, and reading comprehension as measured by the ITBS. 


\section{Organization of the Study}

Chapter 2 presented a summary and review of the critical and seminal literature related to the areas of vocabulary, reading and comprehension, and spelling in the English language, and how they interact one with the others through different ways of teaching. This chapter also presented and reviewed the use of technology in the classroom, specifically use of computer-based software and an electronic tablet as media for teaching the subjects aforementioned. Singular attention was been dedicated to the use of tablets, particularly iPads and iPad minis in the instruction and practice of literacy skills, including a description of the app VSC, which was the focus of this study.

Chapter 3 offered a description of the statistical methods used to approach this study and the rationale behind their selection. Participant selection, a description of the instrument used, and collection of data were discussed.

Chapter 4 summarized the findings for each research question. Chapter 5

presented a summary of the research including conclusions, implications, and recommendations for further study. 


\section{CHAPTER 2}

\section{LITERATURE REVIEW}

\section{Introduction}

To justify this study, the characteristics involved with teaching and learning vocabulary, reading comprehension, and spelling were described. Because teaching and learning were related to the subject being studied, a summary of learning theories used in classrooms throughout the last century was presented here. Due to the unique characteristics of our technology-driven society and the need to prepare students for technology-driven jobs, seminal research on the aspects of technology in the classroom, instructional leadership and technology, use of tablets for instruction and practice of literacy skills, and computer educational software were reviewed here.

\section{Reading Comprehension and Vocabulary}

Reading comprehension is a complex ability, requiring a combination of cognitive skills including decoding, working memory, linguistic reasoning, executive functioning, inferencing, vocabulary, and prior knowledge (Cutting \& Scarborough, 2006; Kendeou et al., 2014; Perfetti et al., 1996). In addition to all the cognitive skills required for appropriate reading comprehension, Catts and Kamhi (2017) argued that reading comprehension was not a unidimensional construct, requiring consideration of the interaction among the reader, the text, and the task within a sociocultural context. 
According to the reading comprehension results from the Programme for International Student Assessment (Gurria, 2016; OECD, 2016), teenagers from the US were performing below the world average among developed nations. Several factors were suggested as causes, including a lack of teacher quality (Merry, 2013), a decline in text complexity (Adams, 2011; Hayes et al., 1996), and a change in instructional intensity (Vaughn et al., 2010). However, comprehension strategy critics stated that mediocre test scores in reading comprehension were attributed to spending much of the instructional time teaching comprehension strategies at the expense of other important skills such as background knowledge of the text being read (Hirsch, 2006; Willingham, 2006).

According to Kendeou et al. (2014) and Kintsch and Rawson (2005) knowledge is the keystone to comprehension, in the sense that having a denser network of knowledge allows the student to retrieve relevant information when making inferences while reading. Several studies (Chiesi et al., 1979; Kendeou \& van den Broek, 2007; Recht \& Leslie, 1988) showed that readers with more knowledge in a given discipline outperformed readers with less knowledge on reading comprehension and memory tasks. In a study on reading comprehension among fifth-grade students, Compton et al (2013) discovered that prior knowledge was associated with higher levels of comprehension and vocabulary.

Despite the importance of prior knowledge and vocabulary in reading comprehension, little classroom instruction in the elementary school grades was dedicated to reading informational text and building vocabulary (Banilower et al., 2013; Duke, 2000; Palincsar \& Duke, 2004). Suggestions to build knowledge and vocabulary among students included the use of media and software as resources for journaling, 
constructing concept maps, creating digital presentations to be presented to peers, and internet research (Catts \& Kamhi, 2017; Romance \& Vitale, 2012).

In the studies reviewed, there was a strong connection between vocabulary and reading comprehension. Despite the increasingly visual world existing today, words remain the main method of communication (Kress, 2003). Several educational organizations and scholars highlighted the importance of vocabulary instruction as part of the student's literacy learning experience (National Reading Panel, 2000; Snow, 2002). Furthermore, studies showed a high correlation (0.6 to 0.8$)$ between vocabulary knowledge and reading comprehension (Kame'enui \& Baumann, 2012; Pearson et al., 2007; Stahl \& Fairbanks, 1986).

Of particular concern among educational researchers was the importance of teaching academic language. Oral language allows for fairly simple verbal communication; however, learning academic language is more complex because it involves abstract literacy tasks which oral speech does not require (Fang et al., 2006; Zwiers, 2013). Furthermore, Solomon and Rhodes (1995) consider academic language a second language which must be learned in order to access academic knowledge. For English learners, academic language may represent learning a third language (Dalton \& Grisham, 2011). Ultimately, both native speakers and English learners need to be exposed to a community that enjoys playing with words, one that was constructed from individual interests as well as curriculum needs, and that highlights self-efficacy in word learning (Beck et al., 2008; Graves \& Watts-Taffe, 2008).

Past studies contributed support for explicit instruction in vocabulary as a subject in order to enhance comprehension (Beck \& McKeown, 1991; Graves, 1987; Stahl \& 
Fairbanks, 1986). However, explicit vocabulary instruction methods were only effective when new words and concepts were integrated with previous knowledge and students had the opportunity to apply the new information in meaningful ways (Nagy, 1988). The topic of vocabulary, specifically in middle school and secondary education, continues to be a key component in reading comprehension, language arts, and across the curriculum (Wood et al., 2009). During vocabulary instruction students need to be taught the morphology of words and word origins; provided with multiple exposures to the word in different contexts; instructed in word learning strategies such as how to use context clues and cognate information, and helped to know how to decide when a word was important enough to know and remember (Dalton \& Grisham, 2011). After several decades of research on identifying critical components to increase literacy skills, researchers concluded that vocabulary knowledge was one of the most important factors in the area of literacy skills (Anderson \& Freebody, 1981; Baumann et al., 2003; Becker, 1977; Davis, 1942; Whipple, 1925).

\section{Spelling}

The unique nature of the English language creates a need to teach spelling in elementary education, although some educators have switched to a belief that spelling is learned best in the context of reading and writing rather than in formal spelling classes. According to Heald-Taylor's (1998) extensive research there were three approaches to teaching spelling in elementary school: traditional, transitional, and student-oriented. Furthermore, these three practices are, in most cases, intertwined when spelling instruction was implemented. 
The traditional paradigm, according to Graves (1994), was based on the notion that spelling was the foundation of literacy, and therefore should be treated as one of the most important curriculum subjects, alongside reading and mathematics. This approach was based on memorization skills, drills, lists of grade-appropriate words, and phonetics (Cahen et al., 1971; Gates, 1937) and taught as a separate subject. Challenges to the traditional paradigm included the concept that learning to spell was a complex and intricate, cognitive, and linguistic process; that is, much more than plain memorization (Zutell, 1992). Another concern with this paradigm was that only $46 \%$ of English words are spelled phonetically (Graves, 1994). The greatest challenge to the traditional method of teaching spelling arose when students with no formal spelling instruction were shown to be able to spell at the same level or better by fourth grade (Hammill et al., 1977).

The transitional paradigm emerged as the result of phonics not being able to explain the spelling of about half of the English words, especially those with irregular spellings (Barnes, 1982; Templeton 1980). This practice proposes integrating phonology, morphology, orthography, semantics, and syntactic features into spelling instruction (Ehri, 1994). Studies of this approach among students in Grades 4 through 6 showed positive results when phonetic, semantic, visual/graphic, and reading functions were combined (Carlisle, 1985; Cherrington, 1985; Waters et al., 1988). The relationship of reading comprehension to spelling development and performance was established by Zutell (1992) and Zutell and Rasinski, (1989); and relationships between spelling and comprehension by Bear's research (1991). Furthermore, studies including primary and older students reported that good readers who read fluently were also able to spell the majority of spelling words given every week while weak readers were not (Scott, 1991; 
Stanovich, 1986). The conclusion was that the study of spelling should come from student reading materials to make it more meaningful for the child. However, other researchers suggested that word study was important inside and outside of a reading context (Invernizzi et al., 1997). In this transitional paradigm, studies suggested that the inclusion of word games and word sorts was a way to reinforce phonetic, visual, and semantic knowledge, providing the words were organized according to orthographic principles (Bear et al., 1996; Gentry \& Gillet, 1993; Moats, 1995).

According to Heald-Taylor (1998), one of the main concerns with this paradigm was that reading, writing, and spelling work together. Many spelling practices of this paradigm, such as word sorts and spelling games, were conducted separately from contextual reading. Other concerns included the lack of teaching strategies to improve spelling during writing tasks, and the disregard of students' developmental stages.

Heald-Taylor (1998) also pointed out that the student-oriented paradigm had its foundation in the previous two paradigms; however, "there were three main differences: a) learning how to spell was seen as a developmental process, b) reading provides the context for learning to spell, and c) spelling was a functional component of writing" (p. 404). The theories that support this paradigm reside on the contributions of cognitivism (Piaget, 1926), and the social-constructivist theories of Vygotsky (1978) and Bruner (1985), including the zone of proximal development (see section on social constructivism) and scaffolding. Therefore, teaching strategies need to revolve around teacher modeling, exposure, language maturity, and student needs. The expectation was that students would engage actively in their own learning and figure out much spelling on their own. 
In summary, Moir (1995) had shown that teachers used teaching strategies from all three paradigms. Also, there was a connection between spelling performance and word recognition, vocabulary, and reading comprehension. Those who were good readers tended to be good spellers (Stanovich, 1986).

\section{The Use of Technology for Language Arts Instruction and Practice}

Ouyang (1993) conducted a meta-analysis of more than seventy studies on the effectiveness of computer-assisted instruction (CAI) at the elementary level, concluding that the use of software for instruction resulted in significant improvement among kindergarten through sixth-grade students in the areas of spelling, vocabulary, and reading comprehension. The major differences were produced within the first four weeks after software implementation.

Van Daal and Reitsma (2000) found that using specific software for spelling and reading instruction among kindergarteners was successful; in up to 16 hours of computer practice, the students learned as much as was normally attained in the first three months of formal reading and spelling instruction in a classroom.

In England, Singleton and Simmons (2001) reported an evaluation of the effectiveness of the computer software "Wordshark" when used by elementary students to practice spelling and word recognition. Ninety-seven percent of the students surveyed enjoyed using the software; significant improvements in children's reading comprehension and spelling were reported.

In 2008, Mayfield et al., reported positive results in spelling among elementary students when using computer-based instruction (CBI). Some of the benefits of using 
CBI included a rate of differentiated instruction, automatic corrective feedback, collection of student performance data, and an opportunity for constant assessment and retention of skills. Wu and Zhang (2010) reported that "students in the fourth grade who used handheld computers to learn spelling had higher test scores than students who learned spelling without handheld computers" (p. 57).

Another study conducted in Canada by Lysenko and Abrami (2014) among 517 first and second graders, from six different schools in Quebec, concluded that the use of two online software contributed to a better performance in reading comprehension among students belonging to the experimental group.

For reading and reading comprehension $\mathrm{CBI}$ appears to provide better results as well. Greenlee-Moore and Smith (1996), using a three-way analysis of variance, found that reading comprehension scores on the ITBS increased when students read more difficult narratives displayed on a computer screen. In a larger study, using CBI with a sample of 950 students, Mann et al, (1999) observed significant improvement of reading comprehension scores on the Stanford Achievement Test, 9th edition, (SAT-9) among fifth graders.

Continuing, Walport and Fitzpatrick (2001, as cited by Jones et al., 2004) implemented a computer-based tutoring program for at-risk elementary school students. The students were assessed before the beginning of the program and again at the end. Both the Slosson Oral Reading Test-R and the Star Assessment for Reading and Math demonstrated a gain in grade equivalency of three to eight months. Ligas (2002) investigated a five-year program using CBI to determine whether there was any difference in growth of reading comprehension for at-risk middle school students. The 
students who were exposed to the computer training outperformed students who were not exposed by 7.74 points on SAT-8 reading comprehension NCE (normal curve equivalent) scores.

A study by Traynor (2003) sought to determine whether the use of CBI was useful among elementary school students in the subject of capitalization. Pretest and posttest scores were collected over a 70-day period. The treatment group's posttest scores were higher than those who did not use the computer-based program. Another study by Jones et al., (2004) examined the efficacy of a computer software package to improve reading comprehension among elementary students. The SAT-9 results for treatment and control groups were compared for two years. The treatment group demonstrated achievement gains for the dependent variables of reading vocabulary, reading comprehension, spelling, language mechanics, and language expression.

Gegner et al., (2009) studied whether an online reading aid software program for scientific articles helped high school students comprehend the text. They found that students who read the scientific article online using the software achieved better reading comprehension scores when compared to students who read the article online but did not have the software. With fourth graders, Wijekumar et al, (2012) used the structure strategy, such as sequence, description, compare-contrast, cause-effect, and problem solution, to analyze texts using online web-based software to guide students; they found significant improvements in reading comprehension. Ponce et al., (2013) discovered that using graphic organizers and computer software to break down the ideas within the text contributed to better reading comprehension and writing among fourth, sixth, and eighth graders compared to those who did not use the computer software to help with the task. 
Finally, Moon et al., (2017) found positive results in fifth grade students who used reading comprehension activities in electronic tablets (iPad). The students who were exposed to the technology were able to outperform those who were not exposed in the area of reading comprehension.

\section{The Impact on Learning Literacy of Using iPads}

As discussed earlier, since computers were introduced into classrooms, they played an important role in literacy instruction. However, the introduction of mobile technologies such as the iPad, and other electronic tablets, changed learning options for teachers and students (Johnson et al., 2009).

Brand and Kinash (2010) note that devices such as the iPad promote learning everywhere, eliminating the physical restrictions imposed by non-mobile technologies. Additionally, the iPad and electronic tablets offer affordable multi-touch screens, online access, and an endless list of educational applications, providing a wide variety of educational options.

Several studies (Coiro et al., 2008; Lankshear \& Knobel, 2003; Leu, 2006; Leu et al., 2004) established differences between instruction strategies using printed texts and digital texts. These studies suggested that reading digital texts requires a different set of skills and strategies which they named new literacies.

Another advantage of digital text was that iPads and electronic tablets support differentiated instruction based on the student's level of reading comprehension, vocabulary, spelling knowledge, and understanding (Leu \& Reinking, 1996; Reinking, 1992, 1998, 2001). 
In 2009, the IRA issued a statement about the importance of preparing today's students for tomorrow's realities, specifically the use of 21 st century skills, by stating:

To become fully literate in today's world, students must become proficient in the new literacies of $21^{\text {st }}$-century technologies. IRA believes that literacy educators have a responsibility to integrate ICTs into the curriculum, to prepare students for the futures they deserve (n.p.).

The National Education Technology Plan (US Department of Education, 2010) also emphasized the importance of students learning from electronic or digital text, because such formats provide internet connectivity; offer rich, interactive learning experiences, and personalized learning; encourage collaboration; give timely feedback; and support formative assessment in addition to student self-assessment (as cited in Dalton, 2014). Therefore, integrating digital technologies into literacy instruction and providing the necessary tools for students to be successful had become relevant to teachers and instructors of this millennium (Hutchison \& Reinking, 2011).

\section{Benefits of Using Tablets in the Classroom}

According to the US Department of Education (2010) and studies by the National Training and Simulation Association (2012), technology-based instruction reduced the time students needed to reach a learning objective by $30-80 \%$. Another survey conducted by Public Broadcasting Services (2012) found that $77 \%$ of teachers concluded technology had contributed to increases in students' motivation to learn.

Another benefit of using tablets in the classroom was the storage capacity of these devices; they could contain thousands of digital textbooks, online resources, quizzes, homework, and other materials, eliminating the need and expense of coping with physical storage space for books and classroom materials (Price, 2012). From the financial 
perspective, Sumser (2016) noted that the cost of acquiring digital textbooks was significantly less when compared to hard copies. Another benefit of using tablets instead of textbooks or paper and pencil was the savings on paper, copy paper, printing supplies, and related costs when using tablets. A 100-teacher school uses about 250,000 pieces of paper annually, costing $\$ 3-4,000$ in printing expenses. A tablet-based school would save significant amounts of money and help protect the environment (Johnson, 2011;

Williams, 2012). Studies conducted by Maragioglio (cited by Connor, 2016), Moon et al. (2017), and Wang, (2017), used tablets as a method of instruction and practice and found improvements in student academic performance.

Tablets contain many technological features lacking in textbooks. The ability to highlight text, take notes, and make annotations without ruining the textbook for the next user are a few examples. Tablets offer screen brightness control, backlight intensity, and a built-in dictionary allowing students to inquire about the meaning of an unknown word. Digital information could be shared instantaneously with more individuals. Access to videos, interactive graphics, and diagrams increased students' attentiveness and engagement (Apple, 2019; Groff, 2013; Hall, 2017; Harper, 2018; Johnson, 2019).

A disadvantage of print textbooks was the weight which was connected to back injuries among K-12 students in the United States. More than 13,000 students were treated for back, neck, and muscular injuries caused by the use of heavy backpacks during the year 2010-2011. That number dropped to less than half that many by the year 2016, because of the increased use of tablets. The average weight of tablets was between one and two pounds (American Academy of Orthopedic Surgeons, 2017; California Department of Education, 2004; Dallas, 2012). 
The use of tablets contributes to the preparation of students for a world which is immersed in technology. According to the US Bureau of Labor Statistics (2019), technology-related jobs were expected to increase by $18 \%$ between 2010 and 2020 . Another benefit of using tablets was the ability to download hundreds of thousands of educational apps including the option to update textbooks automatically rather than reprinting them (Federal Communications Commission, 2012; Obama, 2013).

One of the greatest benefits of using tablets for instruction and academic practice was the ability of software and apps to differentiate instruction according to the educational needs of each student (Mendelsohn, 2012). Every teacher knows that classrooms include students who perform at different academic levels. Moreover, in the Arizona Seventh-day Adventist educational system, all of the elementary schools had multi-grade classrooms, including GAA.

\section{Considerations for Using Tablets in the Classroom}

As mentioned earlier by Magruder (as cited in Blume, 2013) there were concerns about using tablets in the classroom. Advocates against the use of these devices were concerned about health problems. Handheld devices contributed to computer vision syndrome, eyestrain, blurred vision, and dry eyes (Klamm \& Tarnow, 2015). Individuals presented with musculoskeletal disorders from the constant strain of certain muscles, including carpal tunnel syndrome, neck pain, shoulder pain, and fibromyalgia (Fishman, 2010; Lin, 2009).

Some argued that tablets were more expensive than textbooks because of the investment in technology and infrastructure required to operate them, plus the cost of maintenance and repair (Blazer, 2013; Bowie, 2017; Wilson, 2012). Others claimed that 
tablets were responsible for students' short attention spans, causing distraction more than serving as an educational aid (Gasser \& Palfrey, 2009; Lanir, 2012). According to some studies (Carr, 2010; Mueller \& Oppenheimer, 2014), the brain interpreted digital text differently than paper text. These studies argued that those who read paper-based text had higher comprehension, memorization, and learn more when compared to those who read digital text only.

Those who were opposed to the use of tablets in the classroom pointed out that many students still did not have sufficient internet bandwidth access at their homes, which restricted the use of the devices to the school environment (Federal Communications Commission, 2012; Horrigan, 2015).

Some educators were concerned that students would be more likely to cut corners and cheat while using tablets (Pandolfo, 2012). Students could avoid reading and analyzing texts by looking up answers through the search box in the e-textbook or by going online.

\section{Instructional Leadership and Technology}

The implementation and use of technology in the classroom stems from the decisions made by educational leaders which affect what happens in the classroom regarding the use of those technologies irrevocably. A primary implication is the financial impact technology implementations have on the school and district budget. New technologies tend to be expensive and as leaders ponder the different options and priorities of educational institutions, they are faced with critical and important decisions (Blazer, 2013; Bowie, 2017; Kolb, 2019; Wilson, 2012). 
On the other hand, there is a perceived need that students must be exposed to the latest technological advances in preparation for the more increasing technology-driven workforce (Bybee, 2010; Goldin \& Katz, 2009). Dalton and Grisham (2011) noted that information and communication technologies (ICTs) are tools which literacy educators must incorporate into the 21 st century skills required for students to learn. The International Reading Association ([IRA], 2009) stated that "to become fully literate in today's world, students must become proficient in the new literacies of the 21 st century" (p. 16). Therefore, instructional and educational leaders are required to find a fine balance between budgetary concerns and technology instruction goals.

As a result of this, and according to Kolb (2019), school administrators feel pressured to implement technology in the classrooms yet they lack the conceptual framework for how technology should be incorporated. Hence, Kolb (2019) proposes the Triple-E Framework to assist school administrators and teachers in their decisions regarding types of technologies that could be implemented in the classroom. Kolb (2019) suggests that "engagement, enhancement, and extension should be considered when implementing technology into a learning activity" (p. 22). For engagement, Kolb (2019) argued that learning needs to be social, therefore, teachers cannot afford technology to disrupt the social component of the learning experience, and then suggested ways to use technology accordingly. Learning with technology is more productive when it provides higher-order thinking and skills (Hirsh-Pasek et al., 2015); therefore enhancement happens "when students are using technology to create, analyze, evaluate, gather, and synthesize knowledge, there can be long-term and positive cognitive growth (Kolb, 2019, p. 24). The last component of this framework is called extension, and refers to the 
connection of learning with technology with real-life challenges and problems and how the learning and technology can contribute to solve those (Kolb, 2019; Richardson, 2019).

Another area of concern with which instructional leaders are faced is the amount of professional development often required for preparation of teachers to use technology (Mishra \& Koehler, 2009). In this area, Joo et al. (2018) concluded that using the TPACK framework among college teachers resulted in affecting teacher self-efficacy, the perceived ease of using, and the usefulness of technology positively. In addition, there seemed to be a certain degree of reluctance among teachers to learn new technologies as well as a generational gap between teachers and their students which made the acquisition of technological skills by the teachers a difficult process (Penski, 2001; Uğur \& Koç, 2019). Therefore, principals and teachers must work together to improve the use of technology in the classroom through supervision, evaluation, professional development, and a shared vision (Di Paola \& Wagner, 2018; Hughes et al., 2016; Lennon, 2012).

\section{Theories of Learning}

Throughout the last century, scientists showed increasing interest in human mental faculties; specifically, the way humans learn to provide explanatory theories which would guide teaching practices. In this study, the major learning theories are presented with a summary of their principle tenets and their authors or contributors.

\section{Behaviorism}

Arguably, the first relevant, and one of the most influential, theories of learning coming out of the end of the 19th century and the beginning of the 20th century was the 
behaviorism theory of learning. Although some of the ideas of behaviorism can be traced back to Thomas Hobbes (1588-1679) and David Hume (1711-1776), an American psychologist, John Watson, is the one supposed to be the first to use the term "behaviorism" (Pritchard, 2018).

By definition, behaviorism was a theory of animal and human learning focusing on the behavior of the learner and changes in behavior occurring when learning takes place (Woollard, 2010). Pritchard (2018) adds that behaviorism was a learning theory which focused on observable behaviors and ignored mental activity. Learning was simply defined as the acquisition of a new behavior.

Probably Pavlov (1849-1936), with the classical conditioning theory, and Skinner (1904-1990), with the operant conditioning theory, were the dominant contributors to the behaviorism theory. Pavlov's classical conditioning theory proposed that learning begins with a stimulus-response connection; in other words, certain stimuli lead to specific responses (Pritchard, 2018).

Skinner's operant conditioning theory proposed the strengthening of the desired responses by using "reinforcers," and, preferably, positive rewards, although he did not use the term reward. He also understood the value of punishment when dealing with unwanted or undesired behaviors. On his later work, Skinner began to recognize the influences of mental processes as part of the equation about how learning occurs (Pritchard, 2018).

Behaviorism had implications in the past and continues to influence today's classrooms. Teachers and researchers (Elliot \& Busse, 1991; Pritchard, 2018) found that using a behaviorist approach in the classroom seemed to help create an orderly 
environment which was conducive to learning and helpful to students who struggled academically. When working with students, particularly on basic skills, the process of practice and repetitive drills with a system of rewards had been shown to be effective (Pritchard, 2018).

Behaviorism was applied in CAI and the variety of software, apps, and hardware (computer, electronic tablets, etc.), with "drill and practice" types of activities. According to Pritchard (2018), these software applications allowed children of different academic abilities to work on exercises in their own time and at their own pace. By using a system of rewards, whether moving up a level, receiving a smiley face, or gaining points, these systems reinforced a desired behavior. Furthermore, Pritchard (2018) argued that the contributions made by a variety of educational apps cannot be overlooked, particularly when it comes to differentiated instruction.

In summary, there were aspects of behaviorism that were still relevant in the ways teachers instruct and deliver content. The instrumental McBer report (2001) affirmed that an effective teacher uses rewards to influence behavior and performance positively. These principles should be combined with a cognitive/constructivist paradigm of learning to have an effective and last-longing impact on student learning (Pritchard, 2018).

\section{Cognitive/Constructivist Learning}

Constructivist learning falls under the realm of the cognitive sciences. According to Pritchard (2018), cognitive science was defined as the study of how people learn, remember, and interact, while focusing on mental processes and emphasizing modern technology. Posner (1984) affirmed that cognitive science investigates intelligence and intelligent systems, often emphasizing intelligent behavior. Cognitive science offers an 
interdisciplinary study of the human mind. Constructivist learning was influenced by cognitive psychology, which is the study of mental processes such as learning, perceiving, remembering, using language, reasoning, and solving problems (Pritchard, 2018).

Opposing the traditional views of behaviorism which focus on learning processes that alter and modify external conduct, constructivism viewed learning as a result of mental construction. Explained differently, learning happened when new information was built into and added onto a student's current structure of knowledge, understanding, and skills (Pritchard, 2018). Thus, successful learning was achieved when students constructed their own understanding.

Several scientists contributed in major ways to constructivism theory. One of the most influential was Jean Piaget (1896-1980), a biologist who introduced the developmental stage theory, which presented age-related stages of mental maturity and linked them to cognitive abilities at each stage. Piaget perceived learning to be the result of an individual's need to adjust to the environment by assimilating new experiences which would reinforce or contradict what was already known by the individual and the need to accommodate and construct this new knowledge into what was already known (Pritchard, 2018).

The schema theory was a result of this approach. According to Johnson-Laird (1983), human beings possessed the ability to understand the world by constructing models of it in their minds. This understanding of how human beings form mental models in their minds to conduct mental processes, and therefore to learn, was one of the seminal contributions of Holland et al., (1989). In describing the schema theory, Pritchard (2018) 
points out that multidimensional and multisensorial information is stored in people's minds in clusters or nodes; new information can be added to one of these clusters if there is a connection or relationship to it, or a new node can be created when new experiences, information, emotions, and feelings cannot be linked to a previous formed node. This process of adding and connecting to other items was described as constructivist learning.

\section{Social Constructivism}

Within constructivist learning, social constructivism had its roots in the seminal contributions made by Piaget (1896-1980) (Pritchard, 2018). Several scientists agreed with Piaget, that a child could be considered a "lone scientist" when it came to learning (Gopnik \& Meltzoff, 1997; Karmiloff-Smith, 1994). However, other scientists believed an important component was missing when speaking about constructivist learning, namely, the social element. According to these scientists, for example, Vygotsky (18961934) and Bruner (1915-2016), social interaction and language development were key elements in the individual's learning processes. Students learn language by interacting with other human beings, using dialogue to express and form ideas, which are enriched or changed by other's contributions (Pritchard, 2018).

Vygotsky contributed the concept or notion called zone of proximal development (ZPD). Pritchard (2018) describes ZPD as the next area of knowledge which a student could move into with the assistance of a teacher or tutor. The student would be able to operate comfortably in the ZPD but would need guidance and support from a more knowledgeable individual, who could be a teacher, peer, parent, and/or tutor. Probably, every student has a different ZPD. Sewell (1990) described ZPD as the point at which a student had partially mastered a skill but acted more effectively with the assistance of a 
more skilled adult or peer. This approach has influenced educational practices during the last ten to fifteen years, giving birth to another educational concept called differentiated instruction. In differentiated instruction, the teacher's aim was to discover each student's ZPD and support the construction of new knowledge with the help of peers, parents, tutors, or more recently, the use of technology.

Jerome Bruner (1915-2016) coined a term for this intervention by a more skilled adult or peer and the consequent pedagogical practices reinforcing this intervention: "scaffolding." The concept consisted of providing student support at an appropriate time and with an appropriate level of complexity to meet the needs of the individual (Pritchard, 2018).

Another contribution in the realm of constructivist learning was Bandura's social learning theory (Bandura \& Walters, 1977). Bandura asserted that students live on this world in communities, not in isolation. He coined the term "collective agency," referring to people working together with shared beliefs and common aspirations in order to improve their lives (Pritchard, 2018). Furthermore, according to Bandura and Walters (1977), learning would be extremely difficult and even dangerous if students relied only on their actions to inform them of what to do. From a practical perspective, Bandura and Walters' social learning theory underlined the role of an apprentice (student) observing a skilled master and emulating and practicing what had been seen and perceived. Through this social interaction between the disciple and the master, the student learns.

Within the extensive constructivist learning approach, metacognition was another important facet. According to Flavell (1976; Flavell et al., 1977), metacognitive knowledge is knowledge about cognitive processes in which a student comes to 
understand and control when learning happens. Thus, metacognition referred to one's knowledge and control of one's own cognitive system (Brown, 1987). Applied in the classroom, metacognition informed the student about different mental processes which could be implemented to learn content and allowed the student to reflect on which process was more effective; providing the individual with alternatives and allowing the student to select how best to approach the task in question (Pritchard, 2018).

\section{Multiple Intelligences and Learning Styles}

Arguably, Gardner $(1983,1993)$ and Fleming (2001) were the two main expositors of the multiple intelligences and learning styles theories. Basically, Gardner stated that individuals had different intelligences across a variety of intellectual areas. $\mathrm{He}$ proposed there were a minimum of nine different intelligences such as linguistic, logical/mathematical, musical, spatial/visual, kinesthetic, interpersonal, intrapersonal, naturalistic, and existential, although he did not rule out others which were not defined yet. Gardner affirmed that students would be more effective learners if they approached learning practices and activities from their predominant intelligence(s).

When it comes to learning styles, Fleming (2001), Honey and Mumford (1986), and Barbe and Milone (1981) developed several theories in relationship to the learning preferences of students. Learning styles include activist, reflector, theorist, or pragmatist (Honey \& Mumford, 1986); or visual, auditory, reading, and kinesthetic (Fleming, 2001). According to educational researchers Gardner and Hatch (1990), it would be advantageous for students to discover their learning style preferences to maximize engagement and learning. Several contributions made by other researchers (Dunn et al., 1982; Lemmon, 1985; MacMurren, 1985; Valle, et al., 1986) concurred about the 
connections between multiple intelligence theory and learning styles theory. These studies support the idea that students learn in different ways when compared to other students, that pupil subject performance was related to how they learn, and that students achievement increased when using the student's preferred learning style.

However, in the last fifteen to twenty years, according to Pritchard (2018), there had been an increase in skepticism about the use of these two theories to guide educational practices. For instance, Klein (2003) stated that assuming a correlation between a student's unique cognitive abilities and differentiating learning tasks by the uniqueness of cognitive abilities was theoretically incoherent and empirically mistaken. Even more, Klein (2003) asserted that all learning tasks were complex and involved the use of multiple cognitive abilities at the same time; therefore, cognitive abilities were almost impossible to isolate.

Pashler et al., (2008) questioned the scientific validity of learning styles and the practices based on the theory of learning styles, observing issues in the way research into learning styles was designed. Other researchers in the field concluded that the correlation between learning styles and teaching approaches had yet to be demonstrated (Coffield et al., 2004a, 2004b; Greenfield, 2005; Massa \& Meyer, 2006; Stahl, 2002).

Furthermore, research had not been able to establish a significant difference between students who were being taught with congruent learning styles and teaching approaches versus students who were taught without that congruency (Spoon \& Schell, 1998). 


\section{Vocabulary Spelling City}

According to its website (www.spellingcity.com/about-us, 2019), VSC is an online software application dedicated to helping students, teachers, parent teachers, and school systems with literacy skills. Their mission was to use efficient game-based study of literacy to improve skills in spelling, vocabulary, phonics, writing, and reading. The structure and design uses principles of reward from the theory of behaviorism as well as ZPD from Vygotsky's constructivism approach. VSC was launched on the web in 2008 and has grown to include millions of users around the world. In summary, VSC is an app and online-based educational software that uses research-based game strategies to improve literacy skills among students. This educational software offers a free, more restricted option, or a paid membership which includes enhanced capabilities for the student and for the instructor, teacher, or parent.

A study conducted by Arens and Mace (2017) offered positive insights about the efficacy of using VSC software as a supplementary tool for instilling literacy skills among students. Furthermore, the study focused on the impact VSC would have on student ability to comprehend text and increase vocabulary retention when compared to other students experiencing a traditional way of teaching vocabulary (e.g., paper and pencil, writing definitions from a dictionary). The study concluded that students using VSC performed better at vocabulary retention and reading comprehension skills than their counterparts who were part of the traditional instruction system. 


\section{CHAPTER 3}

\section{METHODOLOGY}

\section{Introduction}

The purpose of this study was to determine the efficacy of using VSC software and iPad Minis as the main instruction and practice tool among students in Grades 5 through 8 at GAA, in the areas of vocabulary, spelling, and reading comprehension. A quantitative quasi-experimental research design was selected for this study because it best suits the research questions, which focus on the efficacy of using VSC with iPad Minis.

In this chapter, the author introduced the methodology component of this study, formed research questions, and described the research design, including the population, sample, instrumentation, treatment of data, and data analysis.

\section{Research Questions}

This study seeks to answer the following research questions:

1. Is there a difference in student performance in spelling when exposed to a technology-based curriculum while controlling for the covariate pretest among students in Grades 5 through 8 at GAA?

2. Is there a difference in student performance in vocabulary acquisition when exposed to a technology-based curriculum while controlling for the covariate pretest among students in Grades 5 through 8 at GAA? 
3. Is there a difference in student performance in reading comprehension when exposed to a technology-based curriculum while controlling for the covariate pretest among students in Grades 5 through 8 at GAA?

\section{Research Design}

Because of the characteristics of the subjects and the setting, a quantitative quasiexperimental design was chosen for this study. More specifically, a between-group preand posttest design was used to establish possible cause and effect between the independent and dependent variables (Creswell \& Guetterman, 2018). Also, a withingroup repeated measures approach was utilized in an effort to track students' academic performance in the areas of spelling, vocabulary, and reading comprehension over a span of three years. In education, many experimental situations occur in which researchers must use intact groups. Because of the availability of participants and restrictions of the setting, artificial random groups cannot be formed. Schools use traditional methods of teaching and students are assigned to grade-level classrooms. Because quasi-experimental designs include assignment, but not random assignment, which was an impossibility in this study, the researcher could use the already assigned groups of students. Thus, the experimental (hereafter technology) group included students in Grades 5 through 8 at GAA; the control group was the students in Grades 5 through 8 from the other Seventhday Adventist schools in Arizona. The independent variable was the teaching method (technology vs. control groups). The covariate variables used for this study were Spelling Pretest, Vocabulary Pretest, and Reading Comprehension Pretest. The dependent variables used were Spelling Posttest 1S, Spelling Posttest 3S, Spelling Posttest 5S; Vocabulary Posttest 1S, Vocabulary Posttest 3S, Vocabulary Posttest 5S; and reading 
comprehension posttest $1 \mathrm{~S}$, reading comprehension posttest $3 \mathrm{~S}$, and reading comprehension posttest 5S. The intervention applied to the technology group (GAA's fifth- through eighth-grade students) was a technology-based instruction approach in which students in this group had access to iPad Mini tablets and used the educational app VSC.

\section{Intervention}

At the beginning of the 2013 school year, the GAA administration implemented iPad Mini tablets in the fifth- through eighth-grade classrooms, in a 1:1 student to iPad Mini ratio. These tablets were equipped with educational apps. The educational app used for the purpose of this study was VSC. The iPad Mini tablets were also used as tools for note taking and electronic mail, as e-readers and calculators, for online assignment completion and submission for other subjects, and as video-tutorial watching. GAA's fifth- through eighth-grade students were tested academically in fall of 2013, using the ITBS, before beginning use of the iPad Mini and VSC. The ITBS was administered as part of the assessment program of all Seventh-day Adventist schools in Arizona.

After prior testing, use of the iPad Mini tablets and VSC began. During the following three school years, GAA's fifth- through eighth-grade students were the only students in the study using iPad Mini tablets and VSC consistently, five days a week, for a period of 30 minutes a day. The other Seventh-day Adventist schools in the Arizona Conference used the traditional textbook, paper, and pencil approaches for teaching spelling, vocabulary, and reading comprehension as they had utilized for years.

Appropriate grade-level word lists were entered by their teachers into the VSC app for each of the students. Students accessed the VSC app a minimum of thirty minutes 
a day, from Monday through Friday. While accessing the VSC app, students had the opportunity to review each week's new word list, play educational games contributing to the memorization of the spelling of the words and their meaning, and create and write sentences using the words from that particular week's word list. Every Friday, students took a spelling and vocabulary test based on the words from the wordlist of the week. An average of the grades from the Friday tests provided part of the grade for the Language Arts subject. This structure was used systematically and consistently during the school years of 2013-2014, 2014-2015, 2015-2016; that is, for the duration of the study.

\section{Vocabulary Spelling City App}

The VSC app is educational software, focused on the English language, specifically on spelling and vocabulary. VSC was designed to provide the user an opportunity to increase knowledge of these subjects by playing educational games. The teacher/instructor had the authority to add word lists to the app and the educational games, thus those word lists were incorporated into the learning experience. In this case, teachers at GAA were responsible for customizing new word lists every week, for every grade level in the study. The word lists were obtained from the spelling and vocabulary series named Working Words in Spelling (Woodruff et al., 2003).

The VSC app or website provided more than forty games and activities in which students may hear, say, write, break down, and play with words. Students were exposed to word lists on a daily basis by interacting with the games and activities displayed on the VSC. Table 2 presents a summary of the most popular games and activities of the VSC app. 
Table 2

VSC Games and Activities

\begin{tabular}{|c|c|c|}
\hline Activity/Game & Discipline & Description \\
\hline Word Study & Vocabulary & $\begin{array}{l}\text { Word Study allows students to select the elements they } \\
\text { want to include in their word study session, including } \\
\text { images, letter sounds, parts of speech, syllables, } \\
\text { synonyms, antonyms, and the words read in contextual } \\
\text { sentences. }\end{array}$ \\
\hline $\begin{array}{l}\text { Vocabulary } \\
\text { Memory } \\
\text { Match }\end{array}$ & Vocabulary & $\begin{array}{l}\text { Students flip a word card and try to find the card that } \\
\text { shows an image, synonym, antonym, or definition that } \\
\text { matches the word. }\end{array}$ \\
\hline $\begin{array}{l}\text { Vocabulary } \\
\text { TestMe }\end{array}$ & Vocabulary & $\begin{array}{l}\text { Vocabulary TestMe provides students with the } \\
\text { opportunity to take a vocabulary test independently and } \\
\text { receive immediate feedback. }\end{array}$ \\
\hline FlashCards & Vocabulary & $\begin{array}{l}\text { FlashCards provides students with the opportunity to } \\
\text { see and hear each word spelled and then read aloud. In } \\
\text { addition, students hear each word used in a contextually } \\
\text { rich sentence. }\end{array}$ \\
\hline $\begin{array}{l}\text { MatchIt } \\
\text { Sentences }\end{array}$ & Vocabulary & $\begin{array}{l}\text { In MatchIt Sentences, students match words from their } \\
\text { spelling and vocabulary word lists with contextually } \\
\text { correct sentences. }\end{array}$ \\
\hline $\begin{array}{l}\text { MatchIt } \\
\text { Definitions }\end{array}$ & Vocabulary & $\begin{array}{l}\text { In MatchIt Definitions, students match words from } \\
\text { their spelling and vocabulary word lists with } \\
\text { definitions. }\end{array}$ \\
\hline $\begin{array}{l}\text { Word-O- } \\
\text { Rama }\end{array}$ & Vocabulary & $\begin{array}{l}\text { In Word-O-Rama, students choose the correct spelling } \\
\text { and vocabulary word for each clue read to them. }\end{array}$ \\
\hline $\begin{array}{l}\text { WhichWord? } \\
\text { Sentences }\end{array}$ & Vocabulary & $\begin{array}{l}\text { WhichWord? Sentences helps students to recognize } \\
\text { contextual sentences for each spelling and vocabulary } \\
\text { word. }\end{array}$ \\
\hline $\begin{array}{l}\text { WhichWord? } \\
\text { Definitions }\end{array}$ & Vocabulary & $\begin{array}{l}\text { In WhichWord? Definitions, students are presented } \\
\text { with a definition and then choose the correct word from } \\
\text { their spelling and vocabulary lists. }\end{array}$ \\
\hline $\begin{array}{l}\text { Spelling } \\
\text { TeachMe }\end{array}$ & Spelling & $\begin{array}{l}\text { Spelling TeachMe helps students learn and memorize } \\
\text { spelling and vocabulary words. }\end{array}$ \\
\hline $\begin{array}{l}\text { Spelling } \\
\text { TeachMe }\end{array}$ & Spelling & $\begin{array}{l}\text { Spelling TeachMe helps students learn and memorize } \\
\text { spelling and vocabulary words. }\end{array}$ \\
\hline
\end{tabular}


Table 2, continued

VSC Games and Activities

\section{Activity/Game Discipline Description}

\begin{tabular}{|c|c|c|}
\hline $\begin{array}{l}\text { Audio Word } \\
\text { Match }\end{array}$ & Spelling & $\begin{array}{l}\text { Audio Word Match is a traditional memory match } \\
\text { game that increases familiarity with terms by allowing } \\
\text { students to match words they both see and hear read } \\
\text { aloud. }\end{array}$ \\
\hline Missing Letter & Spelling & $\begin{array}{l}\text { Missing Letter is a letter recognition game that } \\
\text { provides students with the opportunity to figure out } \\
\text { which letter is missing from each term. }\end{array}$ \\
\hline Test-N-Teach & Spelling & $\begin{array}{l}\text { Test-N-Teach provides students with the opportunity to } \\
\text { practice spelling words and to hear them used in } \\
\text { context-rich sentences. }\end{array}$ \\
\hline $\begin{array}{l}\text { Word } \\
\text { Unscramble }\end{array}$ & Spelling & $\begin{array}{l}\text { In Word Unscramble, students click and drag letters to } \\
\text { rearrange them and correctly spell words from their } \\
\text { spelling or vocabulary lists. }\end{array}$ \\
\hline Word Search & Spelling & $\begin{array}{l}\text { Word Search allows students to search for and } \\
\text { highlight spelling or vocabulary words within a grid of } \\
\text { letters based on the provided clues. }\end{array}$ \\
\hline HangMouse & Spelling & $\begin{array}{l}\text { HangMouse is a traditional hangman game that } \\
\text { provides students with the opportunity to name each } \\
\text { term by filling in letters one at a time. }\end{array}$ \\
\hline WordFind & Spelling & $\begin{array}{l}\text { WordFind challenges students to see how many words } \\
\text { they can find in a group of mixed-up letters, including a } \\
\text { word from a list that uses all the letters. }\end{array}$ \\
\hline LetterFall & Spelling & $\begin{array}{l}\text { In LetterFall, students spell each word by catching } \\
\text { falling letters in the correct order. }\end{array}$ \\
\hline SpeedySpeller & Spelling & $\begin{array}{l}\text { SpeedySpeller provides students with the opportunity } \\
\text { to self-assess by hearing each word read to them and } \\
\text { then typing the correct spelling of the word as fast as } \\
\text { they can. }\end{array}$ \\
\hline Spalt-N-Spell & Spelling & $\begin{array}{l}\text { In Spalt-N-Spell, students spell each word by choosing } \\
\text { and dragging the letters to correctly spell the word. }\end{array}$ \\
\hline Aim 2 Spell & Spelling & $\begin{array}{l}\text { In Aim } 2 \text { Spell, students select one letter at a time to } \\
\text { correctly spell each word from their list. }\end{array}$ \\
\hline
\end{tabular}




\section{Population and Sample}

The population used in this study involved all students in Grades 5 through 8 from Seventh-day Adventist schools in the Arizona Conference of Seventh-day Adventists during the years of 2013-2016. The students who participated in this study were from a variety of ethnic backgrounds; the only requirement was to be enrolled in Grades 5 through 8 during the 2012-2016 school years.

These students were selected because of the implementation of the software and iPad technology at GAA in Grades 5-8. This program was implemented to determine its efficacy in student academic performance as measured by the ITBS. GAA administration had searched for an alternate program for teaching literacy with the goal of boosting student academic performance in these areas.

Because of the characteristics of fixed groups and restricted buildings, sampling was not conducted; all students in the system who took the ITBS were included in the study.

Because this study followed academic performance over four academic years, the number of students oscillated slightly during those years. Between the control group and the experimental group there were 70 students during the school year 2012-2013; 135 students during the school year 2013-2014; 92 in school year 2014-2015; and 58 students in school year 2015-2016. Table 3 provides a more detailed description of the students that participated in the different studies by gender and by groups. 


\section{Table 3}

Description of Participants

\begin{tabular}{lcccc}
\hline Statistical Test & $\begin{array}{c}\text { Experimental } \\
\text { Group }\end{array}$ & $\begin{array}{c}\text { Control } \\
\text { Group }\end{array}$ & Females & Male \\
\hline $\begin{array}{l}\text { Sample paired } t \text {-test } \\
\text { GAA School year }\end{array}$ & 33 & 37 & 34 & 36 \\
$\begin{array}{l}\text { 2012-2013 vs 2013- } \\
2014\end{array}$ & & & & \\
$\begin{array}{l}\text { ANCOVA School } \\
\text { year 2013-2014 }\end{array}$ & 55 & 80 & 61 & 74 \\
$\begin{array}{l}\text { Repeated Measure of } \\
\text { ANCOVA School }\end{array}$ & 33 & 58 & 41 & \\
$\begin{array}{l}\text { Year 2013-2014 and } \\
\text { 2014-2015 }\end{array}$ & & & & \\
Repeated Measure of & & 33 & 23 & \\
$\begin{array}{l}\text { ANCOVA School } \\
\text { Year 2013-2014 } \\
\text { through 2015-2016 }\end{array}$ & 25 & & & \\
\hline
\end{tabular}

\section{Instrumentation}

Both groups, the technology and control, were administered the ITBS twice during each school year, once in the fall and again in spring. The test used each time was Form E, which was normed in 2011, by grade, for spring and fall testing. The ITBS offered academic assessment in most academic areas, including the literacy skills of vocabulary, spelling, and reading comprehension. This study was limited to student academic performance in literacy skills.

Each student received a booklet containing the questions and exercises with an answer sheet on which they uses a pencil to bubble in the answers they thought were 
correct. Students had two 30-minute time frames in which to read several paragraphs of text and answer the reading comprehension questions. For spelling, students had 10 minutes to review a list of words to determine whether they were spelled correctly. For vocabulary, students had 15 minutes to read words in sentences and determine the correct meaning. Table 4 demonstrates the duration and number of questions for each segment of the test.

The ITBS was designed by faculty members from the University of Iowa (2014). According to the Iowa Assessment Research and Development Guide (Iowa Assessments, 2014) and the Standards for Educational and Psychological Testing (American Educational Research Association, American Psychological Association, \& National Council on Measurement in Education, 2014), the validity of an instrument is an attribute indicating the degree to which verification and theory support the elucidation of test scores by proposed users of tests. Furthermore, the University of Iowa (2014) conducted extensive research relevant to test validity concerns including test content, response process, internal structure, and relationships to other variables and growth. Figure 2 demonstrates the steps the University of Iowa (2014) followed to develop the ITBS.

The internal structure of the ITBS was analyzed using exploratory factor analysis. As a result of these analyses, Grades 3 through 11 show an arrangement of constructs consistent with the main areas of the Common Core State Standards (University of Iowa, 2014). Construction of the ITBS included a universal design approach to guarantee that no test takers were disadvantaged unduly because of special needs. Table 5 shows the reliability coefficients for the ITBS for Grades 5 through 8. 


\section{Table 4}

ITBS Number of Items and Test Durations

\begin{tabular}{cccccc}
\hline \multirow{2}{*}{ Test } & Duration & \multicolumn{4}{c}{ Number of Questions } \\
\cline { 3 - 5 } & & Grade 5 & Grade 6 & Grade 7 & Grade 8 \\
\hline Vocabulary & 15 min. & 37 & 39 & 41 & 42 \\
Spelling & 10 min. & 30 & 32 & 34 & 35 \\
$\begin{array}{c}\text { Reading } \\
\text { Comprehension }\end{array}$ & 60 (Part I and Part II) & 43 & 44 & 45 & 46 \\
\hline
\end{tabular}

Note: from Iowa Assessments, 2014.

\section{Table 5}

Reliability Coefficients for Form E of the ITBS

\begin{tabular}{|c|c|c|c|}
\hline \multirow{2}{*}{ Grades } & \multicolumn{3}{|c|}{ Areas } \\
\hline & Reading & Spelling & Vocabulary \\
\hline \multirow{2}{*}{5} & Fall $\quad .909$ & Fall $\quad .864$ & Fall $\quad .900$ \\
\hline & Spring .918 & Spring .921 & Spring .913 \\
\hline \multirow{2}{*}{6} & Fall $\quad .910$ & Fall $\quad .881$ & Fall $\quad .883$ \\
\hline & Spring .915 & Spring .884 & Spring .894 \\
\hline \multirow{2}{*}{7} & Fall $\quad .910$ & Fall $\quad .875$ & Fall $\quad .871$ \\
\hline & Spring .917 & Spring .880 & Spring .885 \\
\hline \multirow{2}{*}{8} & Fall $\quad .913$ & Fall $\quad .870$ & Fall $\quad .889$ \\
\hline & Spring .920 & Spring .876 & Spring .902 \\
\hline
\end{tabular}



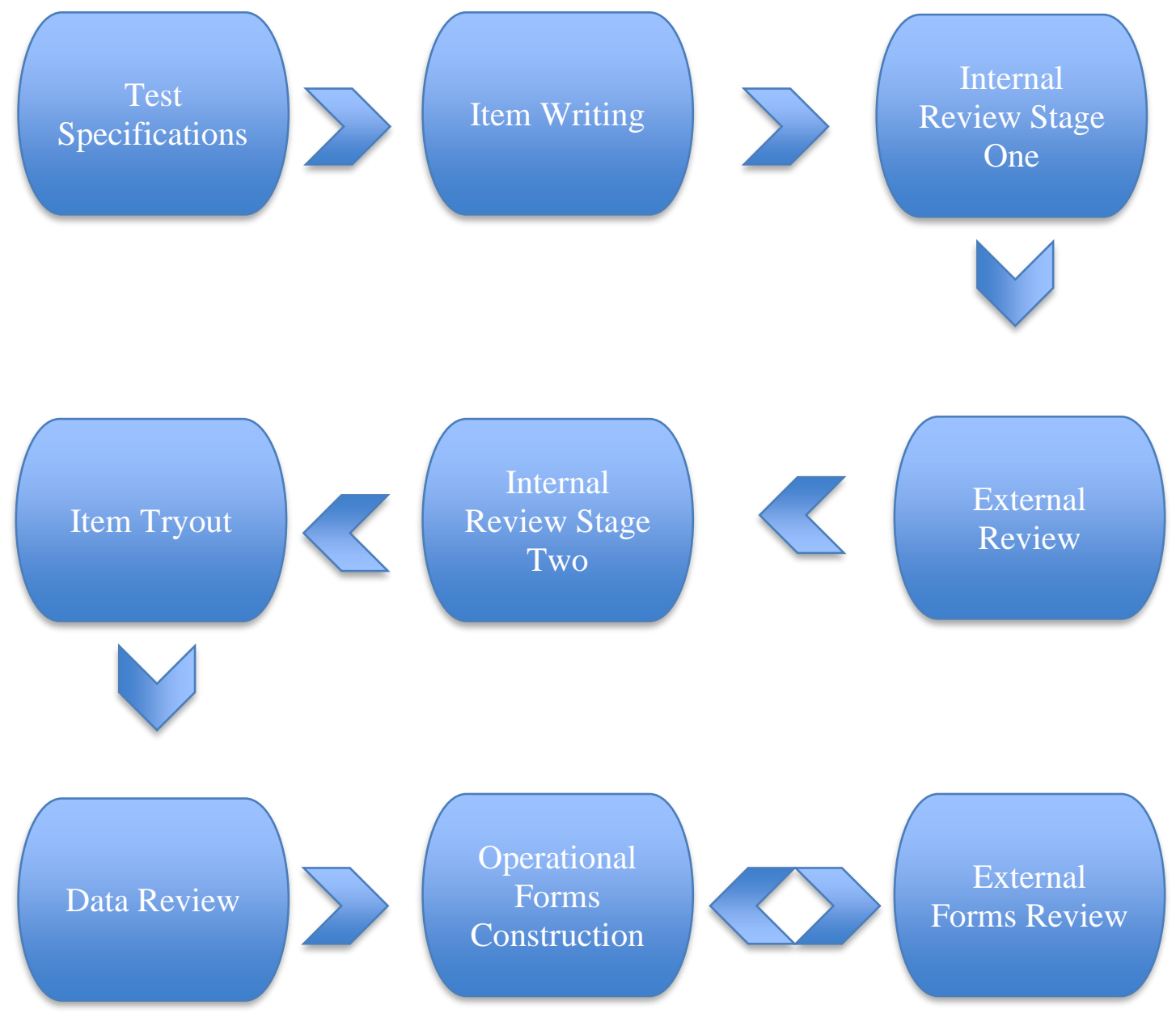

Figure 2. Steps in the development of the ITBS instrument (from Iowa Assessments, 2014). 


\section{Procedure}

Before beginning the study, application to the Andrews University Institutional Research Board was sought and granted. In addition, permission was obtained from the educational department of the Arizona Conference of Seventh-day Adventists. See the Appendix for documentation.

The ITBS was administered during fall and spring terms during the school years 2012-2013, 2013-2014, 2014-2015, and 2015-2016, to all students attending GAA and the other Seventh-day Adventist schools within the Arizona Conference of Seventh-day Adventists. The Department of Education for the NAD, through its Curriculum Committee, chose this assessment tool for all Seventh-day Adventist schools in the NAD. Although only fall testing was mandatory for Seventh-day Adventist schools, the Department of Education of the Arizona Conference of Seventh-day Adventists opted to do spring testing to collect additional data for improvement of instructional and curriculum decisions. Administration of the ITBS was completed by the homeroom teachers in every classroom following the recommendations for test administration from the University of Iowa (2014). Table 6 shows the testing dates for each term.

The ITBS was designed to track and measure student academic achievement; therefore, every test was linked to a student's name and demographic information. To preserve student confidentiality for the purposes of this study, the researcher obtained only the national percentile ranks for all students in Grades 5 through 8, rather than ranks for individual students. 


\section{Table 6}

Testing Dates for Administration of the ITBS in the Arizona Conference

\begin{tabular}{ll}
\hline Term of Testing & Date of Testing \\
\hline Fall 2012 & October 8 \\
Spring 2013 & April 8 \\
Fall 2013 & October 7 \\
Spring 2014 & April 21 \\
Fall 2014 & September 22 \\
Spring 2015 & April 27 \\
Fall 2015 & September 26 \\
Spring 2016 & April 11
\end{tabular}

Note: Glenview Adventist Academy Calendar

\section{Treatment of Data}

The national percentile ranks for students in Grades 5 through 8 in the Arizona Conference of Seventh-day Adventists from all the test dates for the academic years 2013-2016 were entered into the Statistical Package for the Social Sciences (SPSS) as continuous variables (Howell, 2017). Descriptive statistics, including measures of central tendency and frequency distributions, were used to summarize scores for the technology group, the control group, and within the groups.

\section{Data Analysis}

Based on the characteristics of the research design, and in order to respond to the three research questions of this study; the statistical analysis chosen was ANCOVA. According to Mertler and Reinhart (2013), ANCOVA is a variation of ANOVA; the

objective was to increase the sensitivity of a quasi-experimental design by teasing out the 
influence of an independent variable on a dependent variable. Furthermore, Mertler and Reinhart affirmed that ANCOVA allows a more appropriate analysis of data in social science settings; in this case, from the Seventh-day Adventist schools in Arizona. In this particular study, the Spelling Pretest, the Vocabulary Pretest, and the Reading Pretest were the variables used as covariates. The teaching method was the independent variable, and the posttests were the dependent variables.

More specifically, since the goal of this study was to ascertain whether a technology-based teaching method improved student performance in literacy skills more than a traditional instructional approach, in the data analysis, there is a description of the population and sample, then three types of statistical analyses including an analysis of sample paired T test, comparing GAA students only before and after the technology implementation, an analysis of ANCOVA comparing the experimental group (GAA students) and the control group (other students from Seventh-day Adventist schools in Arizona), and an analysis of repeated measures of ANCOVA to track GAA students over time (two years and then three years).

The statistical analyses compared means among the groups of students, using results from the technology and control groups. In addition, GAA student performance means from the previous year were compared with performance means from the first year of the study utilizing a sample paired $t$-test. Other statistical tools used were analysis of covariance (ANCOVA) and analysis of repeated measures of covariance because they allowed appropriate analysis of data collected in social science settings (Mertler \& Vannatta, 2013). Based on the characteristics of this research, using a quasi-experimental design allowed ANCOVA to be more sensitive, teasing out the influence of an 
independent variable on the dependent variable. Table 7 shows the timeline for the different statistical analysis, use of the instrument, and intervention.

Also, descriptive statistics were presented for the groups. Tests of homogeneity and the assumption of a linear relationship between the dependent variables and the covariates follow the descriptive statistics. To conduct ANCOVA the homogeneity of regression was established to determine whether a significant interaction existed between the covariates, defined as the Spelling Pretest, the Vocabulary Pretest, and the Reading Comprehension Pretest, and the groups (technology and control).

\section{Table 7}

ITBS, Intervention, Pre Test, and Post Test Schedule by Analysis

\begin{tabular}{ccccccccc}
\hline & \multicolumn{2}{c}{$2012-2013$} & \multicolumn{2}{c}{$2013-2014$} & \multicolumn{2}{c}{$2014-2015$} & \multicolumn{2}{c}{$2015-2016$} \\
\cline { 2 - 8 } & Fall & Spring & Fall & Spring & Fall & Spring & Fall & Spring \\
\hline ITBS & & & & & & & & \\
GAA & $\mathrm{x}$ & $\mathrm{x}$ & $\mathrm{x}$ & $\mathrm{x}$ & $\mathrm{x}$ & $\mathrm{x}$ & $\mathrm{x}$ & $\mathrm{x}$ \\
Conference & & & $\mathrm{x}$ & $\mathrm{x}$ & $\mathrm{x}$ & $\mathrm{x}$ & $\mathrm{x}$ & $\mathrm{x}$ \\
Intervention & & & $\mathrm{x}$ & $\mathrm{x}$ & $\mathrm{x}$ & $\mathrm{x}$ & $\mathrm{x}$ & $\mathrm{x}$ \\
$t$-test & & Pre & & Post & & & & \\
ANCOVA & & & Pre & Post & & & & \\
Repeated & & & & & & & & \\
Measures & & & Pre & Post1 & & Post2 & & Post3 \\
ANCOVA & & & & & & & & \\
\hline
\end{tabular}




\section{Summary}

The purpose of this study was to determine the efficacy of using VSC software and iPad Minis as the main instruction and practice tool among students in Grades 5 through 8 at GAA, in the areas of vocabulary, spelling, and reading comprehension. A quantitative approach was used to analyze student academic performance in the subjects of reading comprehension, spelling, and vocabulary, as measured by ITBS testing among students in Grades 5 through 8 in the Arizona Conference of Seventh-day Adventists during the 2013-2016 school years. Furthermore, the students at GAA comprised the technology or experimental group, in that they were subjected to a technology-driven curriculum for literacy skills, using VSC through iPad Minis 


\section{CHAPTER 4}

\section{RESEARCH FINDINGS}

\section{Introduction}

The purpose of this study was to determine the efficacy of using VSC software and iPad Minis as the main instruction and practice tool among students in Grades 5 through 8 at GAA, in the areas of vocabulary, spelling, and reading comprehension. A quantitative quasi-experimental research design was selected for this study because it best suited the research questions, which focused on the efficacy of using VSC with iPad Minis.

This chapter includes a description of the population and sample, as well as the statistical analysis and results that address each of the three research questions.

\section{Description of the Population and Sample}

The study was conducted among fifth- to eighth-grade students from seven Seventh-day Adventist schools in the Arizona Conference of Seventh-day Adventists during three consecutive school years: 2013-2014, 2014-2015, and 2015-2016. The fifthto eighth-grade students from GAA formed the experimental (hereafter referred to as technology) group, which was exposed to the VSC app using iPad Minis. The students from the other six schools formed the control group. Table 8 shows a summary of students (subjects) who participated in this study by grade level during the four years of data. 


\section{Table 8}

Number of Subjects by Grade and Year who Participated in the Study

\begin{tabular}{ccccccccc}
\hline \multirow{2}{*}{ Grades } & $2012-2013$ & $2013-2014$ & \multicolumn{2}{c}{$2013-2014$} & \multicolumn{2}{c}{$2014-2015$} & \multicolumn{2}{c}{$2015-2016$} \\
\cline { 2 - 9 } & Pretest & Posttest & Exper. & Control & Exper. & Control & Exper. & Control \\
\hline 5 & 10 & - & 14 & 21 & 10 & 15 & 9 & 12 \\
\hline 6 & 9 & 11 & 11 & 15 & 8 & 6 & 9 & 6 \\
\hline 7 & 18 & 8 & 8 & 25 & 6 & 17 & - & - \\
\hline 8 & - & 22 & 22 & 20 & - & - & - & - \\
\hline
\end{tabular}

\section{Statistical Analyses}

The first set of statistical analyses compared the results for the technology group for the first year of the intervention with the results from the year before the intervention, using a sample paired $t$-test to identify any significant changes in performance in the areas of spelling, vocabulary, and reading comprehension.

The second set of statistical analyses investigated the relationships between the three main covariates (Spelling Pretest, Vocabulary Pretest, and Reading Comprehension Pretest) and their related dependent variables (Spelling Posttest 1S, Vocabulary Posttest 1S, and Reading Comprehension Posttest 1S) during the first year of the study, comparing the control group with the technology group.

For the third group of analyses, a longitudinal statistical analysis was conducted only among the students in the fifth and sixth grades who completed the pretests and posttests for each of the three years of the study. For the technology group 17 students 
were tracked through all three years; in the control group 15 students completed all the tests during the duration of the study.

In all cases, as necessary for ANCOVA, means were adjusted before the analyses in an attempt to reduce the influence of any contaminant variables the researcher could not control. These statistical analysis for each of the academic subjects (spelling, vocabulary, and reading comprehension) are presented, addressing each of the three research questions.

\section{Research Question \# 1: Spelling}

Comparison of GAA Students Before and After Technology Implementation for Spelling

This statistical analysis was a comparison between academic performance in spelling among students from GAA during the year prior to the implementation of the technology (school year 2012-2013) and the same students after a year of using the technology or new teaching method (school year 2013-2014). The goal was to determine whether there was a significance difference among the GAA students between the year prior to the implementation of technology and the year after the implementation of the study.

This statistical analysis compared means among the groups of students, using results from the technology and control groups. Student results from the previous year were compared with results from the first year of the study. The statistical tool was the sample paired $t$-test to compare student performance in spelling from GAA during the year before and the year after the implementation of the technology. Prior to conducting the analysis of sample paired $t$-test, descriptive statistics, and the assumption of normally 
distributed differences scores were examined. Table 9 presents the descriptive statistics for the variable Spelling Pretest (GAA students before implementation of technology) and the variable Spelling Posttest (GAA students after implementation of technology).

To conduct a sample paired $t$-test, the variables Spelling Pretest $(M=42.54, S D=$ 27.64) and Spelling Posttest $(M=56.18, S D=25.34)$ were used to determine any statistical differences among the students at GAA before and after the implementation of technology. The assumption of normally distributed differences among scores was considered satisfied; the skew levels were estimated at 0.485 for the variable Spelling Pretest and -0.029 for the variable Spelling Posttest (less than 1 or -1 levels). Therefore, after conducting a sample paired $t$-test using the variables Spelling Pretest and Spelling Posttest, $t(32)=-2.166, p=0.038$, it was determined there was a significantly higher difference in performance among GAA students before and after implementation of technology. Cohen's $d$ was estimated at -.021, implying a small size effect.

\section{Table 9}

GAA Students Before and After Technology Intervention for Spelling

\begin{tabular}{ccccc}
\hline Group & $N$ & $M$ & $S D$ & $S E$ \\
\hline Spelling Pretest & 37 & 42.54 & 27.56 & 4.81 \\
Spelling Posttest & 33 & 56.18 & 25.34 & 4.41 \\
\hline Total & 70 & & & \\
\hline
\end{tabular}


First-Year Comparisons of Control Group with Technology

Group for Spelling

This statistical analysis compared means among the technology and control groups of students. Results from the previous year were compared with results from the first year of the study. Statistical tools used were analysis of variance (ANOVA) and analysis of covariance (ANCOVA) because they allowed appropriate analysis of data collected in social science settings (Mertler \& Vannatta, 2013). The quasi-experimental design characteristics of this study allowed ANCOVA to be more sensitive and tease out the influence of the independent variable on the dependent variable.

In this section descriptive statistics are presented for the groups. Tests of homogeneity and the assumption of a linear relationship between the dependent variables and the covariates follow the descriptive statistics. Before conducting ANCOVA the homogeneity of regression was established to determine whether a significant interaction existed between the covariates, defined as the Spelling Pretest, the Vocabulary Pretest, and the Reading Comprehension Pretest, and the groups (technology and control).

Before testing for the appropriate assumptions to conduct an analysis of covariance, descriptive statistics are shown in Table 10 for the covariate Spelling Pretest and the dependent variable Spelling Posttest S1 for the technology and control groups, including adjusted means. 


\section{Table 10}

Means and Standard Deviations for Spelling Pretest and Posttests, Fifth Through Seventh Grades

\begin{tabular}{|c|c|c|c|c|c|}
\hline Group & $N$ & $M$ & $S D$ & Adjusted Means & $S E$ \\
\hline \multicolumn{6}{|c|}{ Spelling Pretest (Covariate) } \\
\hline Technology & 53 & 53.28 & 27.11 & - & 3.72 \\
\hline Control & 80 & 49.10 & 29.40 & - & 3.28 \\
\hline Total & 133 & & & & \\
\hline \multicolumn{6}{|c|}{ Spelling Posttest S1 (Dependent Variable) } \\
\hline Technology & 53 & 58.62 & 24.80 & 56.30 & 2.21 \\
\hline Control & 80 & 55.97 & 27.71 & 57.61 & 1.89 \\
\hline Total & 133 & & & & \\
\hline
\end{tabular}

A test of homogeneity of variances was performed using Levene's test; the assumption of homogeneity of variance for both variables (Spelling Pretest and Spelling Posttest S1) was met $(p>0.05)$; the covariate Spelling Pretest at $p=0.508$; and the dependent variable Spelling Posttest S1 at $p=0.224$. Furthermore, there were no differences between the groups (technology and control) on the covariate Spelling Pretest $F(1,131)=0.695, p=0.406$ or on the dependent variable Spelling Posttest S1, $(F$ $(1,116)=0.291, p=0.591)$. The error of variance for Spelling Posttest S1 was 702.275 (MS within).

There was a linear relationship between the dependent variable Spelling Posttest S1 and the covariate Spelling Pretest, thus establishing another assumption. A correlation analysis between the two variables resulted with a Pearson $r=0.819$.

To conduct analysis of covariance the homogeneity of regression was established to determine whether there was a significant interaction between the covariate Spelling 
Pretest and the groups. With $F(1,112)=2.001$, and $p=0.160$, no interaction between the groups on the covariate was demonstrated. Thus, the assumption of homogeneity of regression was met.

Table 11 reflects the analysis of covariance for spelling for the technology and control groups. With an $F(1,113)=0.205, p=0.652$, the conclusion was drawn that there were no significant group differences in the adjusted means on Spelling Posttest S1. Table 11 demonstrates a significant relationship between the covariate Spelling Pretest and the independent variable Teaching Method for both groups (technology and control) with $F(1,113)=229.431, p=0.000$ and $\eta^{2}=0.670$.

Because no significant variation between the control and technology groups existed for the dependent variable Spelling Posttest S1, there was no need to conduct post hoc analysis.

\section{Table 11}

ANCOVA Results for Spelling, Technology, and Control Groups

\begin{tabular}{crrrrrr} 
Source & \multicolumn{1}{c}{$S S$} & $d f$ & \multicolumn{1}{c}{$M S$} & F ratio & \multicolumn{1}{c}{$p$} & $\eta 2$ \\
\hline Spelling Pretest & $54,464.928$ & 1 & $54,464.928$ & 229.431 & 0.000 & 0.670 \\
Teaching Method & 48.639 & 1 & 48.639 & 0.205 & 0.652 & 0.002 \\
Error & $26,825.216$ & 113 & 237.391 & & & \\
\hline Total & $459,044.000$ & 116 & & & & \\
\hline
\end{tabular}




\section{Comparison of Control and Technology Groups over Time for}

Spelling

Analysis of repeated measures of ANCOVA was used to observe whether there were any significant differences in academic performance within the subjects and between the groups when measured repeatedly over time. After testing all students from both groups before intervention occurred for the areas of spelling, vocabulary, and reading comprehension, both groups were tested again after the intervention of the first year and second year. For this first analysis, only fifth, sixth, and seventh grade students in the school year 2013-2014 were used. For the second part of this analysis, only fifth and sixth grade students were used over the period of three school years (2013-2016).

This first statistical analysis compared means among the groups of students, using results from the technology and control groups. In addition, student results from the previous year were compared with results from the first year of the study. The statistical tools used were analysis of variance (ANOVA) and analysis of covariance (ANCOVA) because they allowed appropriate analysis of data collected in social science settings (Mertler \& Vannatta, 2013). Based on the characteristics of this study, using a quasiexperimental design allowed ANCOVA to be more sensitive, teasing out the influence of an independent variable on the dependent variable.

Descriptive statistics are presented for the groups. Tests of homogeneity and the assumption of a linear relationship between the dependent variables and the covariates follow the descriptive statistics. To conduct repeated measures of ANCOVA the homogeneity of regression was established to determine whether a significant interaction existed between the covariates, defined as the Spelling Pretest, the Vocabulary Pretest, and the Reading Comprehension Pretest, and the groups (technology and control). 
Testing for assumptions was needed before conducting an ANCOVA of repeated measures. This analysis included only students from Grades 5, 6, and 7 over a span of two years. Table 10 showed the descriptive statistics of the covariate (Spelling Pretest) and the dependent variables Spelling Posttest 1S and Spelling Posttest 3S for the technology and control groups.

A test of homogeneity of variances was performed, using Levene's test, finding that the homogeneity of variance for the variable Spelling Pretest was met $(p>0.05)$ with the covariate Spelling Pretest at $p=0.929$. Homogeneity of variance for the dependent variables was met for Spelling Posttest $1 \mathrm{~S}, p=0.459$; Spelling Posttest 3S, $p=0.841$. Furthermore, there were differences between the groups on the covariate Spelling Pretest $(F[1,90]=4.162, p=0.044)$. For the dependent variable Spelling Posttest $1 \mathrm{~S}$ there were no significate differences between the groups (technology and control), $F(1,80)=1.375$, $p=0.245$. Also, there were no group differences on the dependent variable Spelling Posttest 3S, $F(1,59)=1.806 p=0.184$. The error of variance for the Spelling Posttest $1 \mathrm{~S}$ was 710.628 (MS within); for Spelling Posttest 3S, 639.125 (MS within).

Another assumption established was the linear relationship between the dependent variables (Spelling Posttest 1S and Spelling Posttest 3S) and the covariate (Spelling Pretest). A correlation analysis for each dependent variable with the covariate was conducted resulting in Pearson $r=0.840$ for Spelling Posttest 1S, and Pearson $r=0.736$ for Spelling Posttest 3S.

Before conducting repeated measures analysis of covariance, homogeneity of regression was established to determine whether there was a significant interaction between the covariate Spelling Pretest and the groups. An $F(1,55)=0.056, p=0.814$ 
demonstrated there was not a significant interaction between groups and the covariate Spelling Pretest; the assumption of homogeneity of regression was met.

Table 12 reflects the repeated measure of ANCOVA for spelling in Grades 5 through 7. In values for within subjects and after adjusting for initial group differences, there was no significant difference between the groups (technology and control) over time in spelling scores (higher scores) when compared to the covariate Spelling Pretest with $F(1,56)=0.999, p=0.322$ and a $\eta^{2}=0.018$. In the between subjects analysis, with an $F(1,56)=0.148, p=0.702$, the conclusion was that there were no significant group differences (technology and control) for the adjusted means on Spelling Posttest $1 \mathrm{~S}$ and Spelling Posttest 3S, combined.

\section{Table 12}

ANCOVA Repeated Measures for Spelling, Fifth Through Seventh Grades, Technology and Control Groups

\begin{tabular}{crrrrrr}
\hline Source & \multicolumn{1}{c}{$S S$} & $d f$ & \multicolumn{1}{c}{$M S$} & F ratio & $p$ & $\eta^{2}$ \\
\hline Between Subjects & & & & & & \\
Spelling Pretest & 45021.486 & 1 & 45021.486 & 128.15 & 0.000 & 0.696 \\
Teaching Method & 52.125 & 1 & 52.125 & .148 & 0.702 & 0.003 \\
Error & 19672.885 & 56 & 351.302 & & & \\
\hline Within Subjects & & & & & & \\
Posttests & 149.437 & 1 & 149.437 & 0.999 & 0.322 & 0.018 \\
Posttests* Teaching Method & 188.393 & 1 & 188.393 & 1.260 & 0.267 & 0.022 \\
Error & 8375.464 & 56 & 149.562 & & & \\
\hline
\end{tabular}


The second statistical analysis over time included only the students from 5th through 6th Grades for the technology and control groups over the span of three school years (2013-2016). Testing for assumptions was needed before conducting an ANCOVA of repeated measures. Table 13 shows the descriptive statistics for the covariate Spelling Pretest and the dependent variables Spelling Posttest S1, Spelling Posttest S3, and Spelling Posttest S5 for the technology and control groups.

\section{Table 13}

Means and Standard Deviations for Spelling Pretest and Posttests, Fifth and Sixth Grades

\begin{tabular}{|c|c|c|c|c|c|}
\hline Group & $N$ & $M$ & $S D$ & Adjusted Means & $S E$ \\
\hline \multicolumn{6}{|c|}{ Spelling Pretest (Covariate) } \\
\hline Technology & 25 & 62.32 & 27.87 & - & 5.57 \\
\hline Control & 35 & 41.00 & 28.29 & - & 4.78 \\
\hline Total & \multicolumn{5}{|l|}{60} \\
\hline \multicolumn{6}{|c|}{ Spelling Posttest 1S (Dependent Variable) } \\
\hline Technology & 23 & 62.17 & 25.94 & 63.72 & 3.20 \\
\hline Control & 29 & 47.79 & 27.70 & 39.20 & 3.57 \\
\hline Total & \multicolumn{5}{|l|}{52} \\
\hline \multicolumn{6}{|c|}{ Spelling Posttest 3S (Dependent Variable) } \\
\hline Technology & 19 & 66.21 & 24.03 & 67.44 & 3.20 \\
\hline Control & 18 & 43.72 & 26.69 & 36.93 & 3.57 \\
\hline Total & 37 & & & & \\
\hline \multicolumn{6}{|c|}{ Spelling Posttest 5S (Dependent Variable) } \\
\hline Technology & 18 & 70.66 & 23.70 & 70.66 & 3.20 \\
\hline Control & 17 & 43.64 & 23.82 & 39.93 & 3.57 \\
\hline Total & 35 & & & & \\
\hline
\end{tabular}


A test of homogeneity of variances was performed, using Levene's test, finding that the homogeneity of variance for the variable Spelling Pretest was met $(p>0.05)$ with the covariate Spelling Pretest at $p=0.742$. Homogeneity of variance for the dependent variables was met for Spelling Posttest $1 \mathrm{~S}, p=0.756$; Spelling Posttest 3S, $p=0.712$; and Spelling Posttest 5S, $p=0.947$. Furthermore, there were differences between the groups on the covariate Spelling Pretest $(F[1,59]=8.380, p=0.005)$. On the dependent variable Spelling Posttest 1S there were no differences between the two groups (technology and control), $F(1,50)=3.654, p=0.062$. However, there were group differences on the dependent variables Spelling Posttest $3 \mathrm{~S}, F(1,35)=7.268 p=0.011$, and Spelling Posttest 5S, $F(1,33)=11.304, p=0.002$. The error of variance for the Spelling Posttest 1S was 726.001 (MS within); for Spelling Posttest 3S, 643.165 (MS within); and for Spelling Posttest 5S, 564.663 (MS within).

Another assumption established was the linear relationship between the dependent variables (Spelling Posttest 1S, Spelling Posttest 3S, and Spelling Posttest 5S) and the covariate (Spelling Pretest). A correlation analysis for each dependent variable with the covariate was conducted resulting in Pearson $r=0.878$ for Spelling Posttest $1 \mathrm{~S}$, Pearson $r$ $=0.838$ for Spelling Posttest 3S, and Pearson $r=0.769$ for Spelling Posttest 5S.

Before conducting analysis of repeated measures of covariance, the homogeneity of regression was established to determine whether there was a significant interaction between the covariate Spelling Pretest and the groups. An $F(1,29)=0.049, p=0.827$ demonstrated there was not a significant interaction between groups and the covariate Spelling Pretest; the assumption of homogeneity of regression was met. 
Table 14 reflects the repeated measures of ANCOVA for spelling in Grades 5

through 6. In values from within subjects and after adjusting for initial group differences, results show there was no significant difference for both groups (technology and control) over time in spelling scores (higher scores) when compared to the covariate Spelling Pretest with $F(1,30)=5.219, p=0.300$ and a $\eta^{2}=0.148$.

From the between subjects analysis, $F(1,30)=0.831, p=0.369$, allowed conclusion there were no group differences (technology and control) in the adjusted means on Spelling Posttest 1S, Spelling Posttest 3S, and Spelling Posttest 5S combined.

\section{Table 14}

ANCOVA Repeated Measures for Spelling, Fifth and Sixth Grade, Technology and Control Groups

\begin{tabular}{crrrrrr}
\hline Source & \multicolumn{1}{c}{$S S$} & $d f$ & $M S$ & F ratio & $p$ & $\eta^{2}$ \\
\hline Between Subjects & & & & & & \\
Spelling Pretest & 28235.693 & 1 & 28235.693 & 62.135 & 0.000 & 0.674 \\
Teaching Method & 377.723 & 1 & 377.723 & 0.831 & 0.369 & 0.027 \\
Error & 13632.785 & 30 & 454.426 & & & \\
\hline Within Subjects & & & & & & \\
Posttests & 753.172 & 1 & 753.172 & 5.219 & 0.300 & 0.148 \\
Posttests* Teaching Method & 548.046 & 1 & 548.046 & 3.797 & 0.061 & 0.112 \\
Error & 4329.613 & 30 & 144.320 & & & \\
\hline
\end{tabular}


Finally, Figure 3 presents a comparison of unadjusted means over time for the technology and control groups of students' performance in spelling. On this chart it can be observed that, although there were no statistical significant differences over time among students from both groups (technology and control) for spelling, it can be perceived an increase of performance in spelling over time for the technology group.

\section{Figure 3}

Unadjusted Mean Comparison for Spelling Over Time for Technology and Control Groups

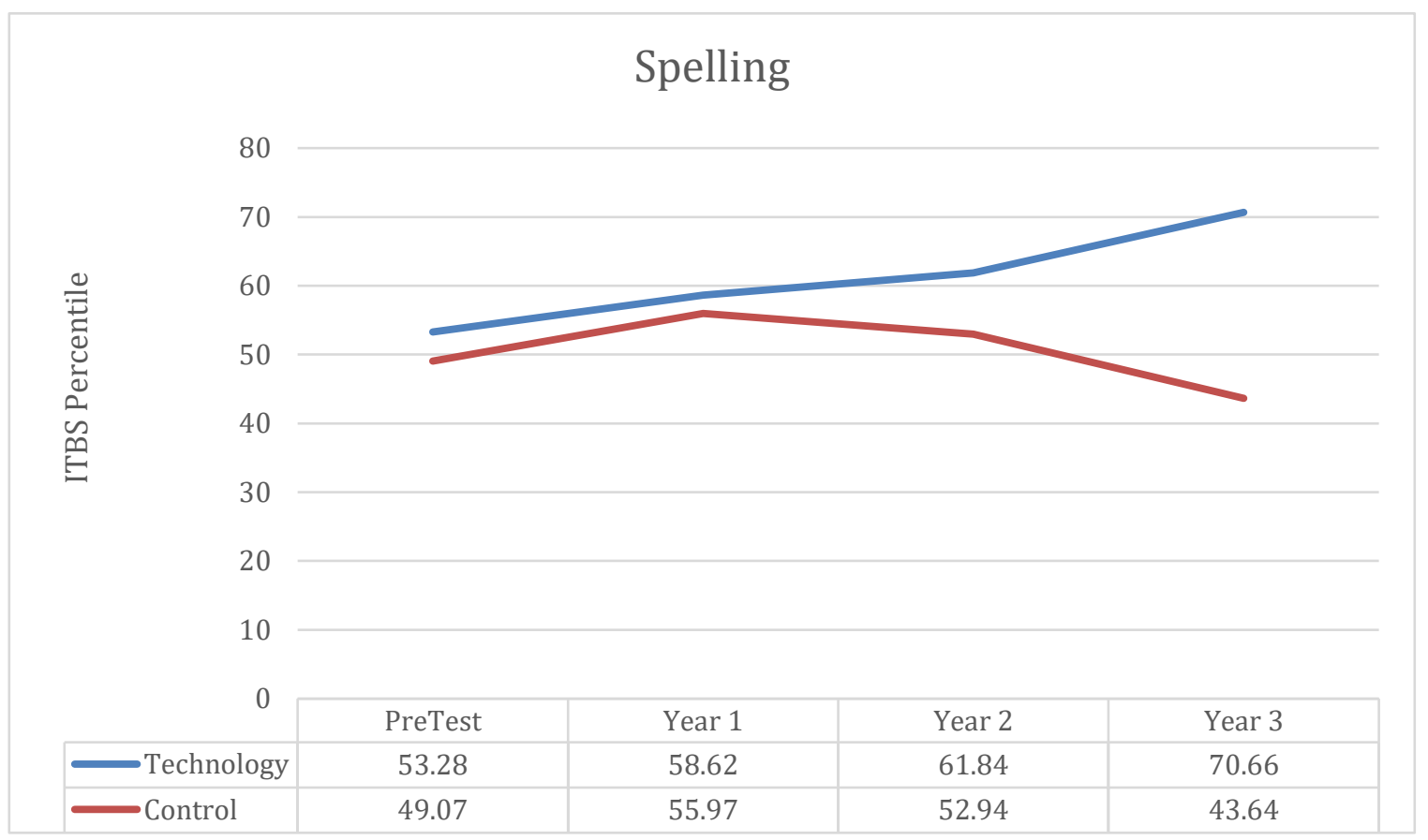




\section{Research Question \# 2: Vocabulary \\ Comparison of GAA Students Before and After Technology \\ Implementation for Vocabulary}

This analysis compared academic performance in vocabulary among students from GAA between the year prior to implementation of technology (school year 20122013) and the year of using technology (school year 2013-2014). The goal was to determine whether there was a difference among the GAA students for the year prior to implementation of technology compared to the year after the intervention.

This analysis compared means among the groups of students, using results from the technology and control groups. Results from the previous year were compared with results from the first year of the study. The statistical tool used was the sample paired $t$ test to compare the GAA students' performance in vocabulary, from the year before and the year after implementation of technology. Prior to conducting the analysis of sample paired $t$-test, descriptive statistics, and the assumption of normally distributed differences scores were examined. Table 15 presents the descriptive statistics for the variable Vocabulary Pretest (GAA students before the implementation of the technology and the variable Vocabulary Posttest (GAA students after the implementation of the technology).

\section{Table 15}

GAA Students Before and After the Technology Intervention for Vocabulary

\begin{tabular}{ccccc}
\hline Group & $N$ & $M$ & $S D$ & $S E$ \\
\hline Vocabulary Pretest & 37 & 47.00 & 25.59 & 4.48 \\
Vocabulary Posttest & 33 & 53.12 & 27.89 & 4.85 \\
\hline Total & 70 & & & \\
\hline
\end{tabular}


To conduct a sample paired $t$-test, the variables Vocabulary Pretest $(M=47, S D$ $=25.59)$ and Vocabulary Posttest $(M=53.12, S D=27.89)$ were used to determine whether there were any significant differences among the students at GAA before and after implementation of the technology. The assumption of normally distributed difference in scores was satisfied; skew levels were estimated at 0.049 for the variable Vocabulary Pretest and -0.114 for the variable Vocabulary Posttest (less than 1 or -1 levels). Therefore, after conducting a sample paired $t$-test using the variables Vocabulary Pretest and Vocabulary Posttest, $t=-0.987$ (32), $p=0.331$, the conclusion was there were no significant differences in performance among GAA students before and after implementation of technology in vocabulary.

First-Year Comparisons of Control Group with Technology Group for Vocabulary

Before testing for the assumptions needed to conduct an analysis of covariance, descriptive statistics appear in Table 16 for the covariate Vocabulary Pretest and the dependent variable Vocabulary Posttest S1 for both groups (technology and control), including the adjusted means for both groups.

Homogeneity of variance analyses were performed, using Levene's test, finding that the assumption of homogeneity of variance for the variables Vocabulary Pretest and Vocabulary Posttest S1 was met $(p>0.05)$. Probabilities for the covariate Vocabulary Pretest were $p=0.707$; for the dependent variable Vocabulary Posttest S1, $p=0.711$. There were no differences between the groups on the covariate Vocabulary Pretest ( $F[1$, $131]=0.920, p=0.339$ or the dependent variable Vocabulary Posttest $\mathrm{S} 1(F[1,116]=$ $1.663, p=0.200$ ). Error of variance for Spelling Posttest S1 was 728.903 (MS within). 


\section{Table 16}

Means and Standard Deviations for Vocabulary Pretest and Posttest S1

\begin{tabular}{|c|c|c|c|c|c|}
\hline Group & $N$ & $M$ & $S D$ & Adjusted Means & $S E$ \\
\hline \multicolumn{6}{|c|}{ Vocabulary Pretest (Covariate) } \\
\hline Technology & 53 & 46.20 & 27.66 & - & 3.80 \\
\hline Control & 80 & 50.71 & 27.60 & - & 3.10 \\
\hline Total & 133 & & & & \\
\hline \multicolumn{6}{|c|}{ Vocabulary Posttest 1 (Dependent Variable) } \\
\hline Technology & 51 & 50.52 & 27.10 & 52.19 & 2.05 \\
\hline Control & 67 & 57.00 & 26.94 & 55.65 & 1.75 \\
\hline Total & 118 & & & & \\
\hline
\end{tabular}

Another assumption established was the linear relationship between the dependent variable Vocabulary Posttest S1 and the covariate Vocabulary Pretest. A correlation analysis between the two variables resulted with a Pearson $r=0.851$.

Before conducting analysis of covariance, homogeneity of regression was established to determine whether there was a significant interaction between the groups (technology and control) on the covariate Vocabulary Pretest. With $F(1,112)=0.429, p$ $=0.514$, the assumption was valid that there was no significant interaction between the groups on the covariate Vocabulary Pretest. The assumption of homogeneity of regression was met. 


\section{Table 17}

ANCOVA Results for Vocabulary, Technology and Control Groups

\begin{tabular}{crccccc}
\hline Source & \multicolumn{1}{c}{ SS } & df & MS & $F$ ratio & p & $\eta^{2}$ \\
\hline Vocabulary Pretest & $608,940.135$ & 1 & $608,940.135$ & 296.278 & 0.000 & 0.724 \\
Teaching Method & 337.684 & 1 & 337.684 & 1.643 & 0.203 & 0.014 \\
Error & $23,224.967$ & 113 & 205.531 & & & \\
Total & $426,008.000$ & 116 & & & &
\end{tabular}

Table 17 reflects ANCOVA results for vocabulary $F(1,113)=1.643, p=0.203$, demonstrating there were no group differences in the adjusted means on the Vocabulary Posttest S1. There was a relationship between the covariate Vocabulary Pretest and the independent variable Teaching Method between both groups with $F(1,113)=296.278, p$ $=0.000$ and $\eta^{2}=0.724$.

Because no significant variation in the control and technology groups was found on the dependent variable Vocabulary Posttest S1, there was no need to conduct post hoc statistical analysis.

\section{Comparison of Control and Technology Groups over Time for} Vocabulary

Testing for assumptions was needed before conducting an ANCOVA of repeated measures. This analysis included only students from Grades 5, 6, and 7 over a span of two years. Table 18 shows the descriptive statistics for the covariate (Vocabulary Pretest) and the dependent variables Vocabulary Posttest $1 \mathrm{~S}$ and Vocabulary Posttest 3S, for the technology and control groups. 


\section{Table 18}

Means and Standard Deviations for Vocabulary Pretest and Posttests, Fifth Through Seventh Grades

\begin{tabular}{cccccc}
\hline Group & $N$ & $M$ & $S D$ & Adjusted Means & $S E$ \\
\hline Technology & 32 & 42.40 & 27.82 & - & 4.91 \\
Control & 60 & 43.75 & 27.10 & - & 3.49 \\
\hline Total & 92 & \multicolumn{5}{c}{ Vocabulary Pretest (Covariate) } \\
\hline Vocabulary Posttest $1 \mathrm{~S}$ (Dependent Variable) & \\
Technology & 31 & 48.77 & 26.67 & 50.25 & 2.67 \\
Control & 50 & 51.14 & 27.46 & 53.51 & 2.21 \\
\hline Total & 81 & & & \\
\hline Technology & 25 & 59.60 & 25.01 & 58.79 & 2.67 \\
Control & 35 & 60.40 & 22.30 & 60.40 & 2.21 \\
\hline Total & 60 & & & \\
\hline
\end{tabular}

A test of homogeneity of variances was performed, using Levene's test, finding that the homogeneity of variance for the variable Vocabulary Pretest was met $(p>0.05)$ with the covariate Vocabulary Pretest at $p=0.922$. Homogeneity of variance for the dependent variables was met for Vocabulary Posttest 1S, $p=0.767$; and Vocabulary Posttest 3S, $p=0.305$. Furthermore, there were no differences between the groups on the covariate Vocabulary Pretest $(F[1,91]=0.050, p=0.823)$. On the dependent variable Vocabulary Posttest 1S there were no significant differences between the groups (technology and control), $F(1,80)=0.145, p=0.704$. Also, there were no group differences on the dependent variables Vocabulary Posttest $3 \mathrm{~S}, F(1,59)=0.017 p=$ 
0.897. The error of variance for the Vocabulary Posttest $1 \mathrm{~S}$ was 738.322 (MS within); for Vocabulary Posttest 3S, 550.697 (MS within).

Another assumption established was the linear relationship between the dependent variables (Vocabulary Posttest 1S and Vocabulary Posttest 3S) and the covariate (Vocabulary Pretest). A correlation analysis for each dependent variable with the covariate was conducted resulting in Pearson $r=0.831$ for Vocabulary Posttest $1 \mathrm{~S}$, and Pearson $r=0.763$ for Vocabulary Posttest 3S.

Before conducting analysis of repeated measures of covariance, the homogeneity of regression was established to determine whether there was a significant interaction between the covariate Spelling Pretest and the groups. An $F(1,55)=0.670, p=0.417$ demonstrated there was not a significant interaction between groups and the covariate Vocabulary Pretest; the assumption of homogeneity of regression was met.

Table 19 reflects the repeated measure of ANCOVA for vocabulary in Grades 5 through 7. In values for within subjects and after adjusting for initial group differences, the conclusion was there was a significant difference for both groups (technology and control) over time in vocabulary scores (higher scores) when compared to the covariate Vocabulary Pretest with $F(1,56)=19.931, p=0.000$ and a $\eta^{2}=0.254$. In the between subjects analysis, with an $F(1,56)=0.324, p=0.572$, the conclusion was that there were no significant group differences (technology and control) for the adjusted means on Vocabulary Posttest $1 \mathrm{~S}$ and Vocabulary Posttest 3S, combined. Therefore, the differences in scores of the two groups between the covariate Vocabulary Pretest and the dependent variables Vocabulary Posttest $1 \mathrm{~S}$ and Vocabulary Posttest $3 \mathrm{~S}$ combined cannot be attributed to group membership. 


\section{Table 19}

ANCOVA Repeated Measures for Vocabulary, Fifth through Seventh Grade, Technology and Control Groups

\begin{tabular}{crrrrrr}
\hline Source & \multicolumn{1}{c}{$S S$} & $d f$ & \multicolumn{1}{c}{$M S$} & F ratio & \multicolumn{1}{c}{$p$} & $\eta^{2}$ \\
\hline Between Subjects & & & & & & \\
Vocabulary Pretest & 49360.321 & 1 & 49360.321 & 144.32 & 0.000 & 0.720 \\
Teaching Method & 110.675 & 1 & 119.675 & .324 & 0.572 & 0.006 \\
Error & 19152.529 & 56 & 342.009 & & & \\
\hline Within Subjects & & & & & & \\
Posttests & 2243.292 & 1 & 2243.292 & 19.031 & 0.000 & 0.254 \\
Posttests* Teaching Method & 1.415 & 1 & 1.415 & 0.012 & 0.913 & 0.000 \\
Error & 6601.098 & 56 & 117.877 & & & \\
\hline
\end{tabular}

The second statistical analysis over time included only students from 5 through 6 Grade for the technology and control groups in a span of three school years (2013 2016). Testing for assumptions was needed before conducting an ANCOVA of repeated measures. Table 18 shows descriptive statistics for the technology and control groups on the covariate Vocabulary Pretest, and for the dependent variables Vocabulary Posttest 1S, Vocabulary Posttest 3S, and Vocabulary Posttest 5S.

A test of homogeneity of variances was performed, using Levene's test, finding that the assumption of homogeneity of variance on the variable Vocabulary Pretest was met $(p>0.05)$ with the covariate Vocabulary Pretest at $p=0.503$; the homogeneity of variance on the dependent variables was met: Vocabulary Posttest $1 \mathrm{~S}, p=0.663$;

Vocabulary Posttest 3S, $p=0.529$; and Vocabulary Posttest 5S, $p=0.393$. Furthermore, there were no differences between the technology and control groups on the covariate 
Vocabulary Pretest $(F[1,59]=0.048, p=0.826)$. In testing the groups versus the posttests there were no significative differences: Vocabulary Posttest $1 \mathrm{~S}, F(1,51)=$ $0.036, p=0.850 ;$ Vocabulary Posttest $3 \mathrm{~S}, F(1,36)=0.383, p=0.540$; and Vocabulary Posttest 5S, $F(1,33)=1.259, p=0.270$. The error of variance for Vocabulary Posttest 1S was 731.368 (MS within); for Vocabulary Posttest 3S, 597.231 (MS within); and for Vocabulary Posttest 5S, 664.599 (MS within).

Another established assumption was the linear relationships among the dependent variables Vocabulary Posttest 1S, Vocabulary Posttest 3S, and Vocabulary Posttest 5S and the covariate Vocabulary Pretest. Correlation analysis between the dependent variables and the covariate demonstrated Pearson $r=0.805$ for Vocabulary Posttest $1 \mathrm{~S}$, Pearson $r=0.744$ for Vocabulary Posttest 3S, and a Pearson $r=0.708$ for Vocabulary Posttest 5S.

Before conducting analysis of covariance, the homogeneity of regression was established to determine whether there was significant interaction between the covariate Vocabulary Pretest and the groups. With $F(1,29)=0.369, p=0.548$, the assumption was that there was no significant interaction between groups and the covariate Vocabulary Pretest. Thus, the assumption of homogeneity of regression was met.

Table 20 reflects the repeated measures of ANCOVA for vocabulary in Grades 5 and 6. In values for within subjects and after adjusting for initial group differences, there was no significant difference in both groups (technology and control) over time in vocabulary scores (higher scores) when compared to the covariate Vocabulary Pretest with and $F(1,30)=5.500, p=0.260$ and a $\eta^{2}=0.155$. 


\section{Table 20}

ANCOVA Repeated Measures Results for Vocabulary, Fifth and Sixth Grades, Technology and Control Groups

\begin{tabular}{crrrrrr}
\hline Source & \multicolumn{1}{c}{$S S$} & $d f$ & $M S$ & F ratio & $p$ & $\eta^{2}$ \\
\hline Between Subjects & & & & & & \\
Vocabulary Pretest & 35910.680 & 1 & 35910.680 & 61.241 & 0.000 & 0.671 \\
Teaching Method & 1392.133 & 1 & 1392.133 & 2.374 & 0.134 & 0.073 \\
Error & 17591.501 & 30 & 586.383 & & & \\
\hline Within Subjects & & & & & & \\
Posttests & 993.550 & 1 & 993.550 & 5.500 & 0.260 & 0.155 \\
Posttests* & & & & & & \\
Teaching Method & 18.219 & 1 & 18.219 & 0.101 & 0.753 & 0.003 \\
Error & 5419.624 & 30 & 180.654 & & & \\
\hline
\end{tabular}

In the between subjects analysis, with an $F(1,30)=2.374, p=0.134$ and a $\eta^{2}=$ 0.073 , the conclusion was there were no significant group differences (technology and control) for the adjusted means on Vocabulary Posttest 1S, Vocabulary Posttest 3S, and Vocabulary Posttest 5S combined.

Finally, Figure 4 presents a comparison of unadjusted means over time for the technology and control groups of students' performance in vocabulary. On this chart it can be observed that, although there were no significant differences over time among students from both groups (technology and control) for vocabulary, there was an increased performance in spelling over time for the technology group. 


\section{Figure 4}

Unadjusted Mean Comparison for Vocabulary Over Time for Technology and Control Groups.

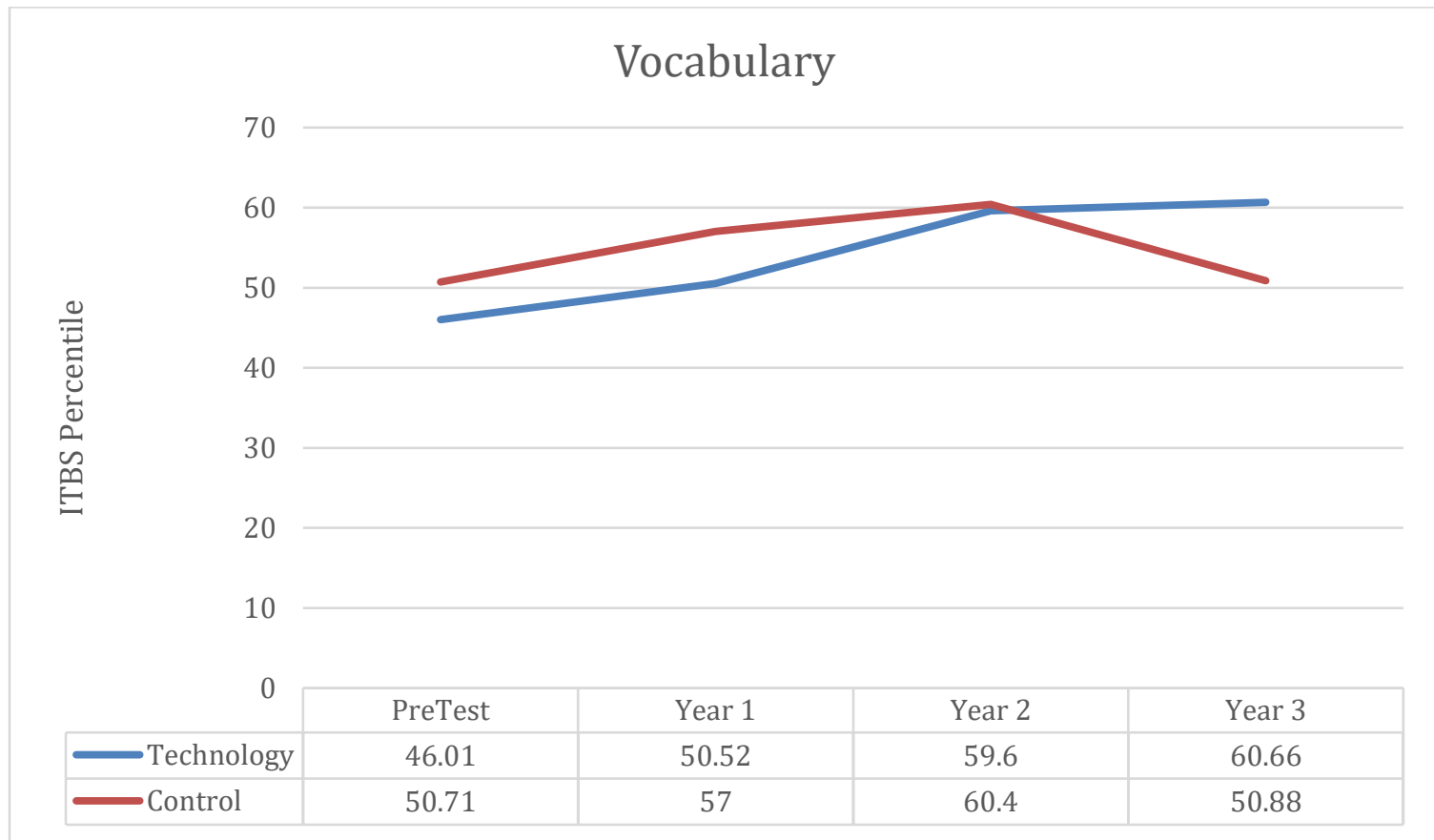

\section{Research Question \# 3: Reading Comprehension}

Comparison of GAA Students Before and After Technology Implementation for Reading Comprehension

This analysis was a comparison between academic performance in reading comprehension among students from GAA during the year prior to implementation of technology (school year 2012-2013) and the same students after a year of using technology, i.e., the new teaching method (school year 2013-2014). The goal was to determine whether there was a difference among GAA students between the year prior to implementation of technology and the year after implementation of technology. 
Also, this analysis compared means among the groups of students, using results from the technology and control groups. In addition, student results from the previous year were compared with results from the first year of the study. The statistical tool used for analysis was the sample paired $t$-test to compare the same group of student performance in reading comprehension from GAA during the year before and the year after implementation of technology. Prior to conducting the analysis of a sample paired $t$ test, descriptive statistics and the assumption of normally-distributed differences were examined. Table 21 presents descriptive statistics for the variable Reading Pretest (GAA students before the implementation of the technology) and the variable reading Posttest (GAA students after the implementation of the technology).

To conduct a sample paired $t$-test, the variables Reading Pretest $(M=46.97, S D=$ 27.70) and Reading Posttest $(M=49.15, S D=25.34)$ were used to determine whether there were significant differences among the students at GAA before and after the implementation of the technology. The assumption of normally distributed differences scores was satisfied, as the skew levels were estimated at -0.019 for the variable Reading Pretest and 0.113 for the variable Reading Posttest (less than 1 or -1 levels). Therefore, after conducting a sample paired $t$-test using the variables Reading Pretest and Reading Posttest, $t(32)=-0.341, p=0.735$, no statistically significant differences in performance among GAA students before and after the implementation of the technology in reading comprehension were observed. 


\section{Table 21}

GAA Students Before and After the Technology Intervention for Reading Comprehension

\begin{tabular}{ccccc}
\hline \multicolumn{1}{c}{ Group } & $N$ & $M$ & $S D$ & $S E$ \\
\hline Reading Pretest & 37 & 46.97 & 27.70 & 4.77 \\
Reading Posttest & 33 & 49.15 & 24.44 & 4.25 \\
\hline Total & 70 & & & \\
\hline
\end{tabular}

First-Year Comparisons of Control Group with Technology Group for Reading Comprehension

Prior to testing for the assumptions needed to conduct an analysis of covariance, descriptive statistics, including adjusted means, are presented in Table 22 for the covariate Reading Comprehension Pretest and the dependent variable Reading Comprehension Posttest S1 for both groups.

The test of homogeneity of variances was performed with Levene's test, finding that the homogeneity of variance for the variable Reading Comprehension Pretest was met $(p>0.05)$ with the covariate Reading Comprehension Pretest at $p=0.187$; the homogeneity of variances for the dependent variable reading comprehension posttest S1 was not met, $p=0.010$. Furthermore, there were differences between the groups on the covariate Reading Comprehension Pretest $(F[1,131]=4.981, p=0.027$. In the case of the dependent variable Reading Comprehension Posttest S1 and the groups there were no differences, $F(1,116)=1.413, p=0.237$. The error of variance for the reading comprehension posttest S1 was 713.069 (MS within). 
Table 22

Means and Standard Deviations for Reading Comprehension Pretest and First Posttest

\begin{tabular}{|c|c|c|c|c|c|}
\hline Group & $N$ & $M$ & $S D$ & Adjusted Means & $S E$ \\
\hline \multicolumn{6}{|c|}{ Reading Pretest (Covariate) } \\
\hline Technology & 53 & 37.71 & 24.99 & - & 3.43 \\
\hline Control & 80 & 48.36 & 28.13 & - & 3.14 \\
\hline Total & 133 & & & & \\
\hline \multicolumn{6}{|c|}{ Reading Posttest 1 (Dependent Variable) } \\
\hline Technology & 51 & 47.17 & 22.84 & 51.89 & 2.03 \\
\hline Control & 67 & 53.07 & 29.28 & 49.42 & 1.73 \\
\hline Total & 118 & & & & \\
\hline
\end{tabular}

Another assumption established was the linear relationship between the dependent variable Reading Comprehension Posttest S1 and the covariate Reading Comprehension Pretest. Correlation analysis between the two variables showed a Pearson $r=0.853$.

Before conducting analysis of covariance, the homogeneity of regression was established to determine there was no significant interaction between the groups (technology and control) on the covariate Reading Comprehension Pretest. With $F$ (1, $112)=4.178, p=0.043$, the conclusion was that a significant interaction between the groups and the covariate Reading Comprehension Pretest existed. Therefore, the assumption of homogeneity of regression was not met.

Table 23 reflects the ANCOVA results for reading comprehension. With $F$ (1, $113)=0.837, p=0.362$, there were no significant group differences in the adjusted means on Reading Comprehension Posttest S1 observed. Table 23 also indicated a significant relationship between the covariate Reading Comprehension Pretest S1 and the 
independent variable Teaching Method for both groups (technology and control) with $F$ $(1,113)=298.491, p=0.000$ and $\eta^{2}=0.725$. Because no significant variation between the control and technology groups was found on the dependent variable reading comprehension posttest $\mathrm{S} 1$, there was no need to conduct post hoc analysis.

\section{Comparison of Control and Technology Groups Over Time for Reading}

Testing for assumptions was conducted using an ANCOVA of repeated measures. This analysis included students from Grades 5, 6, and 7 over a span of two years. Table 24 shows the descriptive statistics of the covariate (Reading Pretest) and the dependent variables Reading Posttest $1 \mathrm{~S}$ and Reading Posttest 3S, for the groups.

Table 23

ANCOVA Results for Reading Comprehension, Technology and Control Groups

\begin{tabular}{|c|c|c|c|c|c|c|}
\hline Source & $S S$ & $d f$ & $M S$ & F ratio & $p$ & $\eta^{2}$ \\
\hline $\begin{array}{l}\text { Reading Comprehension } \\
\text { Pretest }\end{array}$ & $59,407.276$ & 1 & $59,407.276$ & 298.491 & 0.000 & 0.725 \\
\hline Teaching Method & 166.648 & 1 & 166.648 & 0.837 & 0.362 & 0.007 \\
\hline Error & $22,489.841$ & 113 & & & & \\
\hline Total & $378,402.000$ & 116 & & & & \\
\hline
\end{tabular}




\section{Table 24}

Means and Standard Deviations for Reading Pretest and Posttests, Fifth Through Seventh Grades

\begin{tabular}{cccccc}
\hline Group & N & M & SD & Adjusted Means & SE \\
\hline Technology & 32 & 38.09 & 23.71 & - & 4.19 \\
Control & 60 & 41.86 & 27.22 & - & 3.51 \\
\hline Total & 92 & \multicolumn{5}{c}{ Reading Pretest (Covariate) } \\
\hline Technology & 31 & 43.25 & 23.25 & 44.54 & 2.72 \\
Control & 50 & 44.86 & 28.31 & 48.88 & 2.25 \\
\hline Total & 81 & & & \\
\hline & Reading Posttest 3S (Dependent Variable) & \\
Technology & 25 & 52.08 & 27.66 & 52.08 & 2.72 \\
Control & 35 & 53.00 & 30.17 & 53.00 & 2.25 \\
\hline Total & 60 & & & \\
\hline
\end{tabular}

A test of homogeneity of variances was performed, using Levene's test, finding that the assumption of homogeneity of variance for the variable Reading Pretest was met $(p>0.05)$ with the covariate Reading Pretest at $p=0.099$. Homogeneity of variance for the dependent variables was met for Reading Posttest 1S, $p=0.076$; and Reading Posttest $3 \mathrm{~S}, p=0.276$. Furthermore, there were no differences between the groups on the covariate Reading Pretest $(F(1,91)=.437, p=0.510)$. On the dependent variable Reading Posttest $1 \mathrm{~S}$, there were no significant group differences, $F(1,80)=0.070, p=$ 0.792. Also, there were no group differences on the dependent variable Reading Posttest $3 \mathrm{~S}, F(1,59)=0.015 p=0.905$. The error of variance for Reading Posttest $1 \mathrm{~S}$ was 702.759 (MS within); for Reading Posttest 3S, 805.652 (MS within). 
Another assumption established was the linear relationship between the dependent variables (Reading Posttest 1S and Reading Posttest 3S) and the covariate (Reading Pretest). A correlation analysis for each dependent variable with the covariate was conducted resulting in Pearson $r=0.867$ for Reading Posttest 1S, and Pearson $r=0.813$ for Reading Posttest 3S.

Before conducting analysis of repeated measures of covariance, homogeneity of regression was established to determine whether there was a significant interaction between the covariate Reading Pretest and the groups. An $F(1,55)=3.496, p=0.067$ demonstrated there was not a significant interaction between groups and the covariate Reading Pretest; the assumption of homogeneity of regression was met.

Table 25 reflects the repeated measures for ANCOVA for reading comprehension in Grades 5 through 7. In values for within subjects and after adjusting for initial group differences, there was not a significant difference for the groups (technology and control) over time in vocabulary scores (higher scores) for the variable posttest when compared to the covariate Reading Pretest with $F(1,56)=0.624, p=0.433$ and a $\eta^{2}=0.011$. In the between subjects analysis, with an $F(1,56)=1.838, p=0.181$ the conclusion was that there were no significant group differences (technology and control) for the adjusted means on Reading Posttest 1S and Reading Posttest 3S combined.

As mentioned previously, the second part of the analysis of change over time used data from fifth and sixth grade students from the technology and control groups over a period of three school years (2013-2016). A repeated measures of ANCOVA was used to determine whether there were changes in the students' academic performance over time and/or due to the technology. 


\section{Table 25}

ANCOVA Repeated Measures for Reading, Fifth Through Seventh Grade, Technology and Control Groups

\begin{tabular}{crrrrrr}
\hline Source & \multicolumn{1}{c}{$S S$} & $d f$ & \multicolumn{1}{c}{$M S$} & F ratio & $p$ & $\eta^{2}$ \\
\hline Between Subjects & & & & & & \\
Reading Pretest & 67909.406 & 1 & 67909.406 & 193.18 & 0.000 & 0.775 \\
Teaching Method & 645.923 & 1 & 645.923 & 1.838 & 0.181 & 0.032 \\
Error & 19685.178 & 56 & 351.521 & & & \\
\hline Within Subjects & & & & & & \\
Posttests & 345.039 & 1 & 345.039 & 2.931 & 0.920 & 0.050 \\
Posttests* Teaching Method & 73.521 & 1 & 73.521 & 0.624 & 0.433 & 0.011 \\
Error & 6593.216 & 56 & 117.736 & & & \\
\hline
\end{tabular}

Before conducting the analysis of repeated measures of ANCOVA for reading comprehension, tests of assumptions were conducted. Table 26 shows the descriptive statistics for the covariate Reading Pretest, and the dependent variables Reading Posttest 1S, Reading Posttest 3S, and Reading Posttest 5S for the technology and control groups. 


\section{Table 26}

Means and Standard Deviations for Reading Comprehension Pretest and Posttests, Fifth and Sixth Grades

\begin{tabular}{|c|c|c|c|c|c|}
\hline Group & $N$ & $M$ & $S D$ & Adjusted Means & $S E$ \\
\hline \multicolumn{6}{|c|}{ Reading Pretest (Covariate) } \\
\hline Technology & 25 & 37.72 & 23.64 & - & 4.72 \\
\hline Control & 35 & 38.80 & 25.66 & - & 4.39 \\
\hline Total & 60 & & & & \\
\hline \multicolumn{6}{|c|}{ Reading Posttest 1S (Dependent Variable) } \\
\hline Technology & 23 & 43.34 & 23.04 & 45.22 & 3.35 \\
\hline Control & 29 & 40.37 & 27.16 & 35.06 & 3.67 \\
\hline Total & 52 & & & & \\
\hline \multicolumn{6}{|c|}{ Reading Posttest 3S (Dependent Variable) } \\
\hline Technology & 19 & 52.00 & 27.20 & 53.72 & 3.35 \\
\hline Control & 18 & 45.94 & $30.78)$ & 37.00 & 3.67 \\
\hline Total & 37 & & & & \\
\hline \multicolumn{6}{|c|}{ Reading Posttest 5S (Dependent Variable) } \\
\hline Technology & 18 & 53.61 & 22.00 & 53.61 & 3.35 \\
\hline Control & 17 & 45.64 & 27.10 & 46.73 & 3.67 \\
\hline Total & 35 & & & & \\
\hline
\end{tabular}


A test of homogeneity of variances was performed, using Levene's test, finding that the assumption of homogeneity of variance on the variable Reading Pretest was met $(p>0.05)$ with the covariate Reading Pretest at $p=0.254$; the homogeneity of variance on the dependent variables was also met; Reading Posttest 1S, $p=0.250$; Reading Posttest 3S, $p=0.449$; and Reading Posttest 5S, $p=0.118$. Furthermore, there were no differences between the groups (technology and control) on the covariate Reading Pretest $(F(1,59)=0.027, p=0.870)$. On the dependent variables, there were no significant group differences: Reading Posttest $1 \mathrm{~S}, F(1,51)=0.175, p=0.678$; Reading Posttest 3S, $F(1,36)=0.403, p=0.530 ;$ and Reading Posttest $5 \mathrm{~S}, F(1,34)=0.916, p=0.346$. The error of variance for Reading Posttest S1 was 646.801 (MS within), for Reading Posttest 3S, 840.941 (MS within), and Reading Posttest 5S was 605.641 (MS within).

Another assumption established was the linear relationship among the dependent variables Reading Posttest 1S, Reading Posttest 3S, and Reading Posttest 5S with the covariate Reading Pretest. Correlation analysis between each dependent variable and the covariate yielded Pearson $r=0.822$ for Reading Posttest 1S, Pearson $r=0.704$ for Reading Posttest 3S, and Pearson $r=0.747$ for Reading Posttest 5S.

The covariance homogeneity of regression was established to determine whether there was a significant interaction between the covariate Reading Pretest and the groups. The statistics $F(1,29)=1.762, p=0.195$, indicated there was no significant interaction between the groups and the covariate; the conclusion was that the assumption of homogeneity of regression was met.

Table 27 reflects the repeated measures of ANCOVA for reading in Grades 5 through 6. In values for within subjects and after adjusting for initial group differences, 
there was not a significant difference for both groups (technology and control) over time in reading scores (higher scores) when compared to the covariate Reading Pretest with and a $F(1,30)=0.424, p=0.520$ and $\mathrm{a} \eta^{2}=0.014$

In the between subjects analysis, with an, $F(1,30)=3.455, p=0.073$ and a $\eta^{2}$ 0.103 the conclusion was that there were no significant group differences (technology and control) for the adjusted means on Reading Posttest 1S, Reading Posttest 3S, and Reading Posttest 5S combined.

Finally, Figure 5 presents a comparison of unadjusted means over time for the technology and control groups of students' performance in reading comprehension. This chart demonstrates that, although there were no statistical significant differences over time among students from both groups (technology and control) for reading comprehension, there was an increase in performance in reading comprehension over time for the technology group.

\section{Table 27}

ANCOVA Repeated Measures Results for Reading Comprehension, Fifth and Sixth Grades, Technology and Control Groups

\begin{tabular}{crrrrrr}
\hline Source & \multicolumn{1}{c}{$S S$} & $d f$ & $M S$ & F ratio & $p$ & $\eta^{2}$ \\
\hline Between Subjects & & & & & & \\
Reading Pretest & 32348.251 & 1 & 32348.251 & 53.280 & 0.000 & 0.640 \\
Teaching Method & 2097.877 & 1 & 2097.877 & 3.455 & 0.073 & 0.103 \\
Error & 18214.031 & 30 & 607.134 & & & \\
\hline Within Subjects & & & & & & \\
Posttests & 666.266 & 1 & 666.266 & 7.018 & 0.013 & 0.190 \\
Posttests* Teaching Method & 40.229 & 1 & 40.229 & 0.424 & 0.520 & 0.014 \\
Error & 2848.264 & 30 & 90.942 & & & \\
\hline
\end{tabular}




\section{Figure 5:}

Unadjusted Mean Comparison for Reading Over Time for Technology and Control Groups.

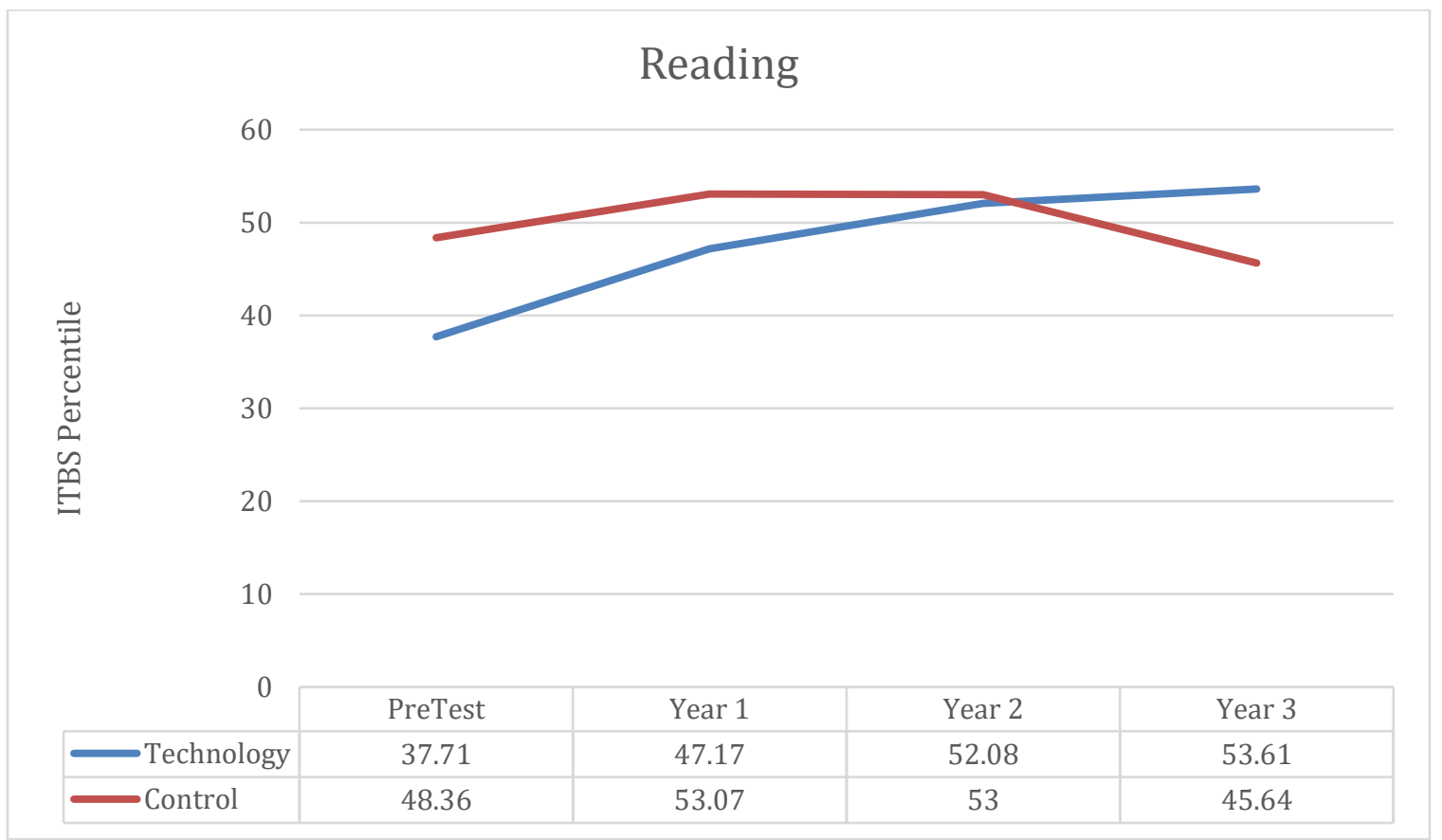




\section{CHAPTER 5}

\section{DISCUSSION, CONCLUSIONS, AND RECOMMENDATIONS}

\section{Introduction}

Chapter 5 discusses the increasing use of technology in the classroom and presents a plan to study the use of software and hardware to establish their efficacy for improving language and literacy skills in faith-based classrooms. A description of the problem was followed by discussion of the use of tablets in the classroom, a statement of the problem and purpose of the study, a theoretical framework, research questions, limitations, delimitations, definitions, and variables. This chapter also provided discussion, conclusions, and recommendations resulting from this study.

\section{Context of the Study}

The study was conducted in the Seventh-day Adventist educational system, which is part of the Seventh-day Adventist Church, in the state of Arizona, specifically in one of its schools, GAA, a kindergarten through eighth grade school. Seventh-day Adventist education is a worldwide institution with more than 7,500 schools and 1.5 million students (www.nadeducation). In North America, the Seventh-day Adventist churches and schools are geographically divided into unions and conferences. The Arizona Conference of Seventh-day Adventists is part of the Pacific Union, with 13 schools scattered throughout the state. GAA is located in the western part of Phoenix, Arizona.

GAA was founded in 1936 and has remained in operation since. During the period of this study (2013-2016) the school's enrollment steadily increased from 95 students in 
2013 to 124 students in 2016. Traditionally, Seventh-day Adventist schools in North America are supported financially by tuition payments from parents, private scholarship programs, donors, and churches. At GAA, there was only one church, Glendale Seventhday Adventist Church, which provided a subsidy to its members whose children were enrolled at the school. The school facility was located in the rear of the property of the Glendale Church, having two wings of classrooms, a sports field, and a gymnasium. Financially, during the period of this study, GAA was going through financial restructuring in an attempt to reverse the state of high receivables. In addition to the large accounts receivables status, GAA had a previous loan for the amount of a quarter-million dollars on which it was making monthly payments.

As stated in the mission statement, "Honoring our rich diverse community, developing independent learners into Christ-centered leaders," GAA has been characterized as ethnically diverse. Phoenix alone had an estimated $42 \%$ Latino population, without counting the satellite towns surrounding Phoenix (US Census Bureau, 2019). At GAA the percentage of Latino students during the period of this study was $65 \%$. The rest of the GAA population included other ethnic groups.

\section{Description of the Problem}

The federal government implemented policies, grants, research, and provided billions of dollars to provide digital access to most elementary and high schools across the nation (Alliance for Excellent Education, 2016; Federal Communications Commission, 2012; Gross, 2013; US Department of Education, Office of Educational Technology, 2010). Those federal funds were to be used for acquiring digital technology, teacher training on the use of technology in the classroom and developing online 
curricula. Some states required implementation of digital technology in K-12 school districts, while other states allowed and encouraged its use. Some states dedicated funding to acquisition of devices and software for implementation in the classroom (Fox \& Jones, 2018). On June 18th, 2013, the Los Angeles Unified School District approved almost $\$ 40$ million to start equipping students, teachers, and administration with educational iPads. This was a significant step toward technology implementation in the second largest school district of the nation, and the first step of a one-billion-dollar investment to provide one-to-one iPads for all students in the district (Blume, 2013).

Tablets, particularly iPads, had been flooding classrooms ever since they came onto the market in 2010. Internet access increased from 51\% in 1998 to $98 \%$ in 2012 within K-12 schools in the United States (LearnStuff, 2012). By the year 2018, 98\% of the K-12 school districts in the nation, covering 81,000 schools and almost 45 million students, had high-speed broadband connectivity services, compared to $31 \%$ in 2013 (Education Super-Highway, 2018). Systematically, school districts and private schools in multiple countries invested in these devices, assuming that implementation would provide a higher level of student performance and student engagement.

When this research project and implementation began in 2013, Norris \& Soloway (2012) stated there were 1.5 million students in the Unites States using iPads as part of their regular instruction; since then, the number of students using this technology has increased steadily. The speed at which this mobile technology was being implemented surpassed all other technology devices used as instructional aids in the past, including desktops and laptops. As of $2018,81 \%$ of 8 - to 17 -year-old children owned a tablet and used it for educational purposes (Pew Research Center, 2019). Seventy-five percent of 
teachers believed that by the year 2026 textbooks would be published in digital formats and students would need digital devices to access them (Deloitte Development, 2016).

This phenomenon raised questions from taxpayers, investors, and educators about the efficacy of tablets and educational apps used as instructional tools. Magruder (as cited in Blume, 2013), demonstrated concern when Los Angeles Unified School District board members approved the multi-million dollar investment in iPads in spite of the lack of conclusive research data corroborating a positive correlation between iPad use and student academic achievement. Only in recent years have studies suggested that the use of educational apps with tablets could lead to increases in student achievement (Moon et al., 2017; Wang, 2017). A survey in 89 different countries found the majority of teachers (95\%), students (75\%), parents (84\%), and school administrators (63\%) reported improved academic performance and student engagement as a result of using digital devices for instructional purposes (ASCD \& OverDrive, 2016; Schoology, 2017).

Correlated to the dramatic increase in iPad use, hundreds of thousands of educational applications were developed and continue to increase (Mendelsohn, 2012). Following this national educational trend, during fall 2013, GAA invested approximately $\$ 40,000$ to implement iPads and Mac Minis in Grades 5 through 8; the objective being to provide state-of-the-art technology and valuable educational resources to its students.

One of the challenges arising with the implementation of one-per-student iPads at GAA was determination of applications to be used by teachers and students, especially in spelling, vocabulary acquisition, and reading comprehension. Traditionally, due to the singular characteristics of the English language, spelling, vocabulary, and reading comprehension instruction included worksheets, flashcards, and crossword puzzles to 
help students learn to decode words and meaning. Another challenge, and part of the problem at GAA, was the below average performance of most students in Grades 5 through 8 in these subjects when taking the Iowa Test of Basic Skills (ITBS).

As shown in Table 28, GAA students were performing at or below the $50^{\text {th }}$ percentile in most grades and subjects. All grades performed below the national mean $\left(50^{\text {th }}\right.$ percentile) in reading comprehension; for GAA only some of the spelling averages were slightly above the national mean.

School administration, in the search for methods to improve that finding, decided to implement iPad Minis and a spelling app named Vocabulary Spelling City (VSC), for the fifth- through eighth-grade students at GAA. Students and teachers would implement a different learning and teaching approach, intending that knowledge about the efficacy and efficiency of this method of teaching spelling, vocabulary, and reading comprehension would assist the school in its quest for academic excellence, including improvement of student performance.

\section{Table 28}

Mean National Percentile Ranks of GAA Students on ITBS, Fall 2013

\begin{tabular}{cccccc}
\hline & \multicolumn{5}{c}{ Percentile Results by Grade for GAA } \\
\cline { 2 - 5 } ITBS Test & Grade 5 & Grade 6 & Grade 7 & Grade 8 & Totals \\
\hline Vocabulary & 50 & 37 & 37 & 52 & 44 \\
Spelling & 81 & 58 & 35 & 47 & 55 \\
Reading Comprehension & 45 & 28 & 32 & 33 & 34 \\
\hline Totals & 59 & 41 & 35 & 44 & \\
\hline
\end{tabular}




\section{Benefits of Using Tablets in the Classroom}

According to the US Department of Education (2010) and reports by the National Training and Simulation Association (2012), technology-based instruction reduced the time students needed to obtain a learning objective by $30-80 \%$. Another survey conducted by Public Broadcasting Services (2012) found that 77\% of teachers concluded technology had contributed to increased student motivation to learn.

Another benefit of using tablets in the classroom was the storage capacity of the devices; they could contain thousands of digital textbooks, online resources, quizzes, homework, and other materials, eliminating the need and expense of coping with physical storage space for books and classroom materials (Price, 2012). From the financial perspective, Sumser (2016) noted that the cost of acquiring digital textbooks was significantly less compared to hard copies. Another benefit of using tablets instead of textbooks or paper and pencil was the savings in paper, copy paper, printing supplies, and related costs when using tablets. A 100-teacher school uses about 250,000 pieces of paper annually, costing $\$ 3-4,000$ in printing expenses. A tablet-based school would save significant amounts of money and help to protect the environment (Johnson, 2011; Williams, 2012). Research studies conducted by Maragioglio (cited by Connor, 2016), Moon et al. (2017), and Wang, (2017), found that tablets used as a method of instruction and practice resulted in improvements in student academic performance.

Tablets contain many technological features lacking in textbooks. The ability to highlight text, take notes, and make annotations without ruining the textbook for the next user are a few examples. Tablets offer screen brightness control, backlight intensity, and a built-in dictionary allowing students to inquire about the meaning of an unknown word. 
Digital information can be shared instantaneously with more individuals. Access to videos, interactive graphics, and diagrams increased students' attentiveness and engagement (Apple, 2019; Groff, 2013; Hall, 2017; Harper, 2018; Johnson, 2019).

A disadvantage of print textbooks was their weight, which was connected to back injuries among K-12 students in the United States. During the year 2010-2011, more than 13,000 students were treated for back, neck, and muscular injuries caused by the use of heavy backpacks. That number dropped to less than half by the year 2016, because of the increased use of tablets. The average weight of tablets was between one and two pounds (American Academy of Orthopedic Surgeons, 2017; California Department of Education, 2004; Dallas, 2012).

The use of tablets contributes to the preparation of students for a world which is immersed in technology. According to the US Bureau of Labor Statistics (2019), technology-related jobs were expected to increase by $18 \%$ between 2010 and 2020 . Another benefit of using tablets was the ability to download hundreds of thousands of educational apps including the option of updating textbooks automatically rather than reprinting them (Federal Communications Commission, 2012; Obama, 2013).

One of the greatest benefits of using tablets for instruction and academic practice was the ability of software and apps to differentiate instruction according to the educational needs of each student (Mendelsohn, 2012). Every teacher knows that classrooms include students who perform at different academic levels. Moreover, in the Arizona Seventh-day Adventist educational system, all of the elementary schools had multi-grade classrooms, including GAA. 


\section{Considerations for Using Tablets in the Classroom}

As mentioned earlier Magruder (as cited in Blume, 2013) expressed concerns about using tablets in the classroom. Advocates against the use of these devices were concerned about health problems. Handheld devices contributed to computer vision syndrome, eyestrain, blurred vision, and dry eyes (Klamm \& Tarnow, 2015). Individuals experienced musculoskeletal disorders from the constant strain on certain muscles, including carpal tunnel syndrome, neck pain, shoulder pain, and fibromyalgia (Fishman, 2010; Lin, 2009).

Some commentators argued that tablets were more expensive than textbooks because of the investment in technology and infrastructure required to operate them, plus the cost of maintenance and repair (Blazer, 2013; Bowie, 2017; Wilson, 2012). Some claimed that tablets were responsible for students' short attention spans, causing distraction more than serving as an educational aid (Gasser \& Palfrey, 2009; Lanir, 2012). According to some studies (Carr, 2010; Mueller \& Oppenheimer, 2014), the brain interpreted digital text differently than paper text. These studies argued that those who read paper-based text had higher comprehension, memorization, and learned more when compared to those who read digital text only.

Those who were opposed to the use of tablets in the classroom pointed out that many students did not have sufficient internet bandwidth access at their homes, which restricted the use of the devices to the school environment (Federal Communications Commission, 2012; Horrigan, 2015).

Some educators were concerned that students would be more likely to cut corners and cheat while using tablets (Pandolfo, 2012). Students could avoid reading and 
analyzing texts by looking up answers through the search box in the e-textbook or by going online.

\section{Implications for Instructional leadership}

Implementation and use of technology in the classroom stems from decisions made by educational leaders which affect what happens in the classroom regarding the use of those technologies irrevocably. One of the main implications is the financial impact of technology implementations on the school and district budget. New technologies tend to be expensive and as leaders ponder the different options and priorities of educational institutions, they are faced with critical and important decisions (Blazer, 2013; Bowie, 2017; Wilson, 2012).

On the other hand, there is a perceived need that students must be exposed to the latest technological advances in preparation for the more increasing technology-driven workforce (Bybee, 2010; Goldin \& Katz, 2009). Technology literacy is part of the new objectives in equipping students with 21-Century skills. Dalton and Grisham (2011) noted that ICTs are tools which literacy educators must incorporate into the 21 st century skills required for students to learn. The IRA (2009) stated that "to become fully literate in today's world, students must become proficient in the new literacies of the $21 \mathrm{st}$ century" (p. 16). Therefore, instructional and educational leaders are required to find a fine balance between budgetary concerns and technology instruction goals.

As a result of this, and according to Kolb (2019), school administrators feel pressured to implement technology in the classrooms but lack the conceptual framework for how technology should be incorporated. Hence, Kolb proposes the Triple-E Framework to assist school administrators and teachers in their decision regarding types 
of technologies that could be implemented in the classroom. Kolb suggests that “engagement, enhancement, and extension should be considered when implementing technology into a learning activity” (p. 22). For engagement, Kolb argues that learning needs to be social, therefore, teachers cannot afford for technology to disrupt the social component of the learning experience; she then suggests ways to use technology accordingly. Learning with technology is more productive when it provides higher-order thinking and skills (Hirsh-Pasek et al., 2015); therefore "when students are using technology to create, analyze, evaluate, gather, and synthesize knowledge, there can be long-term and positive cognitive growth" (Kolb, 2019, p. 24). The last component of this framework is called extension, and refers to the connection of the learning with technology with real-life challenges and problems and how the learning and technology can contribute to solve those (Kolb, 2019; Richardson, 2019).

Another area of concern facing instructional leaders is the amount of professional development often required to prepare teachers for the use of technology (Mishra \& Koehler, 2009). In this area, Joo et al. (2018) concluded that using the TPACK framework among college teachers affected teacher self-efficacy and perceived ease of using and usefulness technology positively. In addition, there seems to be a certain degree of reluctance among teachers to learn new technologies, and a demonstrated generational gap between teachers and their students making acquisition of technological skills by teachers a difficult process (Penski, 2001; Uğur \& Koç, 2019). Therefore, it is imperative that principals and teachers work together to improve the use of technology in the classroom through supervision, evaluation, professional development, and a shared vision (Di Paola \& Wagner, 2018; Hughes et al., 2016; Lennon, 2012). 


\section{Purpose of the Study}

The purpose of this study was to determine the efficacy of using tablets (iPad Mini) and the software VSC for developing literacy skills in spelling, vocabulary, and reading comprehension among students at GAA in Phoenix, Arizona. For three years, students from fifth through eighth grades, experienced the use of tablets and the aforementioned app as the main instructional and practice tools for learning spelling, vocabulary, and reading comprehension.

Technology and communication are part of the 21st century skills students must acquire during the elementary and high school years of instruction (Dalton \& Grisham, 2011). Therefore, teachers should be prepared and instructed in how to foster, model, and teach these skills for the new century. The TPACK theory framework was designed to bridge the gap existing between technology and pedagogy among teachers (Mishra \& Koehler, 2006; Schmidt et al., 2009). Complex interactions exist among a teacher's technological knowledge, pedagogical knowledge, and content knowledge (Hutchinson et al., 2012). The TPACK framework prepared teachers at GAA for the implementation and use of the educational technology among fifth- through eighth-grade students. Also, this study aimed to contribute to the scarce research regarding the use of VSC in middle school, particularly in the Seventh-day Adventist education system.

\section{Summary of the Literature}

Although the use of tablets with a particular software has been implemented in elementary classrooms during the last decade (Deloitte Development, 2016; Education SuperHighway, 2018; LearnStuff, 2012; Pew Research Center, 2019), only in recent 
years have studies suggested that the use of educational apps with tablets could lead to an increase in student academic achievement (Moon et al., 2017; Wang, 2017).

Several benefits of the use of technology-based instructional approaches were documented. Advantages include reducing the time needed for a student to achieve learning objectives (National Training and Simulation Association, 2012; US Department of Education, 2010), increasing students' motivation (Public Broadcasting Services, 2012), making information accessibility faster and in different modalities (Price, 2012), and allowing differentiated instruction to be more effective (Mendelsohn, 2012). Perhaps one of the greatest benefits posed by the use of tablets and educational apps is the preparation of students for a world which is immersed in technology (US Bureau of Labor Statistics, 2019).

Other literature raises health concerns about the use of tablets for students. Handheld devices contribute to computer vison syndrome, eyestrain, blurred vison, and dry eyes (Klamm \& Tarnow, 2015). Other experts argue that tablets are more expensive than textbooks because of the investment in the technology and infrastructure required to operate them, plus the cost of maintenance and repair of the tablets (Blazer, 2013; Bowie, 2017; Wilson, 2012). Some authors claim that tablets are responsible for students' short attention spans and cause distraction rather than being useful as an educational aid (Gasser \& Palfrey, 2009; Lanir, 2012).

The use of technology and computer-based instruction began when computers were made available to schools during the 1970s. Ouyang (1993) conducted a metaanalysis of more than seventy studies on the effectiveness of CAI at the elementary level, concluding that the use of software for instruction resulted in significant improvements 
among kindergarten through sixth-grade students in the areas of spelling, vocabulary, and reading. Singleton and Simmons (2001) evaluated the effectiveness of the computer software "Wordshark" when used by elementary students to practice spelling and word recognition. Ninety-seven percent of the students surveyed enjoyed using the software; significant improvement in children's reading and spelling occurred. Wu and Zhang (2010) reported that "students in fourth grade who used handheld computers to learn spelling had higher test scores than students who learned spelling without handheld computers" (p. 57). More recent studies related to the use of iPads for instruction highlight the importance of students learning from electronic or digital text, because such formats provided internet connectivity, offered rich and interactive learning experiences with personalized learning, encouraged collaboration, gave timely feedback, and supported formative assessment in addition to student self-assessment (The National Education Technology Plan, US Department of Education, as cited in Dalton, 2014). In summary, integrating digital technologies into literacy instruction and providing the necessary tools for students to be successful has become relevant to teachers and instructors during this millennium (Hutchison \& Reinking, 2011).

Another study conducted in Canada by Lysenko and Abrami (2014) among 517 first and second graders, from six different schools in Quebec, concluded that the use of two online software programs contributed to better performance in reading comprehension among students belonging to the experimental group.

A study by Arens and Mace (2017) provided positive insights about the efficacy of using VSC software as a supplementary tool for instilling literacy skills among students. The study results concluded that students using VSC performed better at 
vocabulary retention and reading comprehension skills than their counterparts who were part of a traditional instruction system.

\section{Research Methodology}

Because the purpose of this study was to determine the efficacy of using VSC software and iPad Minis as the main instruction and practice tool among students in Grades 5 through 8 at GAA, in the areas of vocabulary, spelling, and reading comprehension, electronic tablets (iPad minis) were used as a technological medium to deploy a particular app that allowed teachers and students to perform educational activities in spelling, vocabulary, and reading comprehension. The software chosen for this study, VSC, is an online application dedicated to aiding students, teachers, parent teachers, and school systems with literacy skills. Their mission uses an efficient gamebased study of these skills to improve performance in spelling, vocabulary, phonics, writing, and reading. The structure and design uses principles of rewards from the theory of behaviorism as well as ZPD from Vygotsky’s constructivism approach.

In this study ANCOVA offered a technique allowing data collected in social science settings to be analyzed appropriately (Mertler \& Vannatta, 2013). Based on the characteristics of the research scenario, the main objective of ANCOVA is to make a quasi-experimental design research more sensitive by teasing out the influence of an independent variable over the dependent variable. The experimental group was the fifththrough eighth-grade students from GAA, where the technology (iPad Mini and VSC software) was implemented. The control group was formed using the fifth- through eighth-grade students from all other Seventh-day Adventist schools in Arizona which were not using or implementing the technology. The ITBS was used to evaluate students' 
academic performance in spelling, vocabulary, and reading comprehension. Descriptive statistics were presented for the experimental and control groups. Tests of homogeneity and of the assumption of a linear relationship between the dependent variables and the covariates followed the descriptive statistics of the groups. In order to conduct ANCOVA the homogeneity of regression was established to determine there was no significant interaction between the covariate pretests (spelling, vocabulary, and reading) and the groups (technology and control). ANCOVA analyses were displayed in tables with their interpretations.

Another component of this study was a longitudinal analysis among the experimental group, the fifth- and sixth-grade students at GAA, and the control group, the fifth- and sixth-grade students from the other Seventh-day Adventist schools in Arizona. To track these two groups' academic performance in the areas of spelling, vocabulary, and reading comprehension throughout three consecutive academic years (2013-2016), ITBS test results (posttests) were used. These posttests included the testing at the end of the school years of 2013-1014, 2014-2015, and 2015-2016. Using those test results plus the covariate pretest from the beginning of the 2013-2014 school year, statistical analyses using repeated measures of ANCOVA (between and within subjects) were conducted to determine the impact of the technology implementation over a longer period of time.

A final statistical analysis, using a sample paired $t$-test, was conducted comparing the academic performance of students in the fifth through seventh grades at GAA in spelling, vocabulary, and reading comprehension in the year prior to implementation of the technology (2012-2013) and at the end of the year in which the technology was implemented (2013-2014). 


\section{Discussion of Findings}

Besides the study conducted on the efficacy of VSC by Arens and Mace (2017), and during the development of this research project, other studies related to the use of this software were conducted. A project piloted by Krause (2018) among second-language college students in Portland concluded that the use of VSC benefitted students in vocabulary retention when compared to peers who did not have access to VSC. More recently, due to the COVID-19 pandemic, VSC has been recommended as an effective tool for teaching vocabulary and spelling through remote/distance education (Chertoff \& Thompson, 2020). Another study using VSC conducted among at-risk first graders demonstrated that this software was effective for targeted learning in vocabulary acquisition, in the long term it was more effective the use of a previous validated extended vocabulary intervention than the use of the VSC software (Loftus-Rattan \& Furey, 2020). The academic benefits from the use of literature skills tablet apps for students who have challenges with the English language or present educational disabilities seems to have been confirmed by other studies (Seifert \& Simon, 2019).

In this study there were no significant differences between the GAA students (technology group) when compared with the rest of the fifth- through eighth-grade students from other Seventh-day Adventist schools (control group) within the Arizona Conference of Seventh-day Adventists where the traditional methods of instruction in spelling, vocabulary, and reading comprehension were being used. Therefore, the expected academic growth in some of the areas investigated in the study conducted by Arens and Mace (2017) was not seen among the GAA students when compared to their peers from the other Seventh-day Adventist schools in Arizona. 
For the GAA students, the use of the technology was not detrimental to their academic performance. In other words, fifth- through eighth-grade students at GAA grew academically in the areas of spelling, vocabulary and reading comprehension in similar ways as their peers who were exposed to the traditional methods of teaching those subjects; this was consistent with more recent studies (ASCD \& OverDrive, 2016; Moon et al., 2017; Schoology, 2017; Wang, 2017).

Another finding was a group difference in spelling among the GAA students after a year of using the technology when compared to the year prior to the implementation of tablets and the VSC software $(p=0.038)$. There was no significant difference in vocabulary among the same students in the first year of the technology implementation. Furthermore, in reading comprehension, there was no significant difference in growth during the first year of implementation of the technology program.

In summary, implementation of the technology program at GAA, using tablets and the VSC app, did not appear to contribute to increased academic growth in the areas of spelling, vocabulary and reading comprehension, over time, when compared to the students who practiced and were taught using traditional methods of teaching and practice. Furthermore, the prolonged use of the tablets (iPad minis) and the educational VSC app did not hinder the academic growth of the students at GAA when compared to the academic growth of students at the other Seventh-day Adventist schools in Arizona, therefore affirming the principle that use of technology as a method of instruction and practice can be as effective as the traditional method in middle school. 


\section{Research Question 1}

Is there a difference in student performance in spelling when exposed to a technology-based curriculum while controlling for the covariate pretest among students in Grades 5 through 8 at GAA? See Table 9.

A significant difference between groups was found among the students who experienced the technology intervention when compared to their performance during the previous year when they were taught using the traditional methods of teaching spelling ( $p$ $=0.038$ ). No group difference was found in either group of students (technology and control) between the pretest and posttest in spelling $\left(p=0.652 ; \eta^{2}=0.002\right)$ during the first year of technology and software implementation (iPad mini and VSC). After conducting a repeated measures ANCOVA to track the experimental group of students at GAA over a period of two years, there was no significant difference in spelling performance when compared to their counterparts from the other Seventh-day Adventist schools in Arizona $\left(p=0.702 ; \eta^{2}=0.003\right)$. Furthermore, after conducting a repeated measures ANCOVA to track the experimental group of students at GAA over a period of three years, there was no significant difference in spelling performance when compared with the control group $\left(p=0.369 ; \eta^{2}=0.027\right)$.

\section{Research Question 2}

Is there a difference in student performance in vocabulary when exposed to a technology-based curriculum while controlling for the covariate pretest among students in Grades 5 through 8 at GAA? See Table 15.

No significant difference in growth was found among the GAA students who experienced the technology intervention when compared to their performance during the 
prior year when they were taught by using the traditional methods of teaching vocabulary $(p=0.331)$. No difference was found for the GAA students in vocabulary when compared to their peers in other Seventh-day Adventist schools in Arizona after the end of the first year of the technology implementation $\left(p=0.203 ; \eta^{2}=0.014\right)$. After conducting a repeated measures ANCOVA to track the technology group of students at GAA over a period of two years, there was no significant difference in vocabulary performance when compared to their counterparts from the other Seventh-day Adventist schools in Arizona $\left(p=0.572 ; \eta^{2}=0.006\right)$. Furthermore, after conducting a repeated measures ANCOVA to track the experimental group of students at GAA over a period of three years, there was no significant difference in vocabulary performance when compared with the control group $\left(p=0.134 ; \eta^{2}=0.073\right)$.

\section{Research Question 3}

Is there a difference in student performance in reading comprehension when exposed to a technology-based curriculum while controlling for the covariate pretest among students in Grades 5 through 8 at GAA? See Table 21.

No significant group differences was found among the students who experienced the technology intervention when compared to their performance during the prior year, when they were taught using the traditional methods of teaching reading comprehension $(p=0.735)$. No difference was found for the GAA students in reading comprehension when compared to their peers in other Seventh-day Adventist schools in Arizona after the end of the first year of the technology implementation $\left(p=0.362 ; \eta^{2}=0.007\right)$. After conducting a repeated measures ANCOVA to track the experimental group of students at GAA over a period of two years, there was no significant difference in reading 
comprehension performance when compared to their counterparts from the other Seventh-day Adventist schools in Arizona $\left(p=0.181 ; \eta^{2}=0.032\right)$. Furthermore, after conducting a repeated measures ANCOVA to track the experimental group of students at GAA over a period of three years, there was no significant difference in reading comprehension performance when compared with the control group $\left(p=0.073 ; \eta^{2}=\right.$ 0.103).

\section{Limitations}

According to Creswell and Guetterman (2018), the quasi-experimental approach, which was the research design used in this study, introduced considerably more threats to internal validity when compared to a true experimental design. In this study, random selection was not used, and the author worked with intact groups; therefore, there were potential threats of maturation, selection, mortality, and interaction among other uncollected variables.

Because of the nature of this study and the peculiar characteristics of the site and subjects, a control group could not be used from the same site nor facility. Thus, the academic performance of students in Grades 5 through 8 in Seventh-day Adventist schools where the traditional way of teaching these subjects was compared to the GAA students (Grades 5 through 8) who had access to the app VSC, using iPad minis. All schools were located within the Arizona Conference of Seventh-day Adventists.

The researcher of this study was involved in implementation of the technology intervention among students of the experimental group (technology group) as the principal and a teacher at Glenview Adventist Academy. This possibly affected the objectivity of the study, as noted by Croswell and Guetterman (2018). 
Another possible limitation of the study is the efficacy of teacher training in the use of technology or the lack thereof for the technology group and the potential impact on the study results. Some studies suggest the importance of teacher training in the success of technology implementation in the classroom (Nikian et al., 2013; Mishra \& Koehler, 2009). Although the TPACK theoretical framework approach was utilized for the technology implementation at GAA, the objective of the study was not to determine its efficacy but to utilize it to provide guidelines and directions regarding the implementation of the technology.

This study was limited by time and space and was an attempt to glimpse a particular and unique reality of students and teachers belonging to a geographicallylimited educational system. In spite of the efforts made to control all possible variables affecting student testing, it was impossible to control them all. Although a snapshot of a particular place and time, the study contributed to the limited but increasing body of knowledge about technology in the classroom, the use of tablets, and educational software as part of the instructional curriculum.

\section{Conclusions}

1. The results of this study reflect that the implementation of technology did not make a statistical significant difference in performance for spelling, vocabulary, and reading comprehension among GAA 5th through 8th grade students over time. When comparing the technology group from the year before with the year after implementation of technology there was a significant difference in spelling. However, there were no group differences in the areas of vocabulary and reading comprehension. 
2. An implication from these findings was that using tablets and the app VSC seemed not to affect student academic performance negatively when compared to peers who were not part of the technology implementation. This inference comes as a result of the three-year period of research conducted among students belonging to the experimental group (those exposed to the technology). This suggests that a plausible assumption is that students performing at average academic levels would not be affected for better or worse, whether instruction is provided with or without the use of technology, when performance is tested using standardized testing (ITBS) in the subject areas of spelling, vocabulary, and reading comprehension.

\section{Recommendations for Practice}

Based on the results of this study, the use of tablets and educational software did not provide significant academic benefits to students from GAA who were members of the experimental group in the areas of spelling, vocabulary, and reading comprehension. This finding does not align with the results from studies by Arens and Mace (2017), Krause (2018), Loftus-Rattan and Furey (2020), and Seifert and Simon (2019), who demonstrated that students who already had language difficulties (e.g., those coming from non-English-speaking families, thus having disadvantages when compared to their counterparts from English-speaking families) were able to increase their rate of gaining knowledge more than those students who did not show language challenges or difficulties. One reason this study was not able to reflect a significant difference in academic performance among the experimental and control groups could be related to the instrument used to assess students' performance in spelling, vocabulary, and reading 
comprehension. The instrument used for measuring students' academic performance, the ITBS, is a norm based instrument; therefore there is a risk for a lack of sensitivity in measuring the effects of an intervention, since the national percentile rank is determined, and therefore affected, by a normed based approach.

Although the use of tablets and the educational app VSC did not seem to contribute to the academic growth of students who were performing below the national percentile median rank, those for whom English is their second language, and/or those who have learning disabilities; on the other hand, the use of tablets and the app VSC did not affect academic growth negatively. Therefore, the implementation of this technology would not be detrimental to the academic performance of regular students.

A strong recommendation is to equip and prepare teachers for the use of technology in the classroom. Knowing how to use technology does not translate into students achieving the learning goals (Mishra \& Koehler, 2009). Teachers must be trained to facilitate student learning when implementing technology (Nikian et al., 2013). Teacher perception on using technology plays an important role in how they approach technology for education purposes (Domingo \& Garganté, 2016). A negative teacher perception toward technology use and implementation in the classroom may bring negative results regarding its efficacy (Kumar et al., 2008). Furthermore, teachers should be involved in partnership with school administrators when casting the technology vision of a school (Di Paola \& Wagner, 2018; Hughes et al., 2016; Lennon, 2012).

This study has important implications regarding Seventh-day Adventist education in North America. Since VSC is a widely used app among these schools and is part of the published educational software made available for elementary and middle schools on the 
North American Seventh-day Adventist education website (www.nadeducation.org), this study provides a foundation for determining whether using VSC in Seventh-day Adventist middle schools is relevant.

\section{Recommendations for Further Research}

Using a larger population to study the efficacy of the educational app VSC would be helpful (and probably statistically significant), because this study and the one conducted by Arens and Mace (2017) were performed with an unique population (Seventh-day Adventist schools in Arizona) or with small samples. Furthermore, since VSC is widely used among Seventh-day Adventist schools in the NAD, observing the efficacy of this software on a larger population of Seventh-day Adventist schools, therefore increasing the sample size, would be relevant. Including the use of a more sensitive instrument for measuring academic performance and the impact of an intervention is strongly recommended. Utilizing a qualitative or mixed methods research approach could provide a clearer depiction of the extent and impact of technology in the classroom, particularly regarding student academic performance.

Several studies regarding the use of CBI, educational apps, and tablets in educational settings were short-term studies (Arens \& Mace, 2017; Moon et al., 2017; Wang, 2017). Further research over a longer period of time could investigate the degree of student involvement, engagement, self-motivation, teachers' perception toward technology, and satisfaction in classrooms when tablets and educational apps are implemented (Singleton \& Simmons, 2001).

Investigating a blended system of technology and traditional approaches for teaching, instructing, and practicing literacy would be useful to discover whether 
students' academic growth differs when comparing a pure instruction and practice approach, technology alone, or a blended approach. Along with that, an expansion of the theories setting the foundation for best practices among educators who are implementing technology in the classroom would be helpful in pre-teacher education and for in-service training. Currently, the most developed theory regarding technology implementation in education is attributed to Mishra and Koehler's (2009) TPACK approach.

As stated earlier, the need to prepare students for technology jobs in the future (Dalton \& Grisham, 2011) raises the question of how well these students are being prepared through current technology, especially considering the fast-paced changes and improvements in technology. The need to conduct a longitudinal study following elementary and middle school students until they enter adulthood and join the workforce seems to be obvious. 
APPENDIX

APPROVAL DOCUMENTS 


\title{
Andrews University
}

\author{
Office of Research and Creative Scholarship \\ Institutional Review Board \\ (269) 471-6361 Fax: (269) 471-6246 E-mail: irb@andrews.edu \\ Andrews University, Berrien Springs, MI 49104-0355
}

\section{APPLICATION FOR APPROVAL OF HUMAN SUBJECTS RESEARCH}

Please complete this application as thoroughly as possible. Your application will be reviewed by a committee of Andrews University IRB, and if approved it will be for one year. Beyond the one year you will be required to submit a continuation request. It is the IRB's responsibility to assign the level of review: Exempt, Expedited or Full. It is your responsibility to accurately complete the form and provide the required documents. Should your application fall into the exempt status, you should expect a response from the IRB office within 2 weeks; Expedited within 2 weeks and a Full review 4-6 weeks.

Please complete the following application:

\section{Research Project}

a) Title: The Use of the Vocabulary Spelling City App and How that Affects Student Performance in Spelling, Vocabulary, and Reading Comprehension of Students in Grades 5-8 at Glenview Adventist Academy.

Will the research be conducted on the AU campus? __ Yes __ $\mathbf{x}_{-}$No

If no, please indicate the location(s) of the study and attach an institutional consent letter that references the researcher's study.

Adventist schools from the Arizona Conference of SDA (See letter attached).

b) What is the source of funding (please check all that apply)

\begin{tabular}{|l|l|}
\hline $\mathbf{x} \_$Unfunded & \\
\hline Internal Funding & Source: \\
\hline External Funding & Sponsor/Source: \\
\hline Grant title: & Award \# / Charging String: \\
\hline If you do not know the funding/grant information, please obtain it from your department
\end{tabular}

\section{Principal Investigator (PI)}

First Name: Last Name: Telephone: E-mail:

Fernando Lista 678-361-2912 fernando.lista@ gmail.com

_.

First Name: Last Name: Telephone: E-mail:

Dr. Bordes Henry-Saturne 269-471-6702 bordes@ andrews.edu

Advisor's signature:

Department: Program:

Leadership Department Ph.D. K-12 Administration

3. Co-investigators (Please list their names and contact information below)

First Name: Last Name: Telephone: E-mail: 
First Name: Last Name: Telephone: E-mail:

4. Cooperating Institutions

Is this research being done in cooperation with any institutions, individuals or organizations not affiliated with AU?

_ $\mathbf{x}_{-}$Yes _ No If yes, please provide the names and contact information of authorized officials below.

Name of Organization: Address:

Arizona Conference of SDA 13405 N Scottsdale Rd, Scottsdale, AZ 85254

First Name: Last Name: Telephone: E-mail:

Nicole Mattson 480-991-6777. mattson@ azconference.org

First Name: Last Name: Telephone: E-mail

Have you received IRB approval from another institution for this study? _

If yes, please attach a copy of the IRB approval.

\section{Participant Recruitment}

Describe how participant recruitment will be performed. Include how and by whom potential participants are introduced to the study (please check all below that apply)

\begin{tabular}{l} 
AU directory _ Postings, Flyers _ Radio, TV \\
\hline E-mail solicitation. Indicate how the email addresses are obtained: \\
\hline Web-based solicitation. Specify sites:
\end{tabular}

Participant Pool. Specify what pool: $5^{\text {th }}-8^{\text {th }}$ Grade students from Adventist schools in the Arizona Conference of SDA.

_. $\mathbf{X}_{-}$Other, please specify: There is no a recruitment process involved for this study. Data for this study, which consist of academic test results (ITBS), grade level, and gender will be requested to the Office of Education of the Arizona Conference of SDA. According to the guidance on Exemption Category B.1: Normal Education Practices this should be an exempt study.

\section{Please attach any recruiting materials you plan to use and the text of e-mail or web-based} solicitations you will use.

\section{Participant Compensation and Costs}

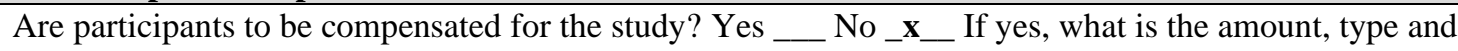
source of funds?

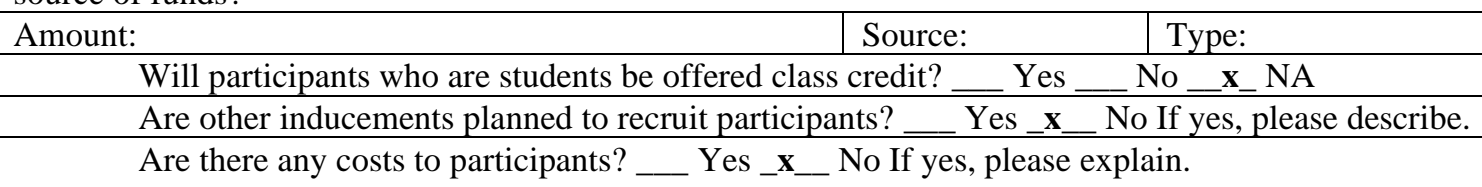

\section{Confidentiality and Data Security}
Will personal identifiers be collected?_x__ Yes $\quad$ Will identifiers be translated to a code? __ No
Will recordings be made (audio, video)? __ Yes __ $\mathbf{x}_{-}$No If yes, please describe.

Who will have access to data (survey, questionnaires, recordings, interview records, etc.)? Please list below.

The investigator/researcher, in this case, Fernando Lista. The identifiers collected will be gender and grade level. The data gathered for this study from the students (ITBS test results, gender, and grade level) will be anonymized by using alphanumerical codes. Therefore, confidentially will be maintained. Then, it will be entered in SPSS. The Anonymized data will be kept in the researcher's computer, as a 
SPSS file, which is password protected as well as the computer. The original data with the students names is kept and maintained by Riverside Insight (ITBS company) safely secured in their online servers. Student's identity (names) will never exit the online servers of Riverside Insight.

\section{Conflict of Interest}

Do you (or any individual who is associated with or responsible for the design, the conduct of or the reporting of this research) have an economic or financial interest in, or act as an officer or director for, any outside entity whose interests could reasonably appear to be affected by this research project:

Yes__ $\mathbf{x}_{-}$No

If yes, please provide detailed information to permit the IRB to determine if such involvement should be disclosed to potential research subjects.

\section{Results}

To whom will you present results (highlight all that apply)

Class Conference Published Article ___ $\mathbf{x}_{-}$Other If other, please specify: Dissertation Publishing

\section{Description of Research Subjects}

If human subjects are involved, please highlight all that apply:

_. _ _ Minors (under 18 years) __ Prison inmates __ Mentally impaired __ Physically disabled Institutionalized residents __ Anyone unable to make informed decisions about participation Vulnerable or at-risk groups, e.g., poverty, pregnant women, substance abuse population

\section{Risks}

Are there any potential damage or adverse consequences to researcher, participants, or environment? These include physical, psychological, social, or spiritual risks whether as part of the protocol or a remote possibility.

Please highlight all that apply (Type of risk):

Physical harm __ Psychological harm Social harm Spiritual harm

\section{Content Sensitivity}

Does your research address culturally or morally sensitive issues? describe:

\section{Please provide (type in or copy - paste or attach) the following documentation in the boxes} below:

Protocol : Students grades 5-8 at Glenview Adventist Academy were administered the tablets (iPad minis) and the software Vocabulary Spelling City during the school years 2013-2016. This group has become the experimental group. The control group are the rest of the Adventist schools in the Arizona Conference that were not using iPad minis nor the software Vocabulary Spelling City. The main objective of this study is to measure the efficacy of use of tablets and the software Vocabulary Spelling City by assessing the students' academic performances of those who used the tablets and software versus those students from other schools in the Arizona Conference that did not use the tablets nor the software Vocabulary Spelling City. ITBS tests results from that time window (20132016) will be used to be inputted on SPSS for statistical purposes. 
Because of the characteristics of the subjects and the setting; a quantitative quasi-experimental design was chosen for this study. More specifically, a Between-Group Pre-and Posttest design was used to established possible cause and effect between the independent and dependent variables (Creswell \& Guetterman, 2018). Also, a Within-Group Time Series approach was utilized in an effort to track students' academic performance in the areas of spelling, vocabulary, and reading comprehension in a span of three years (Creswell \& Guetterman, 2018). In education, many experimental situations occur in which researchers have to use intact groups. Due to the availability of participants and setting restrictions it is difficult to form artificial, random groups, because many schools use traditional methods of teaching, students are assigned to grade-level classrooms, etc. Because quasiexperimental designs include assignment, but not random assignment, which is an impossibility in this study, the researcher could use the already assigned groups of students (Creswell \& Guetterman, 2018). Thus, the experimental group included students in grades 5-8 at GAA; the control group was the students in grades 5-8 from the other Seventh-day Adventist schools in Arizona. The independent variables used for this study were Spelling Pretest, Vocabulary Pretest, and ReadingPretest. The dependent variables used for this study were Spelling Posttest 1S, Spelling Posttest 2F, Spelling Posttest 3S, Spelling Posttest 4F, Spelling Posttest 5S, Vocabulary Posttest 1S, Vocabulary Posttest 2F, Vocabulary Posttest 3S, Vocabulary Posttest 4F, Vocabulary Posttest 5S, and Reading Comprehension Posttest 1S, Reading Comprehension Posttest 2F, Reading Comprehension Posttest 3S, Reading Comprehension Posttest 4F, Reading Comprehension Posttest 5S. The intervention applied to the experimental group (GAA's $5^{\text {th }}-8^{\text {th }}$ Grade students) was the implementation of a technology-based instruction approach in which students from this experimental group had access to iPad Mini tablets and the use of the educational app VSC. The following section of this study provides more detailed information about the intervention component of this study.

As aforementioned, in the beginning of the 2013 school year, the GAA administration decided the implementation of iPad Mini tablets in the $5^{\text {th }}-8^{\text {th }}$ Grade classrooms, in a 1:1 student to iPad Mini ratio. These tablets were equipped with different educational apps. One of the main educational apps that was used for the purpose of this study was VSC. It is important to mention that the iPad Mini tablets were also used as a note taker tool, electronic mail tool, online assignment completion and submission for a variety of subjects, e-reader, calculator, and video tutorial watching. GAA's $5^{\text {th }}-8^{\text {th }}$ Grade students were academically tested before beginning the use of the iPad Mini and VSC using ITBS in fall of 2013.

After the GAA's $5^{\text {th }}-8^{\text {th }}$ Grade students were tested in the beginning of the 2013 school year, the use if the iPad Mini tablets and VSC began. During the lapse of the following three school years, GAA's $5^{\text {th }}-8^{\text {th }}$ Grade students were the only students using iPad Mini Tablets and VSC consistently, five days a week, for a period of 30 minutes a day in the Arizona Conference Seventh-day Adventist schools. The rest of the Adventist schools in the Arizona Conference used the traditional textbook paper and pencil approach for teaching spelling, vocabulary, and reading comprehension as they have been utilizing for years.

Appropriate grade-level word lists were entered in the VSC app for each one of the $5^{\text {th }}-8^{\text {th }}$ Grade students at GAA by their teachers. Students accessed the VSC app a minimum of a thirty minutes period a day, from Monday through Friday. While accessing the VSC app, students had the opportunity to review each week's new word list, play educational games that would contribute to the memorization of spelling of the words and their meaning, and create and write sentences using the words from the that particular week's word list. Every Friday, students took a spelling and vocabulary test based on the words from the wordlist of that week. An average of the grade from all those Friday's tests provided part of the quarter grade of the Language Art subject. This structure was in placed systematically and consistently during the school years of 2013-2014, 2014-2015, 20152016, which encompassed the duration of this study.

Please see attachment for a full protocol description. 
Survey instrument or interview protocol: ITBS (Iowa Test of Basic Skills). Adventist schools in the North American Division are required to academically test their students every year. This is valid, reliable, and normed instrument for measuring academic performance created by the University of IOWA. (Please attachment).

Institutional approval letter (if off AU campus): Please see attachment

Consent form (for interviews and focus groups): Obtaining this consent form would be an impossibility since it would be extremely difficult to track and contact parents of students during the years 2013-2016. According to Guidance on Exemption Category B.1: Normal Education Practices requesting test results from a school district (In this case, Arizona Conference) parental consent is not required as long as identifiers are used for the individuals in order to keep their identity protected.

Participants recruitment documents: There was no need to recruit any students since this study is based on a curriculum implementation at Glenview Adventist Academy. The whole purpose of this study is to measure the efficacy of the curricular implementation of the software Vocabulary Spelling City and the use of electronic tablets (iPad Mini).

\section{Principal Investigator's Assurance Statement for Using Human Subjects in Research}

__ $\mathbf{x}$ _ I I certify that the information provided in this IRB application is complete and accurate.

__ $\mathbf{x}$ _ _ I understand that as Principal Investigator, I have ultimate responsibility for the conduct of IRB approved studies, the ethical performance of protocols, the protection of the rights and welfare of human subjects, and strict adherence to the study's protocol and any stipulation imposed by Andrews University Institutional Review Board.

__ $\mathbf{x}$ __ I will submit modifications and / or changes to the IRB as necessary prior to implementation.

_ as with all applicable federal, state, and local laws, regarding the protection of human participants in research.

__ _ _ _ My advisor has reviewed and approved my proposal. 


\section{Andrews University}

March 30, 2020

Fernando Lista

Tel: 269-471-6702

Email: bordes@andrews.edu

\section{RE: APPLICATION FOR APPROVAL OF RESEARCH INVOLVING HUMAN SUBJECTS}

IRB Protocol \#: 20-016 Application Type: Original Dept.: Leadership

Review Category: Expedited Action Taken: Approved Advisor: Bordes Henry-Saturne Title: The Use of Vocabulary Spelling City App and How that Affects Student Performance in Spelling, Vocabulary, and Reading Comprehension of Students in Grades 5-8 at Glenview Adventist Academy.

This letter is to advise you that the Institutional Review Board (IRB) has reviewed and approved your IRB application for research involving human subjects entitled: "The Use of Vocabulary Spelling City App and How that Affects Student Performance in Spelling, Vocabulary, and Reading Comprehension of Students in Grades 5-8 at Glenview Adventist Academy" IRB protocol number 20-016 under Expedited category. This approval is valid until March 30, 2021. If your research is not completed by the end of this period you must apply for an extension at least four weeks prior to the expiration date. We ask that you inform IRB whenever you complete your research. Please reference the protocol number in future correspondence regarding this study.

Any future changes made to the study design and/or consent form require prior approval from the IRB before such changes can be implemented. Please use the attached report form to request for modifications, extension and completion of your study.

While there appears to be no more than minimum risk with your study, should an incidence occur that results in a research-related adverse reaction and/or physical injury, this must be reported immediately in writing to the IRB. Any project-related physical injury must also be reported immediately to the University physician, Dr. Katherine, by calling (269) 473-2222. Please feel free to contact our office if you have questions.

Best wishes in your research.

Sincerely,

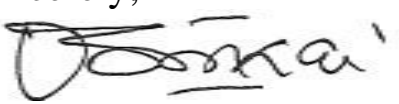

Mordekai Ongo, $\mathrm{PhD}$.

Research Integrity \& Compliance Officer

Institutional Review Board -8488 E Campus Circle Dr Room BUL 234 - Berrien Springs, MI 491040355 Tel: (269) 471-6361 E-mail: irb@andrews.edu 


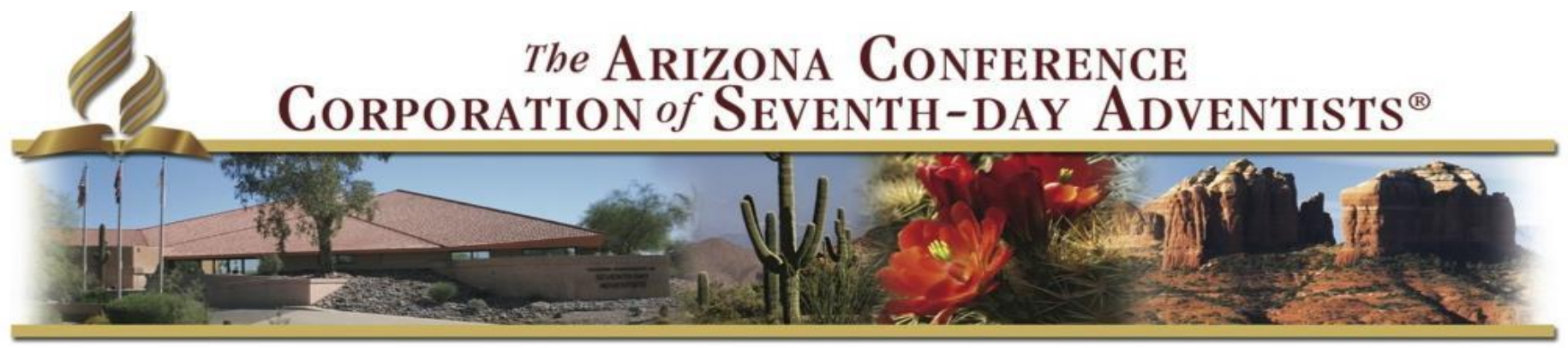

13405 N. Scottsdale Road, Scottsdale, Arizona 85254-4040 • MAIL: PO Box 12340, Scottsdale, AZ 85267-2340 Phone: (480) 991-6777 • Fax: (480) 991-4833 • www.azconference.org

January 28, 2020

Dr. Bordes Henry Saturné, Chair

Andrews University Leadership Department

Bell Hall Room 174

4195 Administration $\mathrm{Dr}$

Berrien Springs MI 49104-0111

Dear Dr. Saturné,

This is to inform you that the Department of Education of the Arizona Conference of Seventh-day Adventists has agreed to give your doctoral student, Fernando Lista, access to the data he needs to complete his dissertation at Andrews University. Specifically, under the condition of strict anonymity, he will have access to the students' academic records, their ITBS test scores, their grade levels, and their gender information. Students' identity will be protected by the use of identification numbers.

His research on the use of technology, more specifically, the use of Vocabulary Spelling City software in the classroom will greatly contribute to the current educational practices of our schools in Arizona.

Please, don't hesitate to contact me for any questions or concerns.

Sincerely,

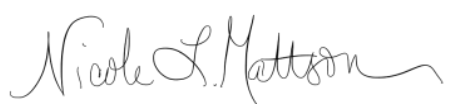

Nicole Mattson, MEd

Superintendent of Education for the Arizona Conference of SDA 


\section{REFERENCES}

Adams, M. J. (2011). Advancing our students' language and literacy: The challenge of complex texts. American Educator, 34(4), 3.

Alliance for Excellent Education. (2016). Every student succeeds act primer: Digital learning. https://all4ed.org/reports-factsheets/every-student-succeeds-act-primerdigital-learning/

American Academy of Orthopedic Surgeons, (2017). Back-to-school: Smart tips to ease the load of kids' backpacks. http://newsroom.aaos.org/mediaresources/news/backpack-safety-tips.htm

American Educational Research Association (AERA), American Psychological Association (APA), and National Council on Measurement in Education (NCME) (2014). Standards for educational and psychological testing. American Educational Research Association.

Anderson, R. C., \& Freebody, P. (1981). Vocabulary knowledge. In I. T. Guthrie (Ed.), Comprehension and teaching: Research reviews (pp. 77-117). Newark, DE: International Reading Association.

Apple, (2019). iPad in education results. https://www.apple.com/education/docs/ipad-ineducation-results.pdf

Arens, S. A., \& Mace, K. (2017). Efficacy study: Vocabulary Spelling City ${ }^{\circledR}$ proven to increase vocabulary retention and reading comprehension. Denver, CO: MREL.

ASCD \& OverDrive. (2016). Digital content goes to school: Trends in K-12 classroom elearning.

http://www.ascd.org/ASCD/pdf/siteASCD/misc/DigitalContentTrendsReport.pdfa scd.org, 2016.

Bandura, A., \& Walters, R. H. (1977). Social learning theory (Vol. 1). Englewood Cliffs, NJ: Prentice-hall.

Banilower, E. R., Smith, P. S., Weiss, I. R., Malzahn, K. A., Campbell, K. M., \& Weis, A. M. (2013). Report of the 2012 national survey of science and mathematics education. Horizon Research, Inc. (NJ1).

Barbe, W. B., \& Milone Jr, M. N. (1981). What we know about modality strengths. Educational Leadership, 38(5), 378-80. 
Barnes, W. (1982). The developmental acquisition of silent letters and orthographic images in English spelling. [Doctoral dissertation. University of Virginia]. https://elibrary.ru/item.asp?id=7368549

Baumann, J. F., Kame’enui, E. J., \& Ash, G. E. (2003). Research on vocabulary instruction: Voltaire redux. In D. Lapp, D. Fisher, J. Flood, J. M. Jensen, \& J. R. Squire, (Eds.), Handbook of research on teaching the English language arts. $\left(2^{\text {nd }}\right.$ ed., pp. 752-785). International Reading Association and the National Council of Teachers of English.

Bayer, B. L., (2017). Assessing the factors impacting professional learning for teachers in Seventh-day Adventist schools: A comparison of millennials and nonmillennials. [Doctoral dissertation, Andrews University]. https://digitalcommons.andrews.edu/dissertations/1634

Bear, D. (1991). Determining criteria for the development of a qualitative scale of higher levels of orthographic knowledge. [Unpublished manuscript]. University of Nevada-Reno.

Bear, D. R., Invernizzi, M., Johnston, F., \& Templeton, S. (1996). Words their way: Word study for phonics, vocabulary, and spelling. Merrill.

Beck, I. L., McKeown, M. G., \& Kucan, L. (2008). Creating robust vocabulary: Frequently asked questions and extended examples (Vol. 10). Guilford Press.

Beck, I., \& McKeown, M. (1991). Conditions of vocabulary acquisition. In R. Barr, M. L. Kamil, P. B. Mosenthal, \& P. D. Pearson (Eds.), Handbook of reading research (Vol. 2, pp. 789-814). Lawrence Erlbaum Associates, Inc.

Becker, W. (1977). Teaching reading and language to the disadvantaged: What we have learned from field research. Harvard Educational Review, 47(4), 518-543. https://doi.org/10.17763/haer.47.4.51431w6022u51015

Blazer, C. (2013). Literature review: Digital textbooks. http://drs.dadeschools.net/AdditionalReports/LiteratureReviewonDigitalTextbook s.pdf

Blume, H. (2013, June 18). LA school board OKs \$30 million for Apple iPads. Los Angeles Times.

Bowie, L. (2017). Librarians share their best book repair tips. https://ideas.demco.com/blog/librarians-share-best-book-repair-tips/ 
Brand, J., \& Kinash, S. (2010). Pad-agogy: A quasi-experimental and ethnographic pilot test of the iPad in a blended mobile learning environment. In Proceedings 27th Annual Conference of the Australian Society for Computers in learning in Tertiary Education. Sydney, Australia. https://www.researchgate.net/profile/Jeffrey_Brand/publication/47929709_Padagogy_A_quasi-

experimental_and_ethnographic_pilot_test_of_the_iPad_in_a_blended_mobile_le arning_environment/links/02e7e52ca5c67a858c000000/

Brown, A. (1987). Metacognition, executive control, self-regulation, and other more mysterious mechanisms. In F. E. Weinert \& R. H. Kluwe (Eds), Metacognition, motivation, and understanding $\left(3^{\text {rd }}\right.$ ed). Lawrence Erlbaum Associates.

Bruner, J.S. (1985). Vygotsky: A historical and conceptual perspective. In J.V. Wertsch (Ed.), Culture, communication, and cognition: Vygostkian perspectives (pp. 2134). Cambridge University Press.

Bybee, R. W. (2010). Advancing STEM education: A 2020 vision. Technology and Engineering Teacher, 70(1), 30.

Cahen, L. S., Craun, M. J., \& Johnson, S. K., (1971). Spelling difficulty: A survey of the research. Review of Educational Research, 41(4), 281-301. https://doi.org/10.3102\%2F00346543041004281

California Department of Education. (2004). Textbook Weight in California: Data and Analysis. https://www.cde.ca.gov/ci/cr/cf/txtbkwght.asp

Carlisle, J. (1985). The relationship between knowledge of derivational morphology and spelling ability in fourth, sixth, and eighth grades. [Doctoral dissertation, University of Connecticut]. http://www.haskins.yale.edu/SR/SR082/SR082_11.pdf

Carr, N. (2010). The web shatters focus, rewires brains. Wired, May 29. https://www.wired.com/2010/05/ff-nicholas-carr/

Catts, H. W., \& Kamhi, A. G. (2017). Prologue: Reading comprehension is not a single ability. Language, Speech, and Hearing Services in Schools, 48(2), 73-76. https://doi.org/10.1044/2017_LSHSS-16-0033

Cherrington, C. (1985). The relationship of spelling ability to knowledge of semantic identities of morphemes in the English spelling system. [Doctoral dissertation, University of Virginia]. https://elibrary.ru/item.asp?id=7463937

Chertoff, N. G., \& Thompson, A. B. (2020). Applied strategies for remote student teaching due to COVID-19. CUNY Academic Works. https://academicworks.cuny.edu/oaa_pubs/18 
Chiesi, H. L., Spilich, G. J., \& Voss, J. F. (1979). Acquisition of domain-related information in relation to high and low domain knowledge. Journal of Verbal Learning and Verbal Behavior, 18(3), 257-273. https://doi.org/10.1016/S00225371(79)90146-4

Coffield, F. J., Moseley, D. V., Hall, E., \& Ecclestone, K. (2004a). Learning styles and pedagogy in post-16 learning: A systematic and critical review. Learning and Skills Research Centre.

Coffield, F., Moseley, D., Hall, E., \& Ecclestone, K. (2004b). Should we be using learning styles? What research has to say to practice (p. 82). Learning and Skills Research Centre.

Coiro, J., Knobel, M., Lankshear, C., \& Leu, D. J. (Eds). (2008). Central issues in new literacies and new literacies research. Handbook of research on new literacies, (pp. 1-21). Routledge.

Compton, D. L., Miller, A. C., Gilbert, J. K., \& Steacy, L. M. (2013). What can be learned about the reading comprehension of poor readers through the use of advanced statistical modeling techniques? In L.E. Cutting, B. Miller, \& P McCardle (Eds.). Unraveling the behavioral, neurobiological, \& genetic components of reading comprehension (pp. 135-147). Brookes.

Connor, C. M. (Ed.). (2016). The cognitive development of reading and reading comprehension. Routledge.

Creswell, J. W. \& Guetterman, T. C. (2018). Educational research: Planning, conducting, and evaluating quantitative and qualitative research. ( $6^{\text {th }} \mathrm{ed}$.). Pearson.

Cutting, L. E., \& Scarborough, H. S. (2006). Prediction of reading comprehension: Relative contributions of word recognition, language proficiency, and other cognitive skills can depend on how comprehension is measured. Scientific Studies of Reading, 10(3), 277-299. https://doi.org/10.1207/s1532799xssr1003_5

Dallas, M. E. (2012). Overloaded backpacks can injure kids: Experts. https://consumer.healthday.com/bone-and-joint-information-4/backache-news53/overloaded-backpacks-can-injure-kids-experts-667521.html

Dalton, B. (2014). E-text and e-books are changing literacy landscape. Phi Delta Kappan, 96(3), 38-43. https://doi.org/10.1177\%2F0031721714557451

Dalton, B., \& Grisham, D. L. (2011). eVoc strategies: 10 ways to use technology to build vocabulary. The Reading Teacher, 64(5), 306-317. https://doi.org/10.1598/RT.64.5.1 
Davis, F. B. (1942). Two new measures of reading ability. Journal of Educational Psychology, 33(5), 365. https://psycnet.apa.org/doi/10.1037/h0053582

Deloitte Development. (2016). After the bell rings: Expanding the classroom. In 2016 Digital Education Survey. https://www2.deloitte.com/content/dam/Deloitte/us/Documents/technologymedia-telecommunications/us-tmt-digital-education-survey.pdf

DiPaola, M., \& Wagner, C. A. (2018). Improving instruction through supervision, evaluation, and professional development. IAP.

Domingo, M. G., \& Garganté, A. B. (2016). Exploring the use of educational technology in primary education: Teachers' perception of mobile technology learning impacts and applications' use in the classroom. Computers in Human Behavior, 56, 21-28. https://doi.org/10.1016/j.chb.2015.11.023

Duke, N. K. (2000). 3.6 minutes per day: The scarcity of informational texts in first grade. Reading Research Quarterly, 35(2), 202-224. https://doi.org/10.1598/RRQ.35.2.1

Dunn, R., Cavanaugh, D., Eberle, B., \& Zenhausern, R. (1982). Hemispheric preference: The newest element of learning style. American Biology Teacher 44(5): 291-294.

Education SuperHighway. (2019). 2019 State of the States: Expanding digital learning to every classroom, every day. https://stateofthestates.educationsuperhighway.org/

Ehri, L. C. (1994). Development of the ability to read words: Update. In R. B., Ruddell, M. R., \& Singer, H. (Eds.), Theoretical Models and Processes of Reading ( $4^{\text {th }}$ ed., pp. 323-359). International Reading Association. https://files.oakland.edu/users/mceneane/web/rdg414/pdf/ehri15.pdf

Elliot, S., \& Busse, R. (1991). Social skills assessment and intervention with children and adolescents: Guidelines for assessment and training procedures. Social Psychology International, 12(1-2), 63-83. https://doi.org/10.1177/0143034391121006

Fang, Z., Schleppegrell, M. J., \& Cox, B. E. (2006). Understanding the language demands of schooling: Nouns in academic registers. Journal of Literacy Research, 38(3), 247-273. https://doi/pdf/10.1207/s15548430j1r3803_1

Federal Communications Commission (2012). Digital textbook playbook. https://ransition.fcc.gov/files/Digital_Textbook_Playbook.pdf

Fishman, D. (2010). Neck pain from texting. The Text Neck Institute. https://www.textneck.com/ 
Flavell, J. H. (1976). Metacognitive aspects of problem solving. In L. B. Resnick (Ed.), The nature of intelligence. Lawrence Erlbaum.

Flavell, J. H., Miller, P. H., \& Miller, S. A. (1977). Cognitive development. (3 ${ }^{\text {rd }}$ ed.) Prentice-Hall.

Fleming, N. D., Ed. (2001). Teaching and learning styles: VARK strategies. IGI Global.

Fox, C., \& Jones, R. (2018). Navigating the digital shift 2018: Broadening student learning opportunities. State Educational Technology Directors Association. https://eric.ed.gov/?id=ED594415

Gardner, H. (1983). Frames of mind: The theory of multiple intelligences. Basic Books.

Gardner, H. (1993). Multiple intelligences: The theory in practice. Basic Books.

Gardner, H., \& Hatch, T. (1990). Multiple Intelligences Go to School: Educational Implications of the Theory of Multiple Intelligences. Technical Report No. 4. https://eric.ed.gov/?id=ED324366

Gasser, U., \& Palfrey, J. (2009). Mastering multitasking. Educational Leadership, 66(6), 14-19.

Gates, A.I. (1937). A list of spelling difficulties in 3,876 words. Unpublished Manuscript, New York: Teachers College, Columbia University. http://hdl.handle.net/123456789/12985

Gegner, J. A., Mackay, D. H., \& Mayer, R. E. (2009). Computer-supported aids to making sense of scientific articles: Cognitive, motivational, and attitudinal effects. Educational Technology Research and Development, 57(1), 79-97. https://doi.org/10.1007/s11423-008-9088-3

Gentry, J.R., \& Gillet, J.W. (1993). Teaching kids to spell. Heinemann.

Goldin, C. D., \& Katz, L. F. (2009). The race between education and technology. Harvard University Press.

Gopnik, A., \& Meltzoff, A. N. (1997). Words, thoughts, and theories. MIT Press.

Graves, D. H., (1994). A fresh look at writing. Heinemann.

Graves, M. F. (1987). The roles of instruction in fostering vocabulary. In M. G. McKeown \& M. E. Curtis (Eds.), The nature of vocabulary acquisition (pp. 165184). Lawrence Erlbaum.

Graves, M. F., \& Watts-Taffe, S. (2008). For the love of words: Fostering word consciousness in young readers. The Reading Teacher, 62(3), 185-193. https://doi.org/10.1598/RT.62.3.1 
Greenfield, S. (2005). Answer rich, question poor. Times Educational Supplement, 28.

Greenlee-Moore, M. E., \& Smith, L. L. (1996). Interactive computer software: The effects on young children's reading achievement. Reading Psychology: An International Quarterly, 17(1), 43-64. https://doi.org/10.1080/0270271960170102

Groff, J. (2013). Technology-rich innovative learning environments. http://www.oecd.org/education/ceri/TechnologyRich\%20Innovative\%20Learning\%20Environments\%20by\%20Jennifer\%20Groff .pdf

Gross, D. (2013) Obama wants high-speed internet in schools by 2018. https://www.cnn.com/2013/06/06/tech/innovation/obama-internetschools/index.html

Gurria, A. (2016). PISA 2015 Results in Focus. OECD, https://doi.org/10.1787/22260919

Hall, S. H. (2017). 8 ways teachers can benefit from cloud storage. https://www.cloudwards.net/?s=8+ways+teachers+can+benefit+from+cloud+stor age

Hammill, D. D., Larsen, S., \& McNutt, G. (1977). The effects of spelling instruction: A preliminary study. Elementary School Journal, 78(1), 67-72.

https://www.journals.uchicago.edu/doi/abs/10.1086/461085? journalCode=esj

Harper, E. (2018). The best way to take notes. https://www.techlicious.com/tip/best-notetaking-apps-and-devices/

Hayes, D. P., Wolfer, L. T., \& Wolfe, M. F. (1996). Schoolbook simplification and its relation to the decline in SAT-verbal scores. American Educational Research Journal, 33(2), 489-508. https://doi.org/10.3102\%2F00028312033002489

Heald-Taylor, B. G. (1998). Three paradigms of spelling instruction in grades 3 to 6 . The Reading Teacher, 51(5), 404-413. https://www.jstor.org/stable/20201936?seq=1

Heinrich, P. (2012). The iPad as a tool for education. NAACE: The ICT Association. https://ecitblog.skoleblogs.dk/files/2012/09/The-iPad-as-a-Tool-for-EducationNaace-report-supported-by-9ine-Consulting.pdf

Hiemstra, J. L., \& Brink, R. A. (2006). The advent of a public pluriformity model: Faithbased school choice in Alberta. Canadian Journal of Education, 29(4), 11571190.

Hirsch, E. (2006). Building knowledge. American Educator, 30(1), 8-51. 
Hirsh-Pasek, K., Zosh, J. M., Golinkoff, R. M., Gray, J. H., Robb, M. B., \& Kaufman, J. (2015). Putting education in "educational" apps: Lessons from the science of learning. Psychological Science in the Public Interest, 16(1), 3-34. https://doi.org/10.1177\%2F1529100615569721

Holland, J. H., Holyoak, K. J., Nisbett, R. E., \& Thagard, P. R. (1989). Induction: Processes of inference, learning, and discovery. MIT press.

Honey, P., \& Mumford, A. (1986). Manual of learning styles (2 ${ }^{\text {nd }}$ ed.). P. Honey.

Horrigan, J. B., (2015). The number behind the broadband 'homework gap.' http://www.pewresearch.org/fact-tank/2015/04/20/the-numbers-behind-thebroadband-homework-gap/

Howell, D. C., (2017). Fundamental statistics for the behavioral sciences $\left(9^{\text {th }}\right.$ ed.). Cengage Learning.

Hughes, J. E., Boklage, A., \& Ok, M. W. (2016). A case study of technology leadership in situ: A high school iPad learning initiative. Journal of School Leadership, 26(2), 283-313. https://doi.org/10.1177\%2F105268461602600204

Hutchison, A., \& Reinking, D. (2011). Teachers' perceptions of integrating information and communication technologies into literacy instruction: A national survey in the United States. Reading Research Quarterly, 46(4), 312-333. https://doi.org/10.1002/RRQ.002

Hutchison, A., Beschorner, B., \& Schmidt-Crawford, D. (2012). Exploring the use of the iPad for literacy learning. The Reading Teacher, 66(1), 15-23. https://doi.org/10.1002/TRTR.01090

International Reading Association (IRA). (2009). New literacies and 21st-century technologies: A position statement of the International Reading Association. Author.

Invernizzi, M., Abouzeid, M., \& Bloodgood, J. (1997). Integrated word study: Spelling, grammar and meaning in the language arts classroom. Language Arts, 74(3), 185192. https://www.jstor.org/stable/41482857?seq=1 https://pdfs.semanticscholar.org/ce61/72ff43f568b6deae27f412dc265d75627ed5. pdf

Iowa Assessments. (2014). Iowa assessment research and development guide, 2014: Forms $E$ and $F$. Houghton, Mifflin, Harcourt.

Johnson, B. (2011). Paper and pencil curriculum: How much do you rely on it? https://www.edutopia.org/blog/paperless-schools-techology-ben-johnson 
Johnson, L., Levine, A., Smith, R., \& Smythe, T. (2009). The 2009 horizon report: K-12 edition. The New Media Consortium.

Johnson, M. (2019). The best tablets for reading - our top 10 picks for best e-readers \& tablets. https://tabletunderbudget.com/best-tablets-for-reading/

Johnson-Laird, P. N. (1983). Mental models: Towards a cognitive science of language, inference, and consciousness (No. 6). Harvard University Press.

Jones, J. D., Staats, W. D., Bowling, N., Bickel, R. D., Cunningham, M. L., \& Cadle, C. (2004). An evaluation of the merit reading software program in the Calhoun county (WV) middle/high school. Journal of Research on Technology in Education, 37(2), 177-195. https://doi.org/10.1080/15391523.2004.10782432

Joo, Y. J., Park, S., \& Lim, E. (2018). Factors influencing preservice teachers' intention to use technology: TPACK, teacher self-efficacy, and technology acceptance model. Journal of Educational Technology \& Society, 21(3), 48-59. https://www.jstor.org/stable/26458506

Kame'enui, E. J., \& Baumann, J. F. (Eds.). (2012). Vocabulary instruction: Research to practice, ( $2^{\text {nd }}$ ed.). Guilford Press.

Karmiloff-Smith, B. A. (1994). Beyond modularity: A developmental perspective on cognitive science. European Journal of Disorders of Communication, 29(1), 95105. https://doi.org/10.3109/13682829409041485

Kendeou, P., \& van den Broek, P. (2007). The effects of prior knowledge and text structure on comprehension processes during reading of scientific texts. Memory \& Cognition, 35(7), 1567-1577. https://doi.org/10.3758/BF03193491

Kendeou, P., Walsh, E. K., Smith, E. R., \& O'Brien, E. J. (2014). Knowledge revision processes in refutation texts. Discourse Processes, 51(5-6), 374-397. https://doi.org/10.1080/0163853X.2014.913961

Kintsch, W., \& Rawson, K.A. (2005). Comprehension. In M.J. Snowling \& C. Hulme (Eds.). The Science of Reading: A Handbook (pp. 211-226).

onlinelibrary.wiley.com/doi.org/10.1002/9780470757642.ch12

Klamm, J., \& Tarnow, K. G. (2015). Computer vision syndrome: a review of literature. Medsurg Nursing, 24(2), 89-93. https://search.proquest.com/openview/ab5a69dad94372ab7607cc6828f28934/1?p q-origsite $=$ gscholar $\& \mathrm{cbl}=30764$

Klein, P. D. (2003). Rethinking the multiplicity of cognitive resources and curricular representations: Alternatives to 'learning styles' and 'multiple intelligences'. Journal of Curriculum Studies, 35(1), 45-81. https://doi.org/10.1080/00220270210141891 
Koehler, M., \& Mishra, P. (2009). What is technological pedagogical content knowledge (TPACK)? Contemporary issues in technology and teacher education, 9(1), 6070. https://www.learntechlib.org/p/29544/

Kolb, L. (2019). Smart classroom: Tech integration. Educational Leadership, 76(5), 2026.

Krause, T. (2018). Using VocabularySpellingCity with adult ESOL students in community college. ORTESOL Journal, 35, 43-46. https://files.eric.ed.gov/fulltext/EJ1180312.pdf

Kress, G. (2003). Literacy in the new media age. Routledge.

Kumar, N., Rose, R. C., \& D'Silva, J. L. (2008). Teachers' readiness to use technology in the classroom: An empirical study. European Journal of Scientific

Research, 21(4), 603-616. http://list.shaanan.ac.il/fl/files/454.pdf

Lanir, L. (2012). Digital information overload overwhelms and distracts students. https://medium.com/@1lanirfreelance/digital-information-overload-overwhelmsand-distracts-students-897190191af9

Lankshear, C., \& Knobel, M. (2003). New literacies: Changing knowledge and classroom learning. Open University Press.

LearnStuff. (2012). Graduating with technology. https://edtechtimes.com/2012/10/19/graduating-with-technology-infographic/

Lemmon, P. (1985). A school where learning styles make a difference. Principal, 64(4), 26-28. https://eric.ed.gov/?id=EJ323578

Lennon, L. (2012). The role of the school principal in technology integration: a literature review. https://scholarworks.uni.edu/grp/198/

Leu, D. J. (2006). New literacies, reading research, and the challenges of change: A deictic perspective. In J. V. Hoffman, D. L. Shallert, C. M. Fairbanks, J. Worthy, \& B. Maloch. 55th yearbook of the National Reading Conference (pp. 1-20). National Reading Conference.

Leu, D. J., \& Reinking, D. (1996). Bringing insights from reading research to research on electronic learning environments. Advances in Discourse Processes, 58, 43-76.

Leu, D. J., Kinzer, C. K., Coiro, J. L., \& Cammack, D. W. (2004). Toward a theory of new literacies emerging from the Internet and other information and communication technologies. Theoretical Models and Processes of Reading, 5(1), 1570-1613. 
Ligas, M. R. (2002). Evaluation of Broward County alliance of quality schools project. Journal of Education for Students Placed at Risk, 7(2), 117-139. https://doi.org/10.1207/S15327671ESPR0702_2

Lin, I. M., (2009). Psychophysiological patterns during cell phone text messaging: A preliminary study, Applied Psychophysiological Biofeedback, 34(1), 53-57.

Loftus-Rattan, S. M., \& Furey, J. (2020). Word learning in first grade: Evaluating the effectiveness of a technology-based and an extended vocabulary intervention. Reading \& Writing Quarterly, 1-19. https://doi.org/10.1080/10573569.2020.1800540

Lysenko, L. V., \& Abrami, P. C. (2014). Promoting reading comprehension with the use of technology. Computers \& Education, 75, 162-172. https://doi.org/10.1016/j.compedu.2014.01.010

MacMurren, H. (1985). A comparative study of the effects of matching and mismatching sixth-grade students with their learning style preferences for the physical element of intake and their subsequent reading speed and accuracy scores and attitudes. [Doctoral Dissertation, St. John's University]. https://elibrary.ru/item.asp?id=7466413

Mann, D., Shakeshaft, C., Becker, J. D., \& Kottkamp, R. (1999). West Virginia story: Achievement gains from a statewide comprehensive instructional technology program. https://scholarscompass.vcu.edu/edlp_pubs/2/

Massa, L. J., \& Mayer, R. E. (2006). Testing the ATI hypothesis: Should multimedia instruction accommodate verbalizer-visualizer cognitive style? Learning and Individual Differences, 16(4), 321-335 https://doi.org/10.1016/j.lindif.2006.10.001.

Mayfield, K. H., Glenn, I. M., \& Vollmer, T. R. (2008). Teaching spelling through prompting and review procedures using computer-based instruction. Journal of Behavioral Education, 17(3), 303. https://doi.org/10.1007/s10864-008-9069-y

McBer, H. (2001). Research into teacher effectiveness. In F. Banks \& A. S. Mayes (Eds.) Early professional development for teachers (pp. 193-209). The Open University.

Mendelsohn, T. (2012). Ten great free education apps for the iPad, The Independent, Jan. 30, 2012. https://www.independent.co.uk/student/student-life/technologygaming/ten-great-free-education-apps-for-the-ipad-6297153.html

Merry, J. J. (2013). Tracing the US deficit in PISA reading skills to early childhood: Evidence from the United States and Canada. Sociology of Education, 86(3), 234252. https://doi.org/10.1177\%2F0038040712472913 
Mertler, C. A., \& Vannatta, R. A. (2013). Advanced and multivariate statistical methods ( $5^{\text {th }}$ ed.). Routledge.

Mertler, C.A., \& Reinhart, R.V. (2013). Advanced and multivariate statistical methods: Practical application and interpretation. (5 $5^{\text {th }}$ ed.) Pyrczak Publishing.

Mishra, P., \& Koehler, M. J. (2006). Technological pedagogical content knowledge: A framework for teacher knowledge. Teachers College Record, 108(6), 1017-1054. https://www.learntechlib.org/p/99246/?nl=1

Moats, L.C. (1995). Spelling: Development, disabilities, and instruction. York Press.

Moir, L. (1995). An examination of teaching strategies used by teachers at grade four to eight levels. [Unpublished Master's Thesis, University of Windsor].

Moon, A. L., Wold, C. M., \& Francom, G. M. (2017). Enhancing reading comprehension with student-centered iPad applications. TechTrends, 61(2), 187-194. https://doi.org/10.1007/s11528-016-0153-1

Mueller, P. A., \& Oppenheimer, D. M. (2014). The pen is mightier than the keyboard: Advantages of longhand over laptop note taking, Psychological Science 25(6), 1159-1168. https://doi.org/10.1177\%2F0956797614524581

NAD Education. (2020). Moving Hearts and Minds Upward: The CognitiveGenesis Study. https://adventisteducation.org/cg1.html

Nagy, W. E. (1988). Teaching vocabulary to improve reading comprehension. National Council of Teachers of English.

http://www.cscanada.org/index.php/sll/article/view/10013

National Reading Panel (2000). Report of the National Reading Panel. Teaching children to read: An evidence- based assessment of the scientific research literature on reading and its implications for reading instruction (00-4769). National Institute of Child Health \& Human Development, National Institutes of Health.

National Reading Panel (US), National Institute of Child Health, Human Development (US), National Reading Excellence Initiative, National Institute for Literacy (US), United States. Public Health Service, \& United States Department of Health. (2000). Report of the National Reading Panel: Teaching children to read: An evidence-based assessment of the scientific research literature on reading and its implications for reading instruction: Reports of the subgroups. National Institute of Child Health and Human Development, National Institutes of Health.

National Reading Panel \& National Institute for Literacy. (2000). Teaching children to read. an evidence-based assessment of the scientific research literature on reading and its implications for reading instruction. National Institute for Literacy. 
National Training and Simulation Association. (2012).

https://www.trainingsystems.org/resources

Nikian, S., Nor, F. M., \& Aziz, M. A. (2013). Malaysian teachers' perception of applying technology in the classroom. Procedia-Social and Behavioral Sciences, 103, 621627. https://doi.org/10.1016/j.sbspro.2013.10.380

Norris, C., \& Soloway, E. (2012). Want increased student achievement using iPads? District Administration, 48(7), 42.

Obama, B. (2013). President Obama speaks on technology in schools. https://obamawhitehouse.archives.gov/photos-andvideo/video/2013/06/06/president-obama-speaks-technology-schools

Organisation for Economic Co-operation and Development. (2016). PISA 2015 results (Volume I): Excellence and equity in education, OECD Publishing.

Ouyang, R. (1993). A meta-analysis: Effectiveness of computer-assisted instruction at the level of elementary education $(K-6)$. [Doctoral Dissertation, Indiana University of Pennsylvania]. https://dl.acm.org/doi/book/10.5555/919919

Palincsar, A. S., \& Duke, N. K. (2004). The role of text and text-reader interactions in young children's reading development and achievement. The Elementary School Journal, 105(2), 183-197.

https://www.journals.uchicago.edu/doi/abs/10.1086/428864

Pandolfo, N. (2012, March 7). Lessons from a one-to-one iPad program. The Hechinger Report. https://hechingerreport.org/lessons-from-a-one-to-one-ipad-program/

Pashler, H., McDaniel, M., Rohrer, D., \& Bjork, R. (2008). Learning styles: Concepts and evidence. Psychological Science in the Public Interest, 9(3), 105-119. https://doi.org/10.1111\%2Fj.1539-6053.2009.01038.x

Pearson, P. D., Hiebert, E. H., \& Kamil, M. L. (2007). Vocabulary assessment: What we know and what we need to learn. Reading Research Quarterly, 42(2), 282-296. https://doi.org/10.1598/RRQ.42.2.4

Perfetti, C. A., Marron, M. A., \& Foltz, P. W. (1996). Sources of comprehension failure: Theoretical perspectives and case studies. In C. Cornoldi \& J. V. Oakhill (Eds.), Reading comprehension difficulties: Processes and intervention (pp. 137166). Lawrence Erlbaum.

Pew Research Center. (2019). Mobile fact sheet. https://www.pewresearch.org/internet/fact-sheet/mobile/

Piaget, J. (1926). The language and thought of the child. Harcourt Brace Jovanovich. 
Ponce, H. R., Mayer, R. E., \& Lopez, M. J. (2013). A computer-based spatial learning strategy approach that improves reading comprehension and writing. Educational Technology Research and Development, 61(5), 819-840. https://doi.org/10.1007/s11423-013-9310-9

Posner, M. I. (1984). Foundations of Cognitive Science. MIT Press.

Prensky, M. (2001). Digital natives, digital immigrants: Part 1. On the Horizon, 9(5), 1-6.

Price, E. (2012, March 7). How much storage does your tablet need? http://www.wopular.com/how-much-storage-does-your-tablet-need

Pritchard, A. (2018). Ways of learning: Learning theories for the classroom. Routledge.

Public Broadcasting Services. (2012). National PBS survey finds teachers want more access to classroom tech. http://www.pbs.org/about/blogs/news/national-pbssurvey-finds-teachers-want-more-access-to-classroom-tech/

Recht, D. R., \& Leslie, L. (1988). Effect of prior knowledge on good and poor readers' memory of text. Journal of Educational Psychology, 80(1), 16-20. https://psycnet.apa.org/doi/10.1037/0022-0663.80.1.16

Reinking, D. (1992). Differences between electronic and printed texts: An agenda for research. Journal of Educational Multimedia and Hypermedia, 1(1), 11-24. https://eric.ed.gov/?id=EJ450342

Reinking, D. (1998). Introduction: Synthesizing technological transformations of literacy in a post-typographic world. In D. Reinking, M. C. McKenna, L. D. Labbo, \& R. D. Kieffer, (Eds.), Handbook of literacy and technology: Transformations in a post-typographic world (pp 11-30). Erlbaum.

Reinking, D. (2001). Multimedia and engaged reading in a digital world. In L. Verhoeven, \& C. E. Snow (Eds.), Literacy and motivation: Reading engagement in individuals and groups (pp. 195-221). Erlbaum.

Richardson, W. (2019). Sparking student agency with technology. Educational Leadership, 76(5), 12-18.

Romance, N. R., \& Vitale, M. R. (2012). Science IDEAS: A research-based K-5 interdisciplinary instructional model linking science and literacy. Science Educator, 21(1), 1-11. http://www.scienceideas.org/RefDocs/2_BScienceEducator2012Published.pdf

Roser, M. (2017). iPadegogy of reading: Do iPads influence student's reading? Teachers and Curriculum, 17(2), 25-32. https://eric.ed.gov/?id=EJ1161597 
Schmidt, D. A., Baran, E., Thompson, A. D., Mishra, P., Koehler, M. J., \& Shin, T. S. (2009). Technological pedagogical content knowledge (TPACK) the development and validation of an assessment instrument for preservice teachers. Journal of Research on Technology in Education, 42(2), 123-149. https://doi.org/10.1080/15391523.2009.10782544

Schoology. (2017). The global state of digital learning in K-12 education. https://info.schoology.com/rs/601-CPX-764/images/2017-Global-State-of-DigitalLearning-in-K-12\%20Education.pdf

Scott, R. (1991, April). Spelling and reading strategies of seventh grade: good readers/good spellers, good readers/poor spellers, and poor readers/poor spellers. [Paper presentation]. American Educational Research Association.

Seifert, T., \& Zimon, V. (2019). Using tablet applications as assistive tools in teaching English as a foreign language. In T. Seifert \& V. Simon (Eds.) Mobile Technologies in Educational Organizations (pp. 263-282). IGI Global.

Sewell, D. (1990). New tools for new minds: A cognitive perspective on the use of computers with young children. Harvester Wheatsheaf.

Singleton, C., \& Simmons, F. (2001). An evaluation of Wordshark in the classroom. British Journal of Educational Technology, 32(3), 317-330. https://doi.org/10.1111/1467-8535.00201

Snow, C. (2002). Reading for understanding: Toward an $R \& D$ program in reading comprehension. RAND.

Solomon, J., \& Rhodes, N.C. (1995). Conceptualizing Academic Language. Research Report 15, Center for Research on Education, Diversity and Excellence. University of California. https://eric.ed.gov/?id=ED389212

Spoon, J. C., \& Schell, J. W. (1998). Aligning student learning styles with instructor teaching styles. Journal of Industrial Teacher Education, 35(2), 41-56. https://eric.ed.gov/?id=EJ560445

Stahl, S. A. (2002). Different strokes for different folks. In L. Abbeduto (Ed.), Taking sides: Clashing on controversial issues in educational psychology $\left(2^{\text {nd }}\right.$ ed., pp. $98-$ 107). McGraw-Hill.

Stahl, S. A., \& Fairbanks, M. M. (1986). The effects of vocabulary instruction: A modelbased meta-analysis. Review of Educational Research, 56(1), 72-110. https://doi.org/10.3102\%2F00346543056001072

Stanovich, K. E. (1986). Matthew effects on reading: Some consequences of individual differences in the acquisition of literacy. Reading Research Quarterly, 21(4), 360407. https://doi.org/10.1177\%2F0022057409189001-204 
Sumser, A. (2016). Discovery education makes e-textbooks easy: Reference online. https://www.slj.com/?detailStory=discovery-education-makes-e-textbooks-easyreference-online

Templeton, S. (1980). Spelling, phonology, and the older student. In E.H. Henderson \& J.W. Beers (Eds.), Developmental and Cognitive Aspects of Learning to Spell: A Reflection of Word Knowledge (pp. 85-96). International Reading Association.

Traynor, P. L. (2003). Effects of computer-assisted instruction on different learners. Journal of Instructional Psychology, 30(2), 137-143. http://www.patricktraynor.com/Journal_of_Instructional_Pscyhology_Vol_30_2 -03.pdf

Uğur, N. G., \& Koç, T. (2019). Leading and teaching with technology: School principals' perspective. International Journal of Educational Leadership and Management, 7(1), 42-71. http://dx.doi.org/10.17583/ijelm.2019.3758

University of Iowa, (2014). Iowa Assessment of Research and Development Guide. Houghton Mifflin Harcourt.

US Bureau of Labor Statistics, (2019). Occupational outlook handbook. https://www.bls.gov/ooh/

US Census Bureau, (2019). Quick Facts Phoenix, Arizona. https://www.census.gov/quickfacts/fact/table/phoenixcityarizona/RHI725219

US Department of Education, Office of Educational Technology. (2010). Transforming American education: learning powered by technology, National Education Technology Plan 2010. https:/www.ed.gov/sites/default/files/netp2010.pdf

Valle, J. D. (1984). An experimental investigation of the word recognition scores of seventh grade students to provide supervisory and administrative guidelines for the organization of effective instructional environments. [Unpublished doctoral dissertation]. St. John's University.

Valle, J. D., Dunn, K., Dunn, R., Geisert, G., Sinatra, R., \& Zenhausern, R. (1986). The effects of matching and mismatching students' mobility preferences on recognition and memory tasks. The Journal of Educational Research, 79(5), 267272. https://doi.org/10.1080/00220671.1986.10885690

Van Daal, V., \& Reitsma, P. (2000). Computer-assisted learning to read and spell: Results from two pilot studies. Journal of Research in Reading, 23(2), 181-193. https://doi.org/10.1111/1467-9817.00113 
Vaughn, S., Wanzek, J., Wexler, J., Barth, A., Cirino, P. T., Fletcher, J., Romain, M., Denton, C. A., Roberts, G., \& Francis, D. (2010). The relative effects of group size on reading progress of older students with reading difficulties. Reading and Writing, 23(8), 931-956. https://doi.org/10.1007/s11145-009-9183-9

Vygotsky, L. S. (1978). Mind in Society. (Edited by M. Cole, V. John-Steiner, S. Scribner, \& E. Souberman). Harvard University Press.

Wang, Y. H. (2016). Reading strategy use and comprehension performance of more successful and less successful readers: A think-aloud study. Educational Sciences: Theory and Practice, 16(5), 1789-1813. https://doi.org/10.12738/estp.2016.5.0116

Waters, G., Bruck, M., \& Malus-Abramowitz, M. (1988). The role of linguistic and visual information in spelling: a developmental study. Journal of Experimental Child Psychology, 45(3), 400-421. https://doi.org/10.1016/0022-0965(88)90039-2

Whipple, G. M. (Ed.). (1925). The twenty-fourth yearbook of the National Society for the Study of Education: Report of the national committee on reading. Public School Publishing Company.

Wijekumar, K. K., Meyer, B. J., \& Lei, P. (2012). Large-scale randomized controlled trial with 4th graders using intelligent tutoring of the structure strategy to improve nonfiction reading comprehension. Educational Technology Research and Development, 60(6), 987-1013. https://doi.org/10.1007/s11423-012-9263-4

Williams, D. (2012). How much is out-of-control printing costing your school? http://www.softwareshelf.com/HTML/products/prod_materials/23/PMP_Academi c_Story.pdf

Willingham, D. T. (2006). The usefulness of brief instruction in reading comprehension strategies. American Educator, 30(4), 39-50.

http://citeseerx.ist.psu.edu/viewdoc/download?doi=10.1.1.461.7299\&rep=rep1\&t ype $=$ pdf

Wilson, L. (2012). Apple's iPad textbooks cost 5x more than print. https://www.educationbusinessblog.com/apples_ipad_textbooks_cost_5x/

Wood, K., Vintinner, J., Hill-Miller, P., Harmon, J. M., \& Hedrick, W. (2009). An investigation of teachers' concerns about vocabulary and the representation of these concerns in content literacy methodology textbooks. Reading Psychology, 30(4), 319-339. https://doi.org/10.1080/02702710802411562

Woodruff, G., Moore, G. N., Forest, R.G., Talbot, R.A., Talbot, A.R., (2003). Working Words in Spelling. DC Heath \& Company. 
Woollard, J. (2010). Psychology for the Classroom: Behaviourism. Routledge. https://doi.org 10.4324/9780203851425

Wu, J., \& Zhang, Y. (2010). Examining potentialities of handheld technology in students' academic attainments. Educational Media International, 47(1), 57-67. https://doi.org/10.1080/09523981003654977

Zutell, J. (1992). An integrated view of word knowledge: Correlational studies of the relationships among spelling, reading and conceptual development. In S.

Templeton \& D. R. Bear (Eds.), Development of orthographic knowledge and the foundations of literacy: A memorial festschrift for Edmund Henderson (pp.213230). Erlbaum.

Zutell, J., \& Rasinski, T. (1989). Reading and spelling connections in third and fifth grade students. Reading Psychology: An International Quarterly, 10(2), 137-155. https://doi.org/10.1080/0270271890100203

Zwiers, J. (2013). Building academic language: Essential practices for content classrooms, grades 5-12. Jossey-Bass. 
VITA

\section{FERNANDO LISTA OLEYNICK}

\section{Education}

$\begin{array}{lll}\begin{array}{l}\text { Andrews University Ph.D. } \\ \text { Berrien Springs, MI }\end{array} & \text { 2010-present } & \text { Ph.D., K-12 Administration } \\ \begin{array}{l}\text { Southern Adventist University } \\ \text { Collegedale, TN }\end{array} & 2007 & \begin{array}{c}\text { Master of Science, } \\ \text { Educational Administration } \\ \text { and Supervision of Education }\end{array} \\ \text { River Plate Adventist University } & 2003 & \begin{array}{l}\text { Bachelor of Arts, Education } \\ \text { Bachelor of Arts, Theology }\end{array}\end{array}$

\section{Professional Experience}

\begin{tabular}{|c|c|c|}
\hline $\begin{array}{c}\text { Nevada-Utah Conference of } \\
\text { Seventh-day Adventists }\end{array}$ & 2018 & Superintendent of Education \\
\hline $\begin{array}{l}\text { Hawaiian Mission Academy } \\
\text { Windward Campus } \\
\text { Kailua, HI }\end{array}$ & 2016-2018 & Principal and Teacher \\
\hline $\begin{array}{l}\text { Glenview Adventist Academy } \\
\text { Phoenix, AZ }\end{array}$ & 2012-2016 & Principal and Teacher \\
\hline $\begin{array}{l}\text { Atlanta Adventist International } \\
\text { School, Jonesboro, GA }\end{array}$ & 2005-2011 & Principal and Teacher \\
\hline $\begin{array}{l}\text { River Plate Adventist University } \\
\text { Entre Rios, Argentina }\end{array}$ & 2003-2005 & Professor/Pedagogic Assessor \\
\hline
\end{tabular}

\section{Professional Certifications}

Professional and administrative denominational certification. 
